\title{
Dual-channel fluorescent probe for the simultaneous monitoring of peroxynitrite and adenosine-5'-triphosphate in cellular applications
}

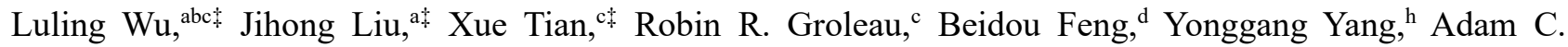
Sedgwick, ${ }^{\mathrm{e}}$ Hai-Hao Han, ${ }^{\mathrm{f} *}$ Yang Wang, ${ }^{\mathrm{b}}$ Han-Min Wang, ${ }^{\mathrm{g}}$ Fang Huang, ${ }^{\mathrm{a}}$ Steven D. Bull, ${ }^{\mathrm{c}}$ Hua Zhang, ${ }^{\mathrm{d} *}$ Chusen Huang ${ }^{\mathrm{b} *}$ Yi Zang, $,{ }^{\mathrm{g}} \mathrm{Jia} \mathrm{Li},{ }^{\mathrm{g}}$ Xiao-Peng He,${ }^{\mathrm{f}}$ Ping Li ${ }^{\mathrm{a} *}$ Bo Tang, ${ }^{\mathrm{a}}$ Tony D. James, ${ }^{\text {acd* }}$ and Jonathan L. Sessler ${ }^{\mathrm{e} *}$

a. College of Chemistry, Chemical Engineering and Materials Science, Key Laboratory of Molecular and Nano Probes, Ministry of Education, Collaborative Innovation Center of Functionalized Probes for Chemical Imaging in Universities of Shandong, Institutes of Biomedical Sciences, Shandong Normal University, Jinan 250014, People's Republic of China. Email: lip@sdnu.edu.cn

b. The Education Ministry Key Laboratory of Resource Chemistry, Shanghai Key Laboratory of Rare Earth Functional Materials, and Shanghai Municipal Education Committee Key Laboratory of Molecular Imaging Probes and Sensors, Department of Chemistry, Shanghai Normal University, 100 Guilin Road, Shanghai 200234, China. Email: huangcs@shnu.edu.cn

c. Department of Chemistry, University of Bath, Bath, BA2 7AY, UK. Email: t.d.james@bath.ac.uk

d. School of Chemistry and Chemical Engineering, Henan Normal University, Xinxiang 453007, P. R. China. Email: zhanghua1106@163.com

e. Department of Chemistry, The University of Texas at Austin, 105 E 24th street A5300, Austin, TX 787121224, USA. Email: sessler@cm.utexas.edu

f. Key Laboratory for Advanced Materials and Joint International Research Laboratory of Precision Chemistry and Molecular Engineering, Feringa Nobel Prize Scientist Joint Research Center, School of Chemistry and Molecular Engineering, East China University of Science and Technology, 130 Meilong Rd., Shanghai 200237, China. Email: hanhaihao@126.com

g. National Center for Drug Screening, State Key Laboratory of Drug Research, Shanghai Institute of Materia Medica, Chinese Academy of Sciences, 189 Guo Shoujing Rd., Shanghai 201203, P. R. China.

h. School of Physics, Henan Normal University, Xinxiang 453007, P. R. China.

$\$$ These authors contribute equally. 
Table of contents

1. Materials and instruments

2. Mechanism of APAP-induced toxicity

3. Synthesis of probe ATP-LW

4. Generation of various ROS/RNS

5. UV-Vis and fluorescence analyses

6. Theoretical calculations to confirm absence of FRET

7. Transient absorption studies confirming the absence of electron transfer

8. Mass spectrometric analyses

9. Protocols for cell culture

10. MTT assay and fluorescence imaging in live cells

11. NMR spectra

12. Author contributions

13. References 


\section{Materials and instruments}

All starting materials, reagents and solvents were purchased from commercial sources and used without further purification. 3-Morpholinosydnonimine hydrochloride (SIN-1) was purchased from Sigma-Aldrich Co., LLC. Uric acid was purchased from Energy Chemical. 4-Acetamidophenol (APAP) and $N$-acetyl-L-cysteine (NAC) were purchased from Shanghai Aladdin Biochemical Technology Co., Ltd. Oligomycin A was purchased from MedChemExpress. Adenosine 5'-triphosphate (ATP) disodium salt hydrate purchased from Acros Organics was used to represent ATP for all solution experiments, and molecular weight is 551.14 (anhydrous basis) for the calculation of ATP concentrations. ATP disodium salt purchased from MedChemExpress for the exogenous addition of ATP in the cell work. All water was deionized which is generated by a reverse osmosis (UltraPurified Type I, 18.2 Megohm water). Thin-layer chromatography was performed using commercially available Fluorochem aluminum-backed plates coated with a layer of silica gel $(60 \AA)$ with fluorescent indicator UV254. These plates were visualized using ultraviolet light with a wavelength of either 254 or $365 \mathrm{~nm}$. Silica gel column chromatography was carried out using Sigma Aldrich $60 \AA$ silica gel (200-400 mesh). Nuclear Magnetic Resonance (NMR) spectroscopy experiments were performed in chloroform- $d$ on either an Agilent ProPlus 500 spectrometer, or in the case of ATP-LW a $500 \mathrm{MHz}$ Bruker Avance III with a prodigy cryoprobe. Proton decoupling was used for all ${ }^{13} \mathrm{C}$ NMR spectra. ${ }^{1} \mathrm{H}$ and ${ }^{13} \mathrm{C}$ NMR chemical shifts $(\delta)$ are quoted in parts per million ( $\mathrm{ppm}$ ) and are referenced to the deuterated solvent. Fluorescence measurements were performed on a BMG Labtech CLARIOstar ${ }^{\circledR}$ plate reader using Greiner Bio-One microplates (96-well, PS, f-bottom (chimney well), black-walled). Data were collected via the BMG Labtech Clariostar data analysis software package MARS. LC-MS analysis were performed using an Agilent QTOF 6545 with Jetstream ESI spray source coupled to an Agilent 1260 Infinity II Quat pump HPLC with 1260 autosampler, column oven compartment and variable wavelength detector (VWD). MTT assay was performed using a Triturus microplate reader. One-photon confocal imaging was performed on Leica SP8 high-resolution fluorescence microscope. The two-photon fluorescence images were taken using a LSM 880 NLO microscope (Zeiss Co., Ltd. Germany). 


\section{Mechanism of APAP-induced toxicity}

CYP2E1 is implicated in the metabolism of APAP to generate $N$-acetyl-p-benzoquinone imine (NAPQI) which highly toxic to the liver. ${ }^{1-2}$ It is believed that the toxicity of NAPQI is partly due to conjunction with crucial proteins and with the antioxidant glutathione (GSH) resulting in an increase in vulnerability towards oxidative stress. ${ }^{3-4}$ NAPQI interferes with complex I/II of the mitochondrial electron transport chain, leading to a release of electrons. The electrons are captured by molecular oxygen, inducing the over-production of superoxide $\left(\mathrm{O}_{2}{ }^{--}\right) .^{5-6}$ Subsequently, endogenous nitric oxide can react with $\mathrm{O}_{2}{ }^{--}$to generate $\mathrm{ONOO}^{-7}$ which is a scavenger of GSH. ${ }^{8}$ However, NAC is a precursor for the substrate (L-cysteine) in the synthesis of hepatic GSH and commonly used for the treatment of APAP overdose. ${ }^{9}$ The mitochondrial permeability transition (MPT) is a vital event in apoptotic and necrotic cell death. ${ }^{10-11}$ An increase of reactive oxygen species (ROS, e.g. $\mathrm{H}_{2} \mathrm{O}_{2}$ ) ${ }^{12}$ or RNS (e.g. ONOO $\left.{ }^{-}\right)^{13}$ promotes MPT. ${ }^{3}$ The onset of MPT increases mitochondrial membrane permeability and changes the mitochondrial electrochemical gradient (i.e. membrane potential and $\mathrm{pH}$ gradient), ${ }^{14-15}$ resulting in reduced ATP production. ${ }^{16-18}$ In addition, defective or impaired ATP production has been associated with interactions between NAPQI and ATP-synthase $\alpha$ subunit. ${ }^{19}$ 


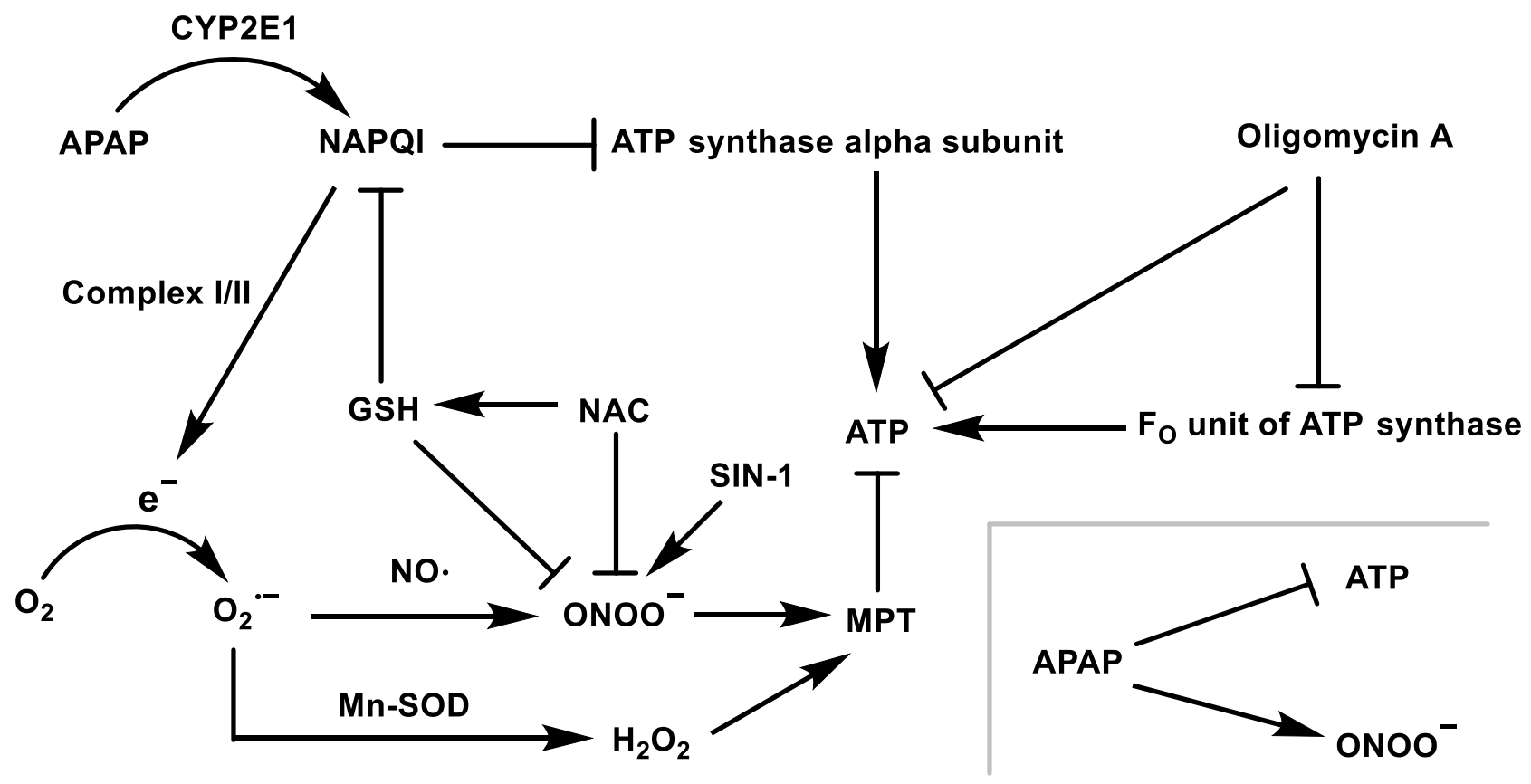

Scheme S1. Mechanism of APAP-induced toxicity. The depletion of ATP and increase of $\mathrm{ONOO}^{-}$cause hepatic necrosis. ${ }^{3}$ The arrows indicate positive regulation, bars indicate negative regulation. Mn-SOD, manganese superoxide dismutase.

3. Synthesis of probe ATP-LW
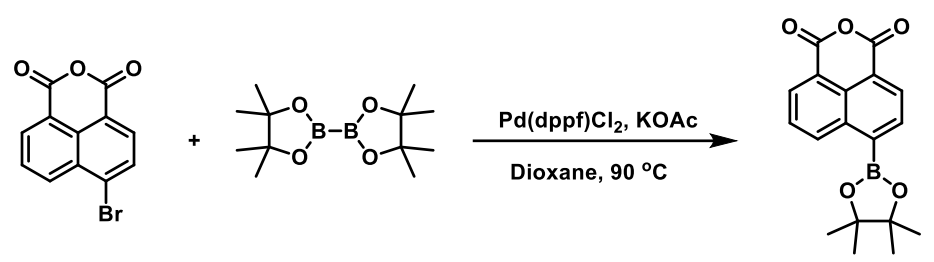

NA-Bpin
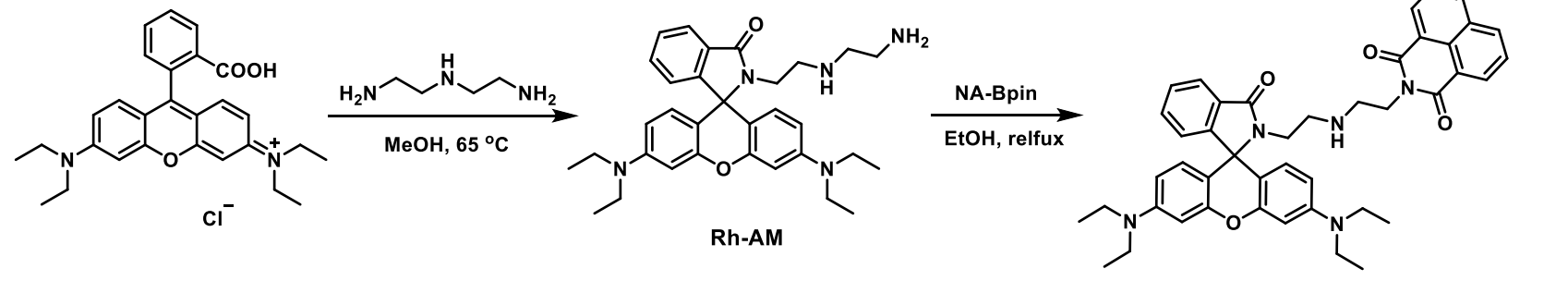

ATP-LW

Scheme S2. Synthesis of probe ATP-LW.

ST 


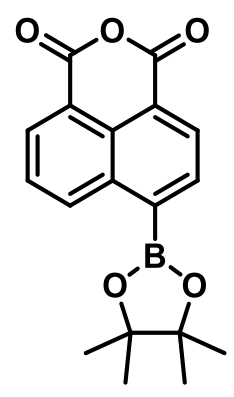

NA-Bpin

NA-Bpin was synthesized using revised published literature procedures. ${ }^{20}$ Characterization data were consistent with previous literature reports. ${ }^{20}{ }^{1} \mathrm{H} \mathrm{NMR}\left(500 \mathrm{MHz}, \mathrm{CDCl}_{3}\right) \delta_{H} 9.22(\mathrm{dd}, J=8.5,1.1 \mathrm{~Hz}, 1 \mathrm{H}$, $\operatorname{Ar} H), 8.61(\mathrm{dd}, J=7.3,1.0 \mathrm{~Hz}, 1 \mathrm{H}, \operatorname{Ar} H), 8.57(\mathrm{~d}, J=7.2 \mathrm{~Hz}, 1 \mathrm{H}, \operatorname{Ar} H), 8.34(\mathrm{~d}, J=7.3 \mathrm{~Hz}, 1 \mathrm{H}, \operatorname{Ar} H), 7.83$ $(\mathrm{dd}, J=8.4,7.3 \mathrm{~Hz}, 1 \mathrm{H}, \mathrm{Ar} H), 1.47\left(\mathrm{~s}, 12 \mathrm{H}, 4 \times \mathrm{CH}_{3}\right) .{ }^{13} \mathrm{C}$ NMR $\left(126 \mathrm{MHz}, \mathrm{CDCl}_{3}\right) \delta_{C} 160.9,160.8,136.6$, $136.2,135.5,133.2,132.0,130.0,127.7,120.9,118.8,85.0,25.1$.

\section{Synthesis of Rh-AM}

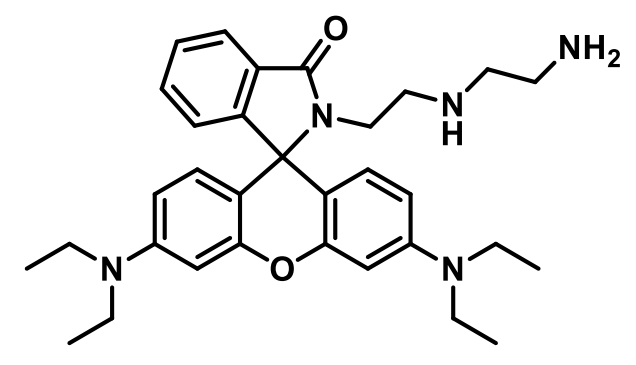

Rh-AM

Rh-AM was synthesized using revised reported literature procedures. ${ }^{21}$ Characterization data were consistent with previous literature reports. ${ }^{21}{ }^{1} \mathrm{H}$ NMR $\left(500 \mathrm{MHz}, \mathrm{CDCl}_{3}\right) \delta_{H} 7.91-7.85(\mathrm{~m}, 1 \mathrm{H}, \mathrm{Ar} H), 7.42(\mathrm{dd}, J=5.6$, $3.1 \mathrm{~Hz}, 2 \mathrm{H}, \mathrm{Ar} H), 7.10-7.05$ (m, 1H, ArH), 6.42 (d, $J=8.8 \mathrm{~Hz}, 2 \mathrm{H}, \mathrm{Ar} H), 6.37$ (d, J=2.6 Hz, 2H, ArH), 6.27 $(\mathrm{d}, J=2.6 \mathrm{~Hz}, 1 \mathrm{H}, \mathrm{Ar} H), 6.25(\mathrm{~d}, J=2.6 \mathrm{~Hz}, 1 \mathrm{H}, \mathrm{Ar} H), 3.32$ (q, $\left.J=7.1 \mathrm{~Hz}, 8 \mathrm{H}, 4 \times \mathrm{CH}_{3} \mathrm{CH}_{2}\right), 3.27$ (t, $\left.J=6.5 \mathrm{~Hz}, 2 \mathrm{H}, \mathrm{CH}_{2}\right), 2.63\left(\mathrm{t}, J=5.9 \mathrm{~Hz}, 2 \mathrm{H}, \mathrm{CH}_{2}\right), 2.48\left(\mathrm{t}, J=5.9 \mathrm{~Hz}, 2 \mathrm{H}, \mathrm{CH}_{2}\right), 2.40(\mathrm{t}, J=6.5 \mathrm{~Hz}, 2 \mathrm{H}$, $\left.\mathrm{CH}_{2}\right), 1.15\left(\mathrm{t}, J=7.1 \mathrm{~Hz}, 12 \mathrm{H}, 4 \times \mathrm{CH}_{3}\right) .{ }^{13} \mathrm{C} \mathrm{NMR}\left(126 \mathrm{MHz}, \mathrm{CDCl}_{3}\right) \delta_{C} 168.7,153.7,153.4,148.9,132.5$, $131.3,128.9,128.1,123.9,122.9,108.2,105.7,97.9,65.2,51.5,47.9,44.5,41.6,40.3,12.7$. 


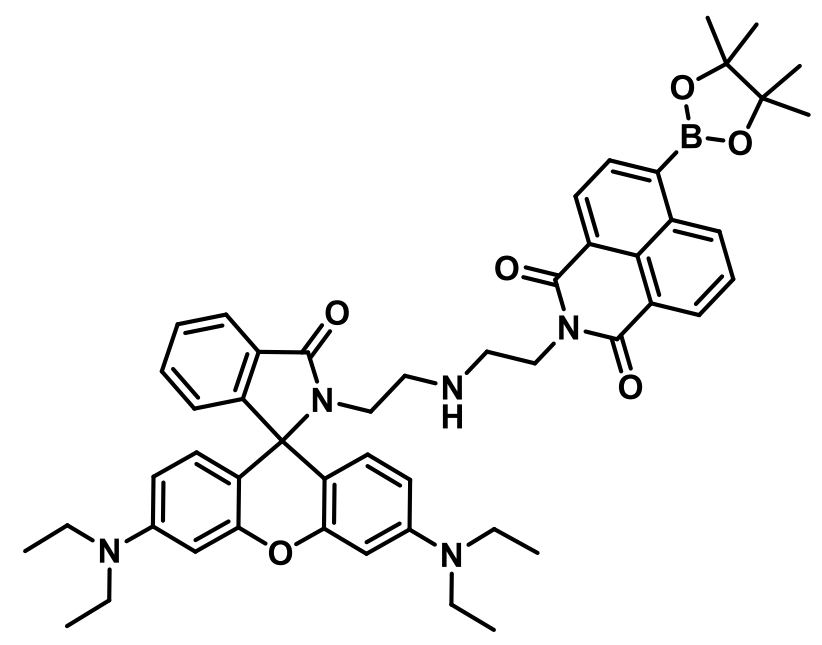

ATP-LW

ATP-LW was synthesized using revised reported literature procedures. ${ }^{22}{ }^{1} \mathrm{H}$ NMR $\left(500 \mathrm{MHz}, \mathrm{CDCl}_{3}\right) \delta_{H} 9.08$ $(\mathrm{d}, J=8.5 \mathrm{~Hz}, 1 \mathrm{H}, \operatorname{Ar} H), 8.52(\mathrm{dd}, J=7.3,1.2 \mathrm{~Hz}, 1 \mathrm{H}, \operatorname{Ar} H), 8.49(\mathrm{~d}, J=7.2 \mathrm{~Hz}, 1 \mathrm{H}, \operatorname{Ar} H), 8.24(\mathrm{~d}, J=7.3 \mathrm{~Hz}$, 1H, $\operatorname{Ar} H), 7.73(\mathrm{dd}, J=8.5,7.3 \mathrm{~Hz}, 1 \mathrm{H}, \operatorname{Ar} H), 7.70-7.61(\mathrm{~m}, 1 \mathrm{H}, \operatorname{Ar} H), 7.42-7.35$ (m, 2H, ArH), $7.04(\mathrm{~d}$, $J=7.6 \mathrm{~Hz}, 1 \mathrm{H}, \operatorname{Ar} H), 6.43(\mathrm{~d}, J=8.9 \mathrm{~Hz}, 2 \mathrm{H}, \operatorname{Ar} H), 6.35(\mathrm{~d}, J=2.6 \mathrm{~Hz}, 2 \mathrm{H}, \operatorname{Ar} H), 6.26(\mathrm{dd}, J=8.9,2.6 \mathrm{~Hz}$, $2 \mathrm{H}, \mathrm{ArH}), 4.22\left(\mathrm{bs}, 2 \mathrm{H},[\mathrm{C}(\mathrm{O})]_{2} \mathrm{NCH}_{2} \mathrm{CH}_{2}\right), 3.38-3.23\left(\mathrm{~m}, 10 \mathrm{H}, 4 \times \mathrm{CH}_{3} \mathrm{CH}_{2}+\mathrm{C}(\mathrm{O}) \mathrm{NCH}_{2}\right), 2.85$ (bs, $2 \mathrm{H}$, $\mathrm{NHCH}_{2} \mathrm{CH}_{2}$ ), 2.49 (bs, $\left.2 \mathrm{H}, \mathrm{NHCH}_{2} \mathrm{CH}_{2}\right), 1.45$ (s, $12 \mathrm{H}, 4$ x OCCH$\left.H_{3}\right), 1.134$ (t, $12 \mathrm{H} \mathrm{J}=7.0 \mathrm{~Hz}, 4$ x NCH $\mathrm{CH}_{3}$ ). ${ }^{13} \mathrm{C}$ NMR $\left(126 \mathrm{MHz}, \mathrm{CDCl}_{3}\right) \delta_{C} 168.7,164.6,164.6,153.8,153.4,148.9,135.8,135.4,135.0,132.5,131.0$, 129.9, 128.8, 128.1, 128.0, 127.1, 124.9, 123.9, 122.9, 122.8, 108.3, 97.9, 84.7, 65.2, 47.7, 47.1, 44.5, 39.8, 38.4, 25.1, 12.7. HRMS $\left(\mathrm{ES}^{+}\right)$: calc. for $\mathrm{C}_{50} \mathrm{H}_{56} \mathrm{BN}_{5} \mathrm{O}_{6}[\mathrm{M}+\mathrm{H}]^{+} \mathrm{m} / \mathrm{z} 834.4405$, found $\mathrm{m} / \mathrm{z} 834.4407$. 


\section{Generation of various ROS/RNS}

\section{ROO•}

ROO• was generated from 2,2'-azobis(2-amidinopropane) dihydrochloride (AAPH). AAPH was added into deionized water, and then stirred at $37{ }^{\circ} \mathrm{C}$ for $30 \mathrm{~min}$ to give $0.1 \mathrm{M} \mathrm{AAPH}$.

\section{$\mathbf{O}_{2}{ }^{\circ}$}

Superoxide was generated from $\mathrm{KO}_{2} . \mathrm{KO}_{2}$ and 18 -crown-6 ether $(2.5 \mathrm{eq})$ was dissolved in DMSO to afford a $0.25 \mathrm{M}$ solution.

\section{$\cdot \mathrm{OH}$}

Hydroxyl radical was generated by the Fenton reaction. To prepare an $\bullet \mathrm{OH}$ solution, hydrogen peroxide $\left(\mathrm{H}_{2} \mathrm{O}_{2}\right.$, 10 eq) was added to $\mathrm{Fe}\left(\mathrm{ClO}_{4}\right)_{2}$ in deionized water.

\section{${ }^{1} \mathbf{O}_{2}$}

${ }^{1} \mathrm{O}_{2}$ was generated by reacting $\mathrm{H}_{2} \mathrm{O}_{2}(1 \mathrm{mM})$ with $\mathrm{NaClO}(1 \mathrm{mM})$. The solution of $\mathrm{H}_{2} \mathrm{O}_{2}$ was added in one portion to the aqueous solution of $\mathrm{NaClO}$ and stirred for 2 minutes. The resulting solution was used immediately.

\section{ONOO}

Simultaneously, 0.6 $\mathrm{M} \mathrm{NaNO}_{2}, 0.6 \mathrm{M}$ in $\mathrm{HCl}, 0.7 \mathrm{M}$ in $\mathrm{H}_{2} \mathrm{O}_{2}$ was added at to a $3 \mathrm{M} \mathrm{NaOH}$ solution at $0{ }^{\circ} \mathrm{C}$. The concentration of peroxynitrite was estimated using an extinction co-efficient of $1670 \mathrm{M}^{-1} \mathrm{~cm}^{-1}$ at $302 \mathrm{~nm}$ in $0.5 \mathrm{M}$ sodium hydroxide aqueous solution.

\section{$\mathrm{ClO}^{-}$}

The concentration of $\mathrm{ClO}^{-}$was determined from the absorption at $292 \mathrm{~nm}\left(\mathcal{E}=350 \mathrm{M}^{-1} \mathrm{~cm}^{-1}\right)$.

\section{$\mathrm{H}_{2} \mathrm{O}_{2}$}

The concentration of $\mathrm{H}_{2} \mathrm{O}_{2}$ was determined from the absorption at $240 \mathrm{~nm}\left(\varepsilon=43.6 \mathrm{M}^{-1} \mathrm{~cm}^{-1}\right)$. 


\section{UV-Vis and fluorescence analyses}

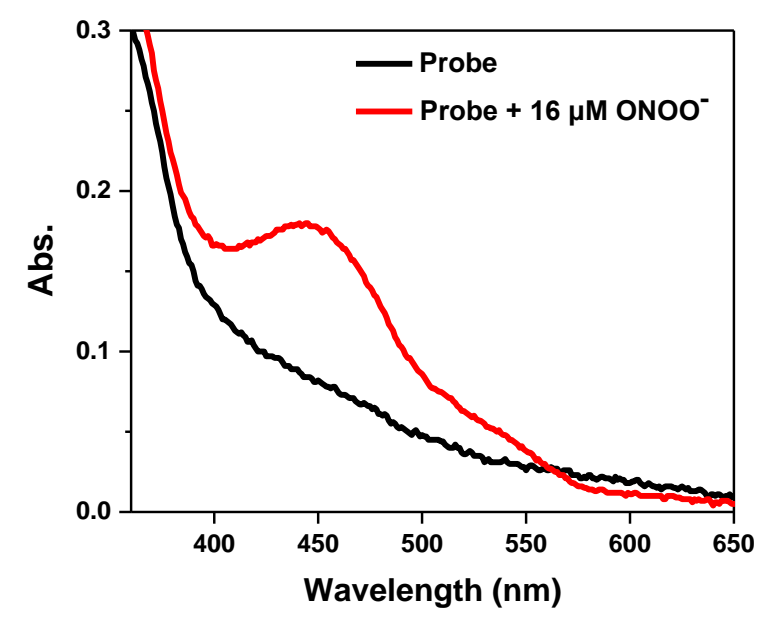

Figure S1. Absorption spectra of probe ATP-LW $(15 \mu \mathrm{M})$ with and without $\mathrm{ONOO}^{-}(16 \mu \mathrm{M})$ in modified PBS buffer solution $\left(10 \mathrm{mM}, \mathrm{V} / \mathrm{V}, \mathrm{EtOH} / \mathrm{H}_{2} \mathrm{O}=1 / 99, \mathrm{pH}=7.40\right)$ after $1 \mathrm{~min}$.

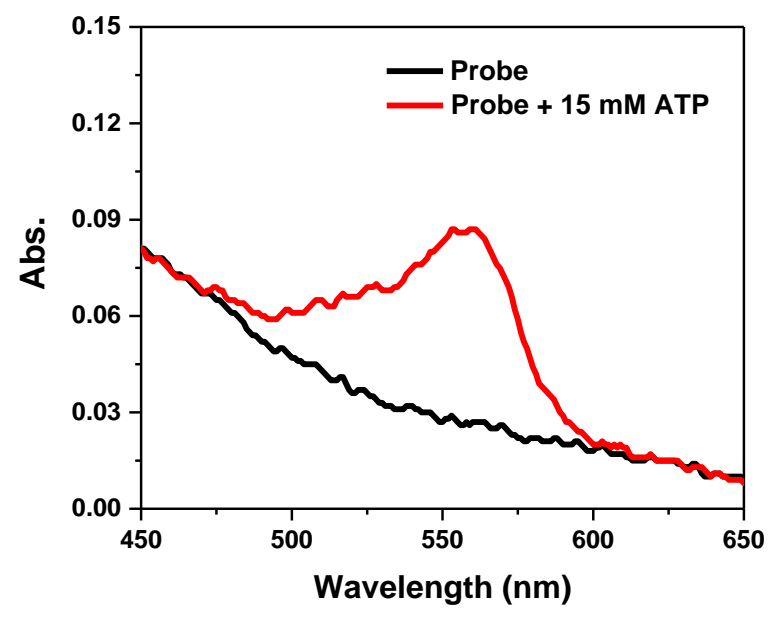

Figure S2. Absorption spectra of probe ATP-LW $(15 \mu \mathrm{M})$ with and without ATP $(15 \mathrm{mM})$ in modified PBS buffer solution $\left(10 \mathrm{mM}, \mathrm{V} / \mathrm{V}, \mathrm{EtOH} / \mathrm{H}_{2} \mathrm{O}=1 / 99, \mathrm{pH}=7.40\right)$ after $100 \mathrm{~min}$. 


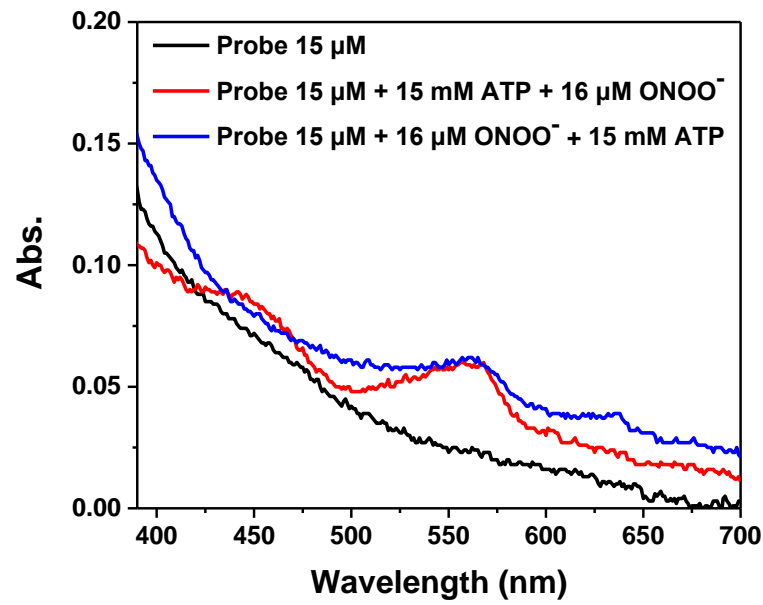

Figure S3. Absorption spectra of probe ATP-LW $(15 \mu \mathrm{M})$, ATP-LW $(15 \mu \mathrm{M})$ with addition of ATP $(15 \mathrm{mM})$ wait 100 min prior to the addition of $\mathrm{ONOO}^{-}(16 \mu \mathrm{M})$ wait $1 \mathrm{~min}$, ATP-LW $(15 \mu \mathrm{M})$ with addition of ONOO $(16 \mu \mathrm{M})$ wait $1 \mathrm{~min}$ then add ATP $(15 \mathrm{mM})$ and wait $100 \mathrm{~min}$ in modified PBS buffer solution $(10 \mathrm{mM}, \mathrm{V} / \mathrm{V}$, $\mathrm{EtOH} / \mathrm{H}_{2} \mathrm{O}=1 / 99, \mathrm{pH}=7.40$ ).

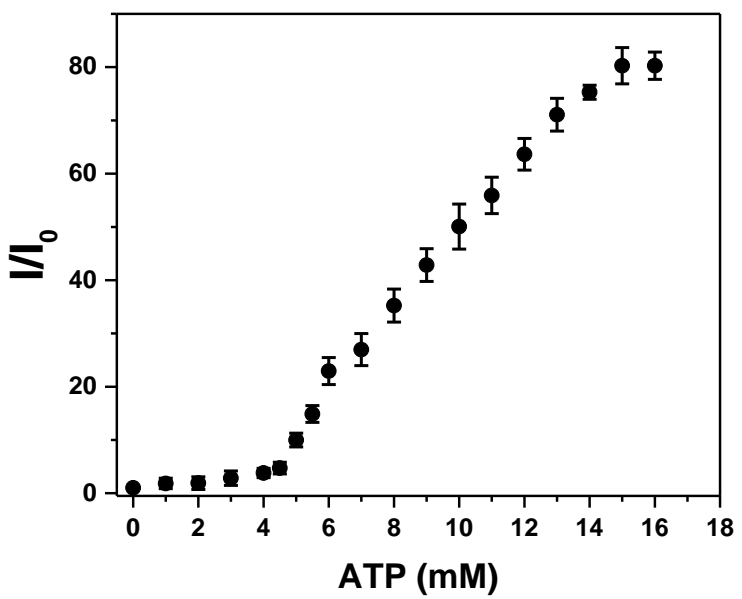

Figure S4. Emission at $587 \mathrm{~nm}$ of the probe ATP-LW $(15 \mu \mathrm{M})$ as a function of increasing ATP concentration (from 0 to $16 \mathrm{mM}$ ) in modified PBS buffer solution $\left(10 \mathrm{mM}, \mathrm{V} / \mathrm{V}, \mathrm{EtOH} / \mathrm{H}_{2} \mathrm{O}=1 / 99, \mathrm{pH}=7.40\right)$ after $100 \mathrm{~min}$. Excited at 520 (bandwidth 8) $\mathrm{nm}$. 


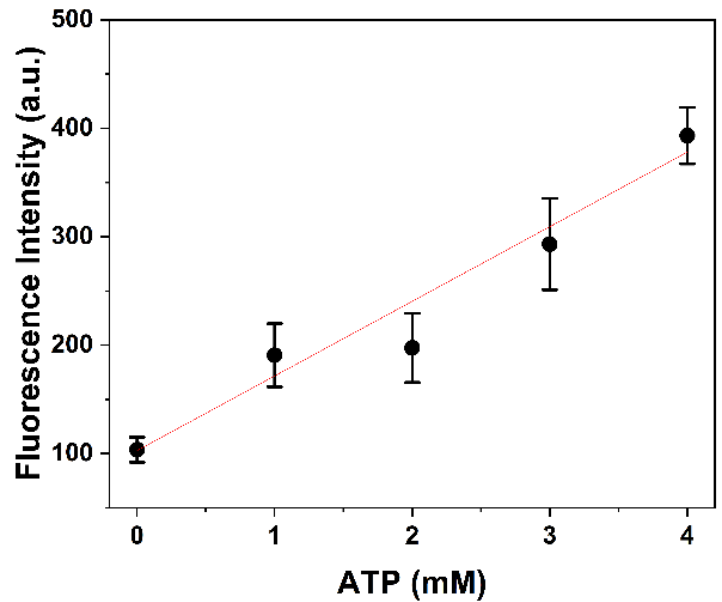

Figure S5. Relationship between fluorescence intensity at at $587 \mathrm{~nm}$ of ATP-LW (15 $\mu \mathrm{M})$ and concentration of ATP $(0-4 \mathrm{mM}) . \lambda_{\mathrm{ex} / \mathrm{em}}=520 / 587 \mathrm{~nm}$. Linear equation: $\mathrm{y}_{1}=102.747+68.812 \times[$ ATP $](\mathrm{mM}), \mathrm{R}^{2}=0.976$. On this basis, the limit of detection is $63 \mu \mathrm{M}$.

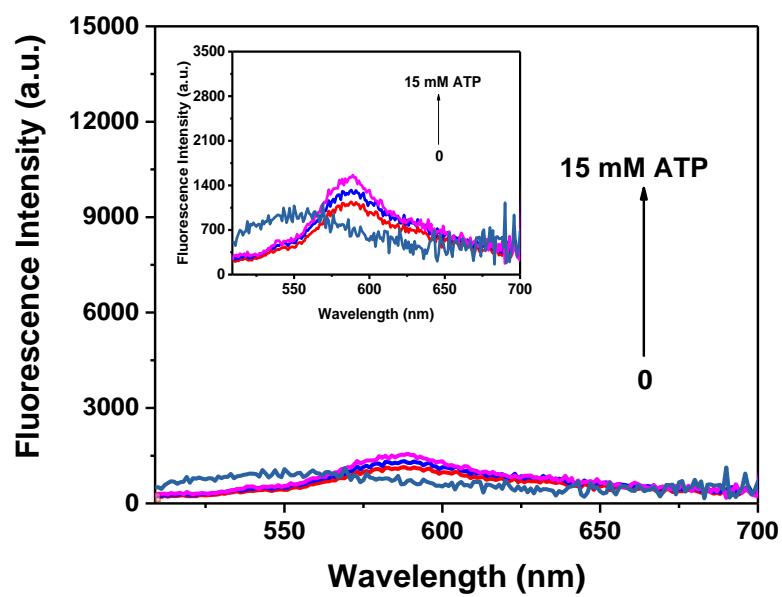

Figure S6. Changes in the fluorescence emission intensity of probe ATP-LW (15 $\mu \mathrm{M})$ seen as a function of increasing ATP concentration (from 0 to $15 \mathrm{mM}$ ) in modified PBS buffer solution $\left(10 \mathrm{mM}, \mathrm{V} / \mathrm{V}, \mathrm{EtOH} / \mathrm{H}_{2} \mathrm{O}\right.$ $=1 / 99, \mathrm{pH}=7.40$ ) after 100 min. Inset: enlarged spectra. Excited at 488 (bandwidth 8) nm. 


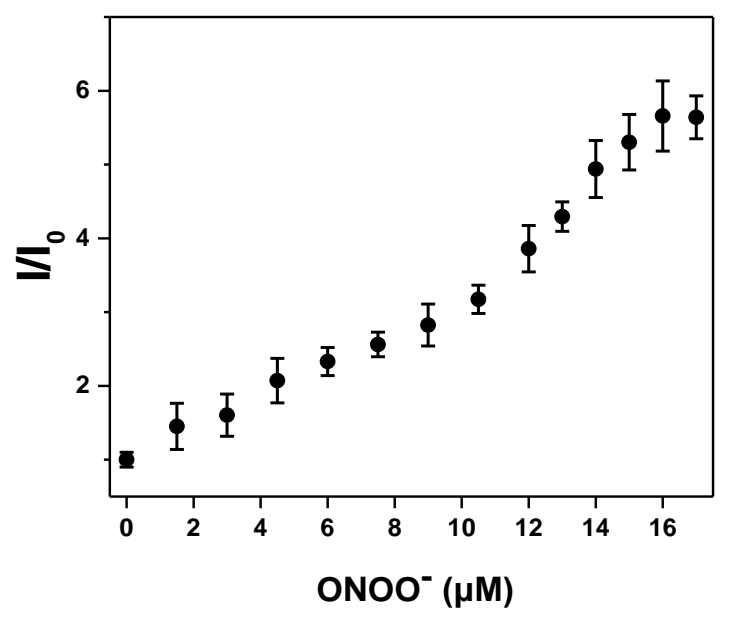

Figure S7. Emission at $562 \mathrm{~nm}$ of the probe ATP-LW $(15 \mu \mathrm{M})$ as a function of increasing $\mathrm{ONOO}^{-}$ concentration (from 0 to $17 \mu \mathrm{M}$ ) in modified PBS buffer solution ( $10 \mathrm{mM}, \mathrm{V} / \mathrm{V}, \mathrm{EtOH} / \mathrm{H}_{2} \mathrm{O}=1 / 99, \mathrm{pH}=7.40$ ) after 1 min. Excited at 450 (bandwidth 8) $\mathrm{nm}$.

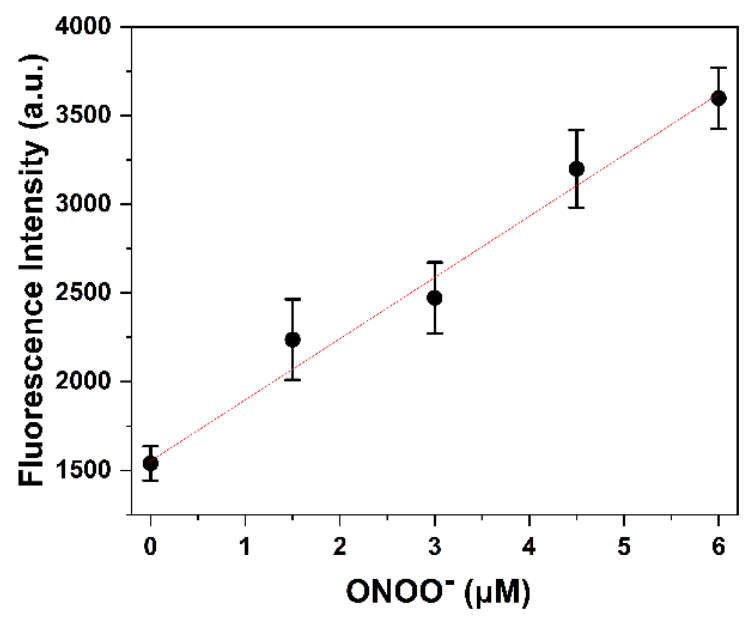

Figure S8. Relationship between fluorescence intensity at $562 \mathrm{~nm}$ of ATP-LW (15 $\mu \mathrm{M})$ and concentration of $\mathrm{ONOO}^{-}(0-6 \mu \mathrm{M}) \cdot \lambda_{\mathrm{ex} / \mathrm{em}}=450 / 562 \mathrm{~nm}$. Linear equation: $\mathrm{y}_{2}=1553.170+344.790 \times\left[\mathrm{ONOO}^{-}\right](\mu \mathrm{M})$, $\mathrm{R}^{2}=0.992$. On this basis, the limit of detection is $26 \mathrm{nM}$. 


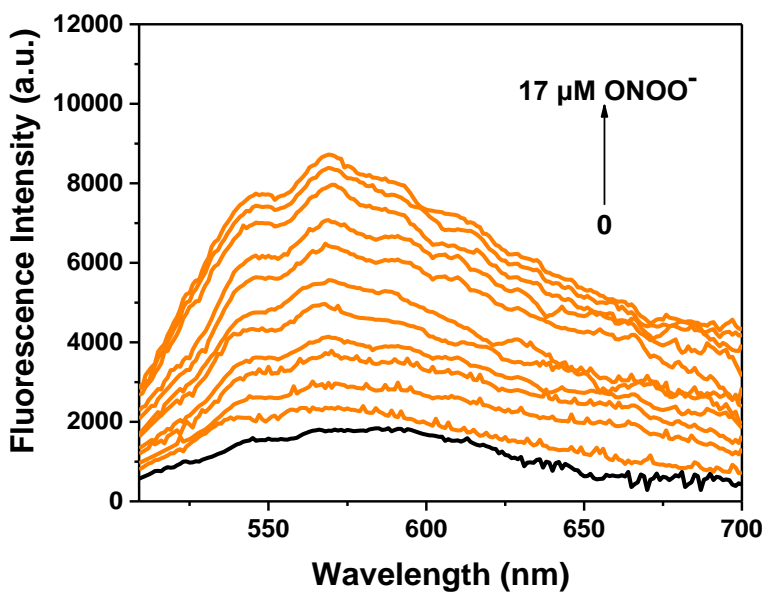

Figure S9. Changes in fluorescence emission intensity of the probe ATP-LW (15 $\mu \mathrm{M})$ as a function of increasing $\mathrm{ONOO}^{-}$concentration (from 0 to $17 \mu \mathrm{M}$ ) in modified PBS buffer solution $\left(10 \mathrm{mM}, \mathrm{V} / \mathrm{V}, \mathrm{EtOH} / \mathrm{H}_{2} \mathrm{O}\right.$ $=1 / 99, \mathrm{pH}=7.40)$ after $1 \mathrm{~min}$. Excited at 488 (bandwidth 8$) \mathrm{nm}$.

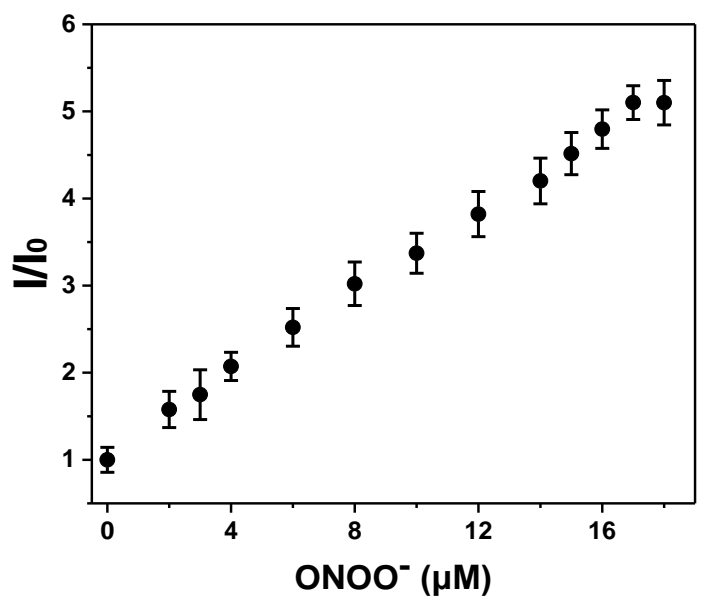

Figure S10. Emission at $568 \mathrm{~nm}$ of the probe ATP-LW $(15 \mu \mathrm{M})$ as a function of increasing $\mathrm{ONOO}^{-}$ concentration (from 0 to $18 \mu \mathrm{M}$ ) in modified PBS buffer solution (10 mM, V/V, EtOH/ $\mathrm{H}_{2} \mathrm{O}=1 / 99, \mathrm{pH}=7.40$ ) after 1 min. Excited at 488 (bandwidth 8) nm. 


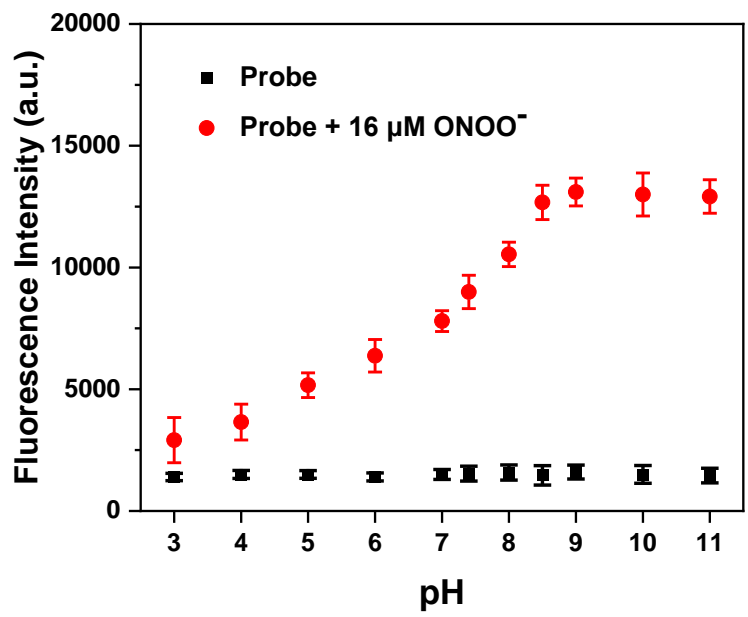

Figure S11. Effects of $\mathrm{pH}$ on the fluorescence of the probe ATP-LW $(15 \mu \mathrm{M})$ in the absence and presence of $\mathrm{ONOO}^{-}(16 \mu \mathrm{M}) \cdot \lambda_{\text {ex } / \mathrm{em}}=450$ (bandwidth 8$) \mathrm{nm} / 562 \mathrm{~nm}$.

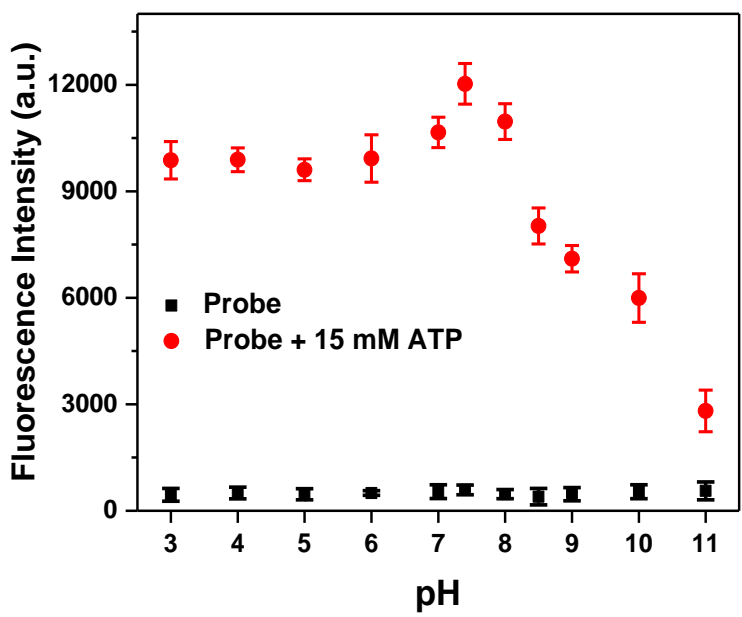

Figure S12. Effects of $\mathrm{pH}$ on the fluorescence of the probe ATP-LW $(15 \mu \mathrm{M})$ in the absence and presence of $\operatorname{ATP}(15 \mathrm{mM}) \cdot \lambda_{\mathrm{ex} / \mathrm{em}}=520$ (bandwidth 8$) \mathrm{nm} / 587 \mathrm{~nm}$. 
Experimental procedure for Figure S13: A solution of $\mathrm{ONOO}^{-}(16 \mu \mathrm{M})$ was added into ATP-LW $(15 \mu \mathrm{M})$, and the fluorescence spectrum (curve 2, in orange) was recorded after $1 \mathrm{~min}$. Then various concentrations of ATP $(1-15 \mathrm{mM})$ were added to the solution, and each line of the fluorescence spectra (curves 3-13, in pink) was recorded after $100 \mathrm{~min} . \lambda_{\mathrm{ex}}=520$ (bandwidth 8) $\mathrm{nm}$.

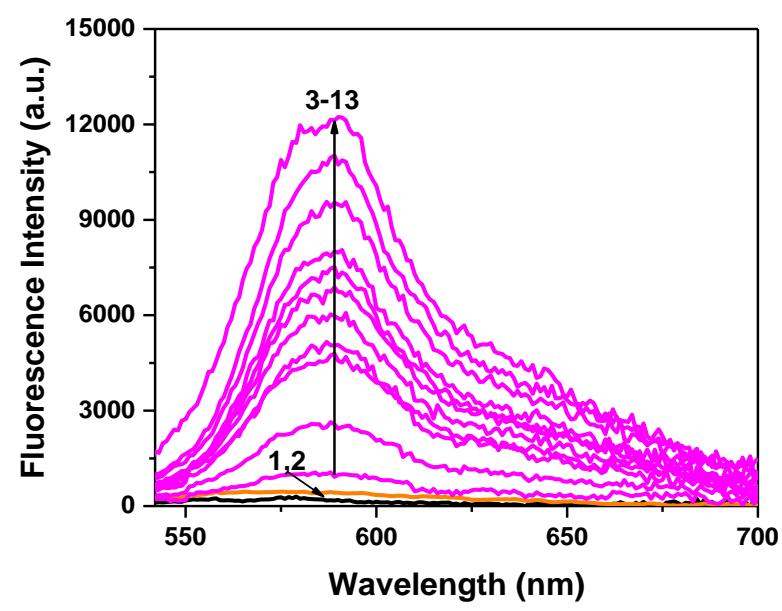

Figure S13. Fluorescence spectra of ATP-LW (15 $\mu \mathrm{M}$, curve 1, black) as a function of increasing $\mathrm{ONOO}^{-}$ concentration (16 $\mu \mathrm{M}$, curve 2, orange) after $1 \mathrm{~min}$ followed by the addition of ATP $(1-15 \mathrm{mM})$ (curves 3-13) in modified PBS buffer solution $\left(10 \mathrm{mM}, \mathrm{V} / \mathrm{V}, \mathrm{EtOH} / \mathrm{H}_{2} \mathrm{O}=1 / 99, \mathrm{pH}=7.40\right)$ after $100 \mathrm{~min} . \lambda_{\mathrm{ex}}=520$ (bandwidth 8) $\mathrm{nm}$.

Experimental procedure for Figure S14: A solution of ATP $(15 \mathrm{mM})$ was added into ATP-LW $(15 \mu \mathrm{M})$, and the fluorescence spectrum (curve 2, in pink) was recorded after $100 \mathrm{~min}$. Then various concentrations of $\mathrm{ONOO}^{-}(1-15 \mu \mathrm{M})$ were added to the solution, and each line of the fluorescence spectra (curves $3-15$, in orange) was recorded after $1 \mathrm{~min} . \lambda_{\mathrm{ex}}=450$ (bandwidth 8 ) $\mathrm{nm}$.

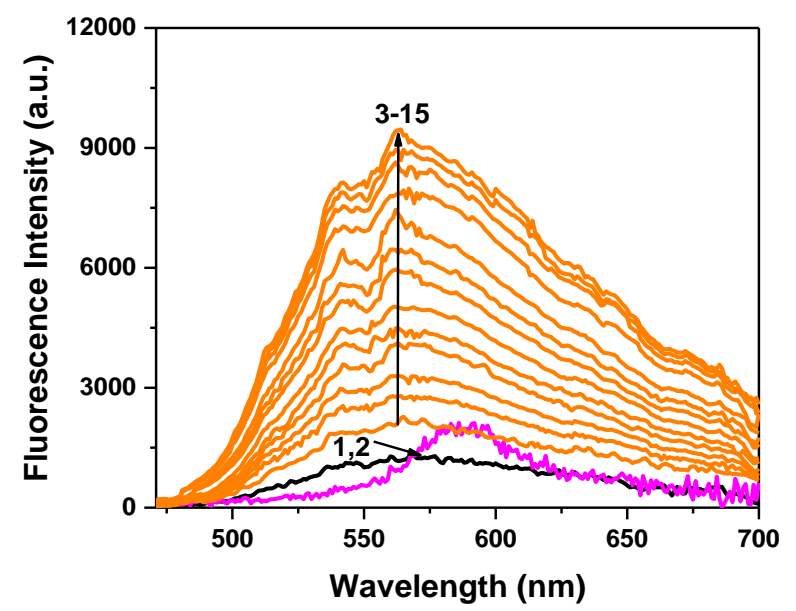

Figure S14. Fluorescence spectra of ATP-LW (15 $\mu \mathrm{M}$, curve 1, black) as a function of increasing ATP concentration ( $15 \mathrm{mM}$, curve 2, pink) after $100 \mathrm{~min}$ followed by the addition of $\mathrm{ONOO}^{-}(1-15 \mu \mathrm{M})$ (curves 3 15) in modified PBS buffer solution $\left(10 \mathrm{mM}, \mathrm{V} / \mathrm{V}, \mathrm{EtOH} / \mathrm{H}_{2} \mathrm{O}=1 / 99, \mathrm{pH}=7.40\right)$ after $1 \mathrm{~min} . \lambda_{\mathrm{ex}}=450$ (bandwidth 8) $\mathrm{nm}$. 
Experimental procedure for Figure S15: A solution of ATP $(15 \mathrm{mM})$ was added into ATP-LW $(15 \mu \mathrm{M})$, and the fluorescence spectrum (curve 2, in pink) was recorded after $100 \mathrm{~min}$. Then various concentrations of $\mathrm{ONOO}^{-}(1-17 \mu \mathrm{M})$ were added to the solution, each line of the fluorescence spectra (curves $3-12$, in orange) was recorded after $1 \mathrm{~min}$. $\lambda_{\mathrm{ex}}=488$ (bandwidth 8 ) $\mathrm{nm}$.

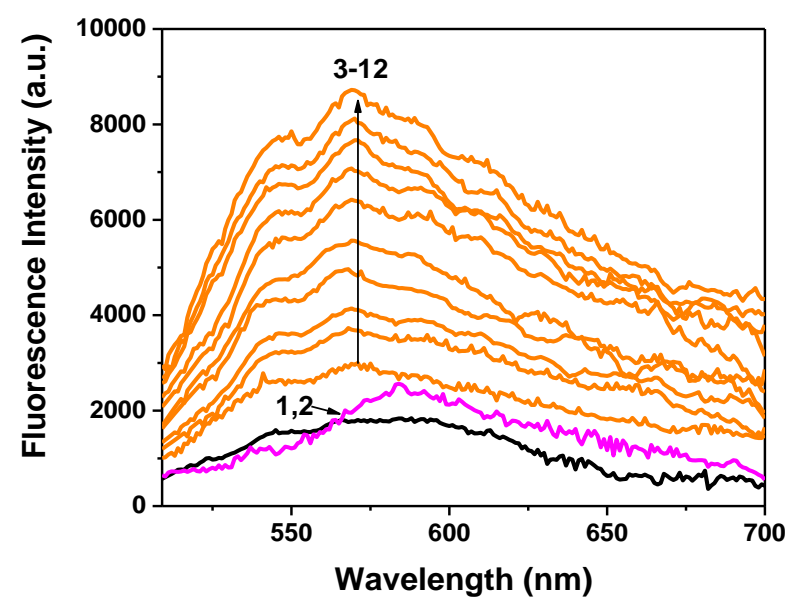

Figure S15. Fluorescence spectra of ATP-LW (15 $\mu \mathrm{M}$, curve 1, black) as a function of increasing ATP concentration ( $15 \mathrm{mM}$, curve 2, pink) after $100 \mathrm{~min}$ followed by the addition of $\mathrm{ONOO}^{-}(1-17 \mu \mathrm{M})$ (curves 3 12) in modified PBS buffer solution $\left(10 \mathrm{mM}, \mathrm{V} / \mathrm{V}, \mathrm{EtOH} / \mathrm{H}_{2} \mathrm{O}=1 / 99, \mathrm{pH}=7.40\right)$ after $1 \mathrm{~min} . \lambda_{\mathrm{ex}}=488$ (bandwidth 8) $\mathrm{nm}$.

Experimental procedure for Figure S16: A solution of $\mathrm{ONOO}^{-}(16 \mu \mathrm{M})$ in modified PBS buffer solution $\left(10 \mathrm{mM}, \mathrm{V} / \mathrm{V}, \mathrm{EtOH} / \mathrm{H}_{2} \mathrm{O}=1 / 99, \mathrm{pH}=7.40\right)$ was placed in a Greiner Bio-One microplate (96-well, PS, $\mathrm{f}$ bottom (chimney well), black-walled), and the intensity was measured every $0.21 \mathrm{~s}$ for $2.95 \mathrm{~s}$. A solution of ATP-LW $(15 \mu \mathrm{M})$ was then pumped into this solution, and the fluorescence spectrum was then recorded every $0.21 \mathrm{~s}$ from $4.15 \mathrm{~s}$ to $29.22 \mathrm{~s}$.

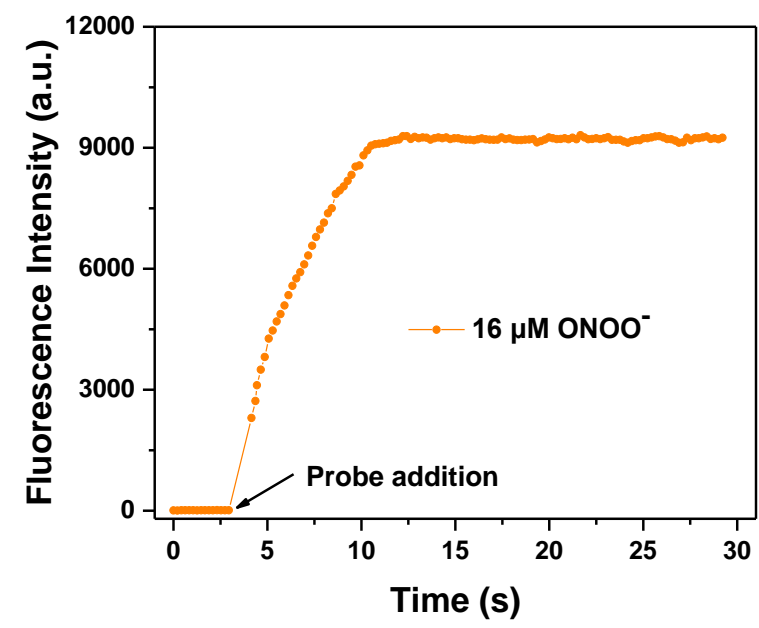

Figure S16. Plots of fluorescence intensity vs. the reaction time of the probe ATP-LW $(15 \mu \mathrm{M})$ with $16 \mu \mathrm{M}$ $\mathrm{ONOO}^{-}\left(\lambda_{\text {ex } / \mathrm{em}}=450\right.$ (bandwidth 8$\left.) \mathrm{nm} / 562 \mathrm{~nm}\right)$ in modified PBS buffer solution $\left(10 \mathrm{mM}, \mathrm{V} / \mathrm{V}, \mathrm{EtOH} / \mathrm{H}_{2} \mathrm{O}=\right.$ $1 / 99, \mathrm{pH}=7.40)$. 
Experimental procedure for Figure S17: A solution of ATP (15 mM) in modified PBS buffer solution (10 $\mathrm{mM}, \mathrm{V} / \mathrm{V}, \mathrm{EtOH} / \mathrm{H}_{2} \mathrm{O}=1 / 99, \mathrm{pH}=7.40$ ) was placed in a Greiner Bio-One microplate (96-well, PS, f-bottom (chimney well), black-walled), and the intensity was measured every $5 \mathrm{~min}$ for $15 \mathrm{~min}$. A solution of ATP$\mathbf{L W}(15 \mu \mathrm{M})$ was then pumped into this solution, and the fluorescence spectrum recorded every 5 min from $20 \mathrm{~min}$ to $165 \mathrm{~min}$.

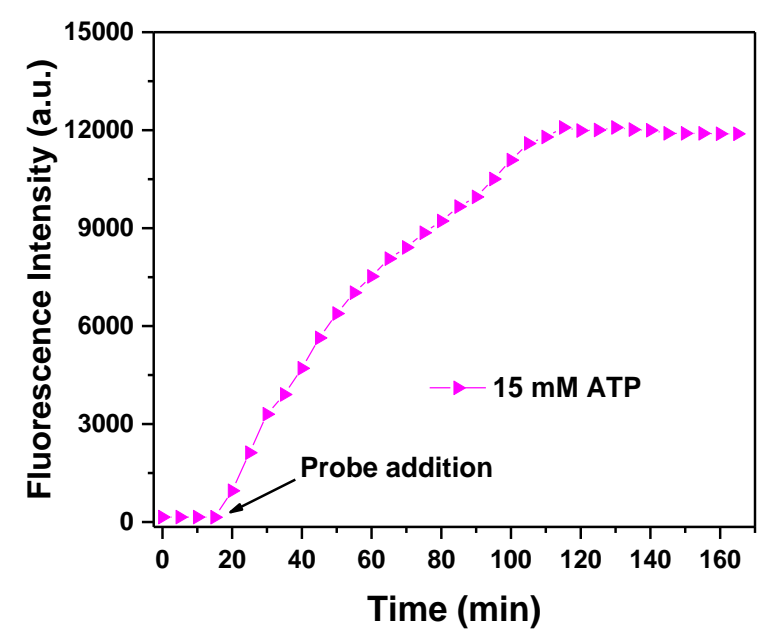

Figure S17. Plots of fluorescence intensity $v s$. the reaction time of the probe ATP-LW (15 $\mu \mathrm{M})$ with $15 \mathrm{mM}$ ATP disodium salt $\left(\lambda_{\text {ex } / \mathrm{em}}=520\right.$ (bandwidth 8$) \mathrm{nm} / 587 \mathrm{~nm}$ ) in modified PBS buffer solution $(10 \mathrm{mM}, \mathrm{V} / \mathrm{V}$, $\mathrm{EtOH} / \mathrm{H}_{2} \mathrm{O}=1 / 99, \mathrm{pH}=7.40$ ).

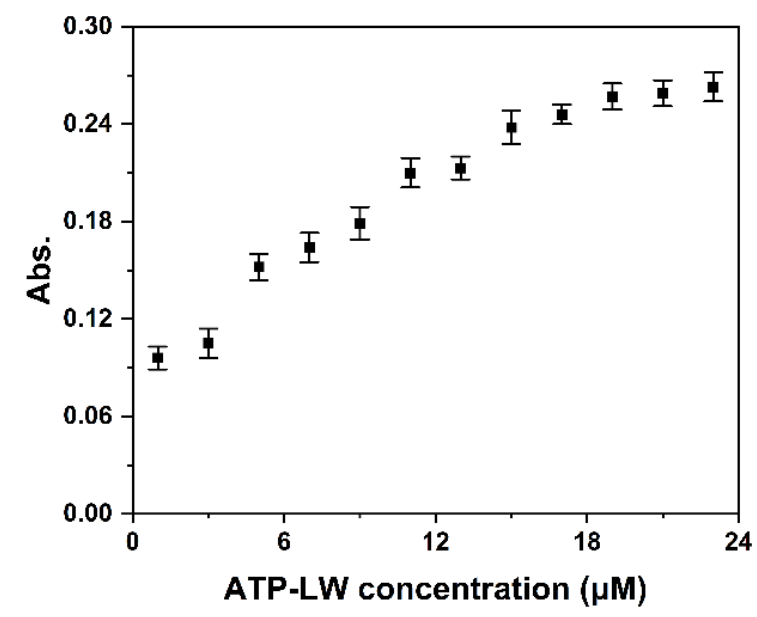

Figure S18. Absorption intensity of various concentrations of ATP-LW $(1-23 \mu \mathrm{M})$ with ONOO$^{-}(16 \mu \mathrm{M})$ in PBS buffer solution $\left(10 \mathrm{mM}, \mathrm{V} / \mathrm{V}, \mathrm{EtOH} / \mathrm{H}_{2} \mathrm{O}=1 / 99, \mathrm{pH}=7.40\right)$ recorded after $1 \mathrm{~min}, \lambda_{\text {abs. }}=445 \mathrm{~nm}$. 


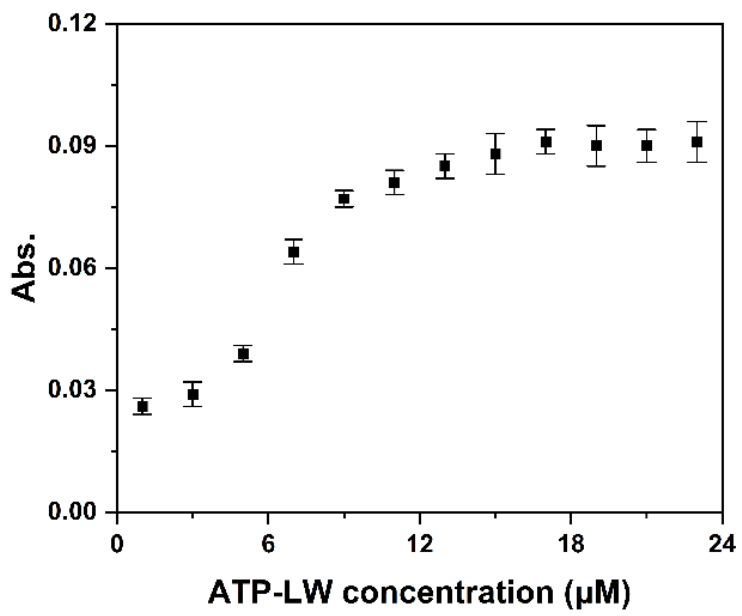

Figure S19. Absorption intensities of various concentrations of ATP-LW $(1-23 \mu \mathrm{M})$ with ATP $(15 \mathrm{mM})$ in PBS buffer solution $\left(10 \mathrm{mM}, \mathrm{V} / \mathrm{V}, \mathrm{EtOH} / \mathrm{H}_{2} \mathrm{O}=1 / 99, \mathrm{pH}=7.40\right)$ recorded after $100 \mathrm{~min}, \lambda_{\text {abs. }}=553 \mathrm{~nm}$.

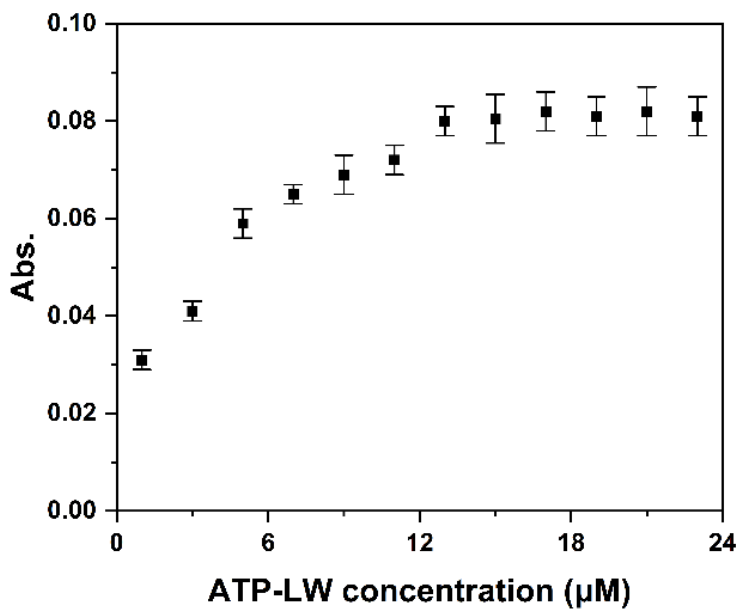

Figure S20. Absorption intensities of various concentrations of ATP-LW (1-23 $\mu \mathrm{M})$ pre-incubated with ONOO $^{-}$ $(16 \mu \mathrm{M})$ for $1 \mathrm{~min}$, followed by addition of ATP $(15 \mathrm{mM})$ and waiting $100 \mathrm{~min}$ before determining the spectral intensity in PBS buffer solution $\left(10 \mathrm{mM}, \mathrm{V} / \mathrm{V}, \mathrm{EtOH} / \mathrm{H}_{2} \mathrm{O}=1 / 99, \mathrm{pH}=7.40\right) ; \lambda_{\text {abs. }}=553 \mathrm{~nm}$. 


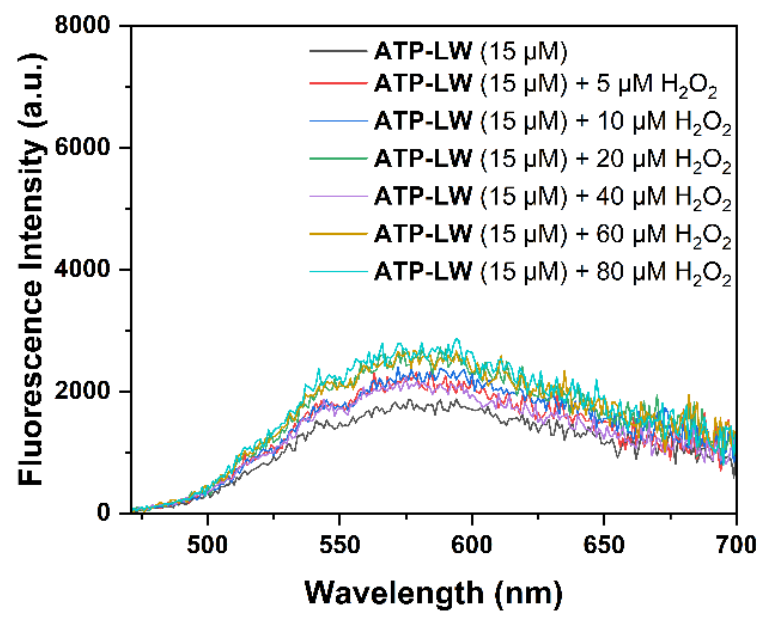

Figure S21. Changes in the fluorescence emission intensity of the probe ATP-LW (15 $\mu \mathrm{M})$ as a function of increasing $\mathrm{H}_{2} \mathrm{O}_{2}$ (from 0 to $80 \mu \mathrm{M}$ ) in PBS buffer solution $\left(10 \mathrm{mM}, \mathrm{V} / \mathrm{V}, \mathrm{EtOH} / \mathrm{H}_{2} \mathrm{O}=1 / 99, \mathrm{pH}=7.40\right.$ ) as recorded after $15 \mathrm{~min}$. Excited at 450 (bandwidth 8) $\mathrm{nm}$. 


\section{Theoretical calculations to confirm absence of FRET}

\section{Quantum Calculations Method}

All calculations of geometric structure and electronic spectra were performed using the Gaussian 16 program. ${ }^{23}$ The functional $\omega$ B97X-D and the TZVP basis set ${ }^{24-26}$ were used in these density functional theoretical (DFT) calculations. ${ }^{27}$ The electronic transition energies and corresponding oscillator strengths were calculated by time-dependent density functional theory (TD-DFT) at the $\omega$ B97X-D/TZVP level. Water was used as solvent in the CPCM calculations to account for solvent effects. ${ }^{28}$

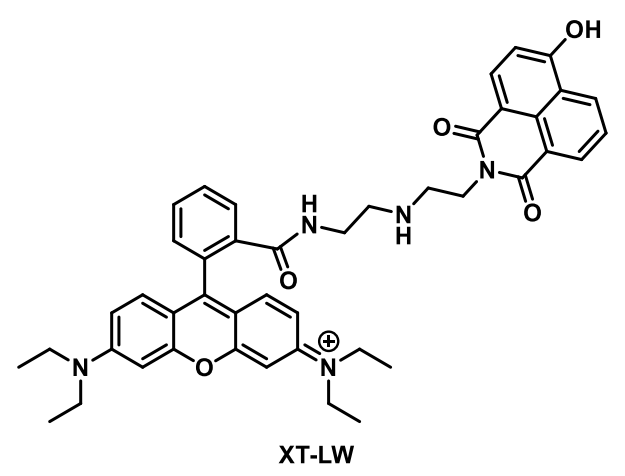

a)

b)
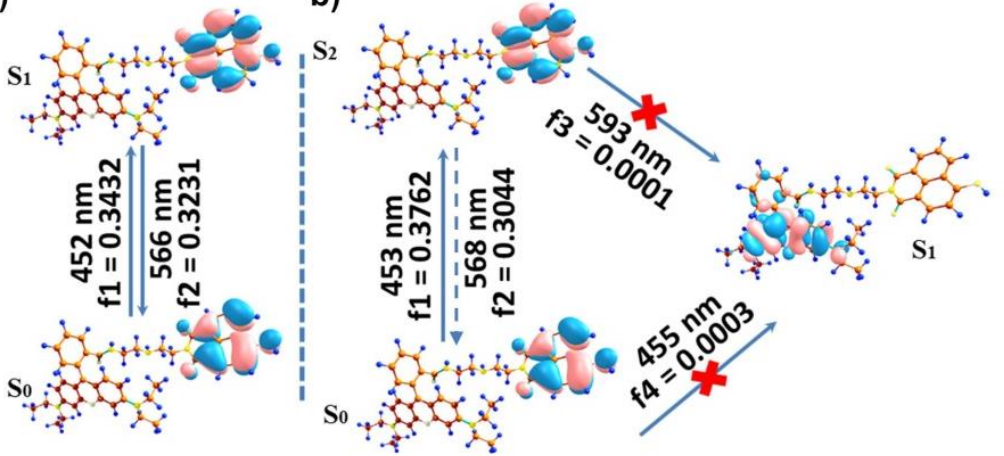

Figure S22. Density functional theoretical calculations of the product XT-LW. (a) Molecular optimal configuration of XT-LW at ground state $\left(S_{0}\right)$ and the first excited singlet state $\left(S_{1}\right)$, where $S_{0}$ and $S_{1}$ are defined by using the 4-hydroxy-1,8-naphthimide fragment as the region of interest (ROI) according to the experimental spectral results. The theoretical absorption and emission wavelengths of XT-LW are $452 \mathrm{~nm}$ and $566 \mathrm{~nm}$, respectively, which is in agreement with the experimental spectral results (Figure S1 and S2). (b) Optimized configuration of XT-LW to confirm no FRET between the two fluorophores. Transitions from the $\mathrm{S}_{2}$ to the $\mathrm{S}_{1}$ and the $S_{0}$ to the $S_{1}$ are forbidden (oscillator strength $\mathrm{f}<0.001$ ). In this case, the rhodamine fragment is the ROI to define $\mathrm{S}_{1}$, and the 4-hydroxy-1,8-naphthimide fragment is the ROI to define $\mathrm{S}_{0}$ and the second excited singlet state $\left(\mathrm{S}_{2}\right)$.

$\begin{array}{crrr}\text { Molecular internal coordinates } & & \\ \mathrm{C} & 9.115606000000 & 2.218460000000 & -1.125342000000 \\ \mathrm{C} & 10.043258000000 & 1.227224000000 & -0.891621000000 \\ \mathrm{C} & 9.699329000000 & 0.070662000000 & -0.135596000000 \\ \mathrm{C} & 8.382515000000 & -0.030106000000 & 0.366387000000 \\ \mathrm{C} & 7.444786000000 & 0.993936000000 & 0.116398000000 \\ \mathrm{C} & 7.819085000000 & 2.095640000000 & -0.620660000000\end{array}$




\begin{tabular}{|c|c|c|c|}
\hline $\mathrm{C}$ & 8.019196000000 & -1.170344000000 & 1.112609000000 \\
\hline $\mathrm{C}$ & 8.933314000000 & -2.169758000000 & 1.349463000000 \\
\hline $\mathrm{C}$ & 10.241829000000 & -2.065793000000 & 0.852705000000 \\
\hline $\mathrm{C}$ & 10.619656000000 & -0.967088000000 & 0.122774000000 \\
\hline $\mathrm{C}$ & 6.080042000000 & 0.883860000000 & 0.635557000000 \\
\hline $\mathrm{N}$ & 5.777985000000 & -0.234674000000 & 1.410433000000 \\
\hline $\mathrm{C}$ & 6.647377000000 & -1.291867000000 & 1.639479000000 \\
\hline $\mathrm{O}$ & 6.270349000000 & -2.272319000000 & 2.261057000000 \\
\hline $\mathrm{O}$ & 11.306066000000 & 1.290114000000 & -1.357131000000 \\
\hline $\mathrm{O}$ & 5.218782000000 & 1.723558000000 & 0.421162000000 \\
\hline $\mathrm{H}$ & 9.401029000000 & 3.088762000000 & -1.702851000000 \\
\hline $\mathrm{H}$ & 7.097206000000 & 2.879238000000 & -0.810086000000 \\
\hline $\mathrm{H}$ & 8.636071000000 & -3.037372000000 & 1.923614000000 \\
\hline $\mathrm{H}$ & 10.951240000000 & -2.858266000000 & 1.047687000000 \\
\hline $\mathrm{H}$ & 11.627602000000 & -0.887388000000 & -0.261434000000 \\
\hline $\mathrm{H}$ & 11.436606000000 & 2.105544000000 & -1.862123000000 \\
\hline $\mathrm{C}$ & -6.605435000000 & -1.271803000000 & -0.102566000000 \\
\hline $\mathrm{C}$ & -5.483284000000 & -0.435293000000 & -0.348213000000 \\
\hline $\mathrm{C}$ & -5.605378000000 & 0.908602000000 & 0.079176000000 \\
\hline $\mathrm{C}$ & -6.738973000000 & 1.411552000000 & 0.668389000000 \\
\hline $\mathrm{C}$ & -7.849372000000 & 0.569603000000 & 0.895874000000 \\
\hline $\mathrm{C}$ & -7.736946000000 & -0.801152000000 & 0.479321000000 \\
\hline $\mathrm{O}$ & -4.572041000000 & 1.771329000000 & -0.065325000000 \\
\hline $\mathrm{C}$ & -3.407366000000 & 1.387156000000 & -0.638834000000 \\
\hline $\mathrm{C}$ & -3.249845000000 & 0.067039000000 & -1.122623000000 \\
\hline $\mathrm{C}$ & -4.288706000000 & -0.857077000000 & -0.942944000000 \\
\hline $\mathrm{C}$ & -2.007175000000 & -0.221677000000 & -1.749118000000 \\
\hline $\mathrm{C}$ & -1.015319000000 & 0.700619000000 & -1.836890000000 \\
\hline $\mathrm{C}$ & -1.180192000000 & 2.026829000000 & -1.308854000000 \\
\hline $\mathrm{C}$ & -2.418698000000 & 2.337848000000 & -0.706372000000 \\
\hline $\mathrm{C}$ & -4.112437000000 & -2.267432000000 & -1.370752000000 \\
\hline $\mathrm{C}$ & -3.142734000000 & -3.082351000000 & -0.773963000000 \\
\hline $\mathrm{C}$ & -2.957937000000 & -4.383845000000 & -1.222585000000 \\
\hline $\mathrm{C}$ & -3.738311000000 & -4.883958000000 & -2.256417000000 \\
\hline $\mathrm{C}$ & -4.699117000000 & -4.079123000000 & -2.850317000000 \\
\hline $\mathrm{C}$ & -4.885370000000 & -2.775987000000 & -2.409529000000 \\
\hline $\mathrm{N}$ & -8.963961000000 & 1.031806000000 & 1.493369000000 \\
\hline $\mathrm{C}$ & -10.178718000000 & 0.214797000000 & 1.537022000000 \\
\hline $\mathrm{C}$ & -10.926534000000 & 0.222047000000 & 0.213850000000 \\
\hline $\mathrm{C}$ & -9.074962000000 & 2.482092000000 & 1.729361000000 \\
\hline $\mathrm{C}$ & -10.338655000000 & 2.922277000000 & 2.438447000000 \\
\hline $\mathrm{N}$ & -0.198159000000 & 2.942795000000 & -1.398214000000 \\
\hline $\mathrm{C}$ & 1.132242000000 & 2.558727000000 & -1.873724000000 \\
\hline $\mathrm{C}$ & 1.947243000000 & 1.831804000000 & -0.815789000000 \\
\hline
\end{tabular}




\begin{tabular}{|c|c|c|c|}
\hline $\mathrm{C}$ & -0.365294000000 & 4.215237000000 & -0.674473000000 \\
\hline $\mathrm{C}$ & 0.775259000000 & 5.198507000000 & -0.833740000000 \\
\hline $\mathrm{C}$ & -2.334707000000 & -2.537078000000 & 0.364562000000 \\
\hline $\mathrm{O}$ & -2.879124000000 & -1.992574000000 & 1.328323000000 \\
\hline $\mathrm{N}$ & -1.008982000000 & -2.652686000000 & 0.258241000000 \\
\hline $\mathrm{H}$ & -6.555176000000 & -2.313040000000 & -0.390920000000 \\
\hline $\mathrm{H}$ & -6.735413000000 & 2.451967000000 & 0.950853000000 \\
\hline $\mathrm{H}$ & -8.559490000000 & -1.482599000000 & 0.624329000000 \\
\hline $\mathrm{H}$ & -1.850131000000 & -1.202073000000 & -2.179605000000 \\
\hline $\mathrm{H}$ & -0.093563000000 & 0.418171000000 & -2.319935000000 \\
\hline $\mathrm{H}$ & -2.629612000000 & 3.310097000000 & -0.290937000000 \\
\hline $\mathrm{H}$ & -2.212974000000 & -5.011737000000 & -0.750350000000 \\
\hline $\mathrm{H}$ & -3.595576000000 & -5.901964000000 & -2.593985000000 \\
\hline $\mathrm{H}$ & -5.306204000000 & -4.462321000000 & -3.659921000000 \\
\hline $\mathrm{H}$ & -5.625841000000 & -2.140419000000 & -2.879198000000 \\
\hline $\mathrm{H}$ & -9.916245000000 & -0.797110000000 & 1.835649000000 \\
\hline $\mathrm{H}$ & -10.811013000000 & 0.600230000000 & 2.330284000000 \\
\hline $\mathrm{H}$ & -11.830606000000 & -0.382768000000 & 0.291455000000 \\
\hline $\mathrm{H}$ & -10.306867000000 & -0.184030000000 & -0.587425000000 \\
\hline $\mathrm{H}$ & -11.213972000000 & 1.239673000000 & -0.056259000000 \\
\hline $\mathrm{H}$ & -8.219414000000 & 2.787726000000 & 2.332329000000 \\
\hline $\mathrm{H}$ & -8.992896000000 & 2.999758000000 & 0.768308000000 \\
\hline $\mathrm{H}$ & -10.276548000000 & 4.001108000000 & 2.581098000000 \\
\hline $\mathrm{H}$ & -10.434063000000 & 2.458630000000 & 3.420384000000 \\
\hline $\mathrm{H}$ & -11.237298000000 & 2.712407000000 & 1.858788000000 \\
\hline $\mathrm{H}$ & 1.023608000000 & 1.949409000000 & -2.767972000000 \\
\hline $\mathrm{H}$ & 1.646471000000 & 3.459519000000 & -2.192602000000 \\
\hline $\mathrm{H}$ & 2.915748000000 & 1.546212000000 & -1.227774000000 \\
\hline $\mathrm{H}$ & 1.433000000000 & 0.928377000000 & -0.481472000000 \\
\hline $\mathrm{H}$ & 2.115285000000 & 2.472057000000 & 0.052280000000 \\
\hline $\mathrm{H}$ & -1.280576000000 & 4.687547000000 & -1.033815000000 \\
\hline $\mathrm{H}$ & -0.513458000000 & 3.994209000000 & 0.387178000000 \\
\hline $\mathrm{H}$ & 0.517870000000 & 6.094526000000 & -0.268931000000 \\
\hline $\mathrm{H}$ & 0.918840000000 & 5.487989000000 & -1.874739000000 \\
\hline $\mathrm{H}$ & 1.715465000000 & 4.812957000000 & -0.439909000000 \\
\hline $\mathrm{C}$ & -0.119399000000 & -1.954337000000 & 1.172114000000 \\
\hline $\mathrm{H}$ & -0.627097000000 & -3.020909000000 & -0.603047000000 \\
\hline $\mathrm{C}$ & 1.275450000000 & -1.888541000000 & 0.586224000000 \\
\hline $\mathrm{H}$ & -0.505172000000 & -0.944410000000 & 1.331230000000 \\
\hline $\mathrm{H}$ & -0.102514000000 & -2.460826000000 & 2.140338000000 \\
\hline $\mathrm{N}$ & 2.167454000000 & -1.189161000000 & 1.500177000000 \\
\hline $\mathrm{H}$ & 1.628493000000 & -2.903551000000 & 0.356401000000 \\
\hline $\mathrm{H}$ & 1.243070000000 & -1.336582000000 & -0.357507000000 \\
\hline $\mathrm{C}$ & 3.508321000000 & -1.070619000000 & 0.944243000000 \\
\hline
\end{tabular}




$\begin{array}{lrrr}\mathrm{H} & 2.228420000000 & -1.733384000000 & 2.357547000000 \\ \mathrm{C} & 4.413258000000 & -0.353028000000 & 1.930150000000 \\ \mathrm{H} & 3.944720000000 & -2.047529000000 & 0.695963000000 \\ \mathrm{H} & 3.450862000000 & -0.493031000000 & 0.018756000000 \\ \mathrm{H} & 4.043380000000 & 0.648973000000 & 2.127066000000 \\ \mathrm{H} & 4.462710000000 & -0.898756000000 & 2.869442000000\end{array}$




\section{Transient absorption studies confirming the absence of electron transfer}

NA-OH: ATP-LW $(0.6 \mathrm{mmol} / \mathrm{L})+\mathrm{ONOO}^{-}(60 \mu \mathrm{mol} / \mathrm{L}, 1 \mathrm{~min})$

Rh-Bpin: ATP-LW $(0.6 \mathrm{mmol} / \mathrm{L})+$ ATP $(7 \mathrm{mmol} / \mathrm{L}, 100 \mathrm{~min})$

XT-LW: ATP-LW $(0.6 \mathrm{mmol} / \mathrm{L})+\operatorname{ATP}(7 \mathrm{mmol} / \mathrm{L}, 100 \mathrm{~min})+\mathrm{ONOO}^{-}(60 \mu \mathrm{mol} / \mathrm{L}, 1 \mathrm{~min})$
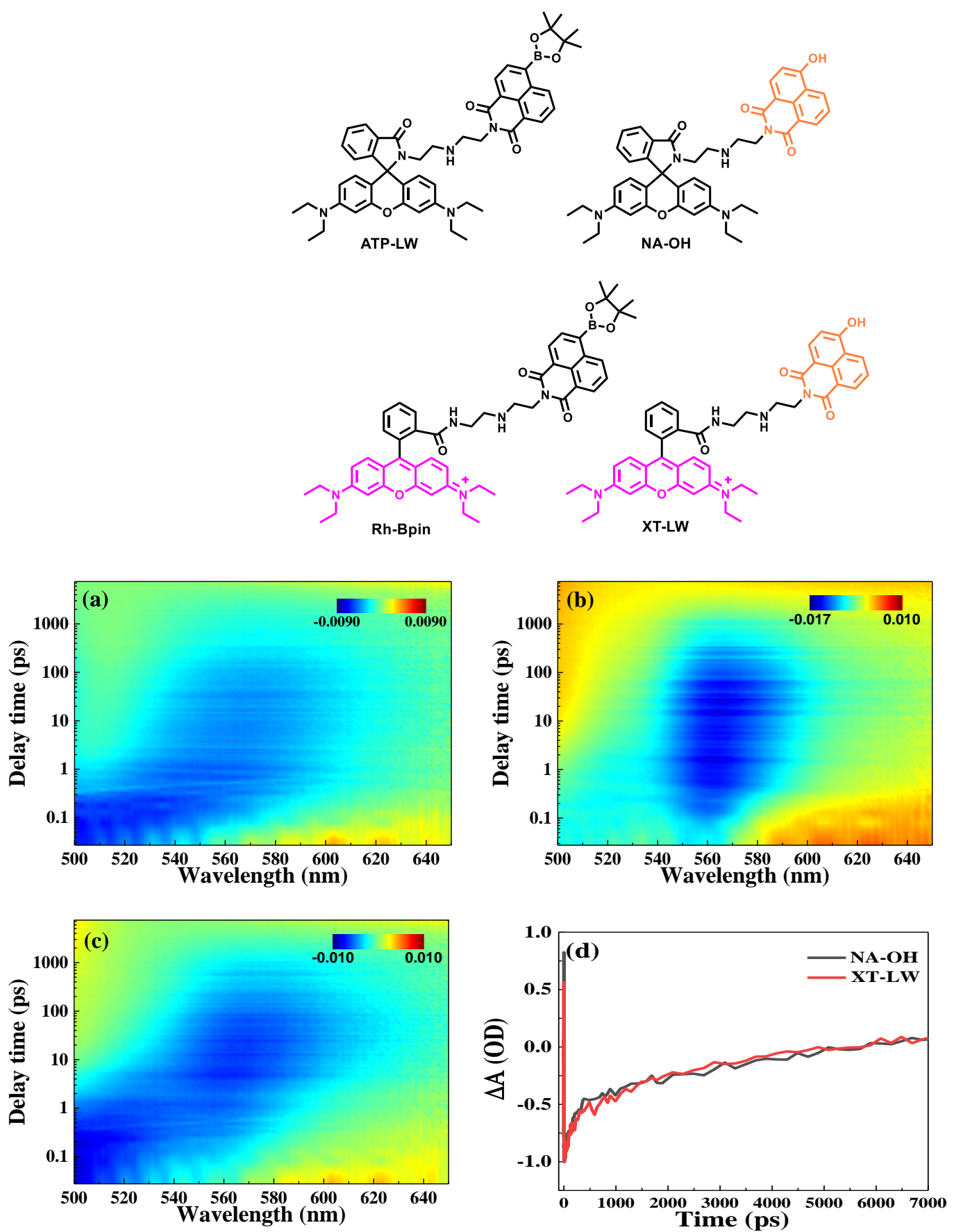

Figure S23. Time- and wavelength-dependent transient absorbance (TA) color maps of ATP-LW $(600 \mu \mathrm{M})$ recorded 1 min after the addition of $\mathrm{ONOO}^{-}(60 \mu \mathrm{M})(\mathrm{a})$, ATP-LW $(600 \mu \mathrm{M})$ after adding ATP $(7 \mathrm{mM})$ and waiting $100 \mathrm{~min}(\mathrm{~b})$, ATP-LW $(600 \mu \mathrm{M})$ after adding ATP $(7 \mathrm{mM})$ and waiting $100 \mathrm{~min}$ prior to the addition of $\mathrm{ONOO}^{-}(60 \mu \mathrm{M})$ and waiting $1 \mathrm{~min}(\mathrm{c})$. Studies were carried out in PBS/acetonitrile (v:v = 1:1, PBS $10 \mathrm{mM}$, $\mathrm{pH}=7.40$ ); solutions pumped at $400 \mathrm{~nm}$. (d) TA attenuation curves corresponding to panels a and $\mathrm{c}$ at $572 \mathrm{~nm}$. 
As can be seen from Figure S23 (a-c), similar fluorescence signatures are seen for NA-OH (ATP-LW (600 $\mu$ M) determined $1 \mathrm{~min}$ after the addition of $\mathrm{ONOO}^{-}(60 \mu \mathrm{M})$ wait $\left.1 \mathrm{~min}\right)$ and for XT-LW (ATP-LW $(600 \mu \mathrm{M})$ after the addition of ATP $(7 \mathrm{mM})$, waiting $100 \mathrm{~min}$ before adding $\mathrm{ONOO}^{-}(60 \mu \mathrm{M})$, and waiting 1 min to carry out the measurement. These signatures differ from those of Rh-Bpin (ATP-LW $(600 \mu \mathrm{M})$ seen upon the addition of ATP $(7 \mathrm{mM})$ and waiting $100 \mathrm{~min}$ to make the measurement. In addition, the dynamic curves (Fig. S23d) show that the signal attenuation curve of NA-OH at $572 \mathrm{~nm}$ is consistent with that of XT-LW. These results lead us to infer that there is no electron transfer from the naphthalimide subunit to rhodamine in XT-LW. 


\section{Mass spectrometric analyses}

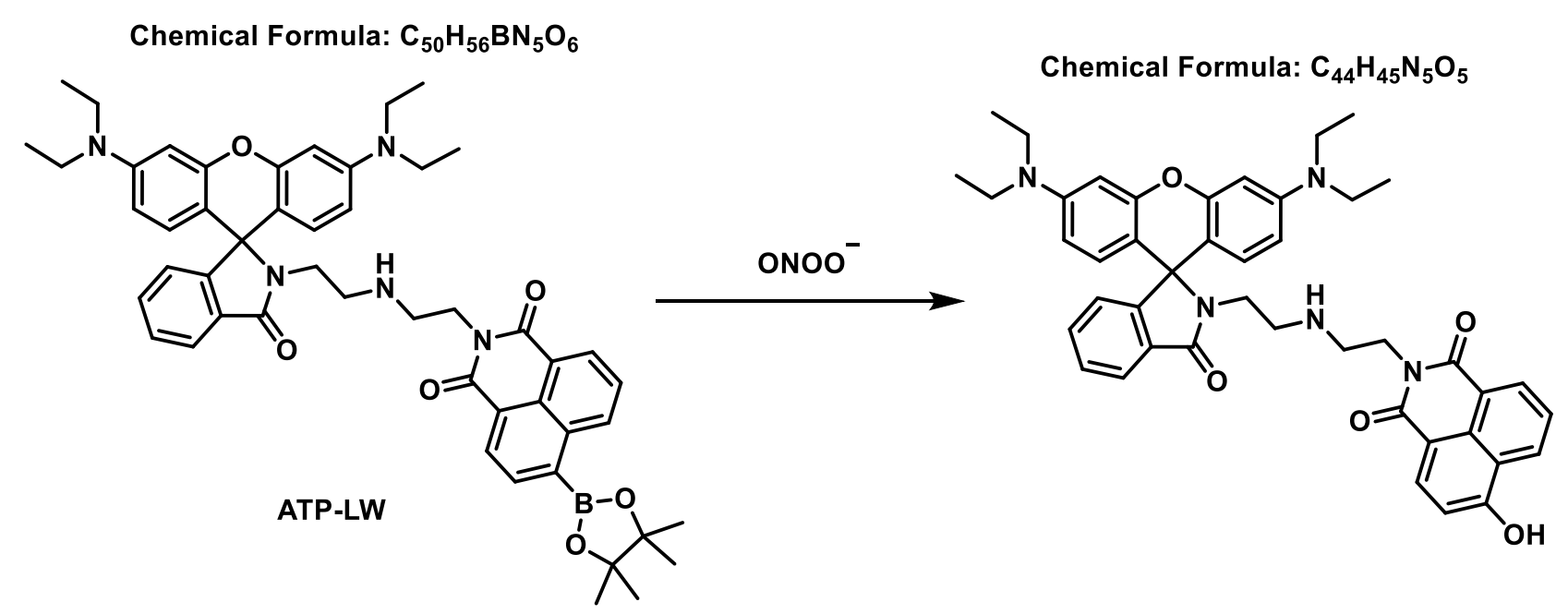

Scheme S3. Proposed reaction between probe ATP-LW and $\mathrm{ONOO}^{-}$.

Probe ATP-LW (5 mM, in DMSO) was diluted to $1 \mu \mathrm{M}$ in water (Figure S24), then $\mathrm{ONOO}^{-}(2 \mu \mathrm{M})$ was added (Figure S25). 


\section{Walkup MS Report}

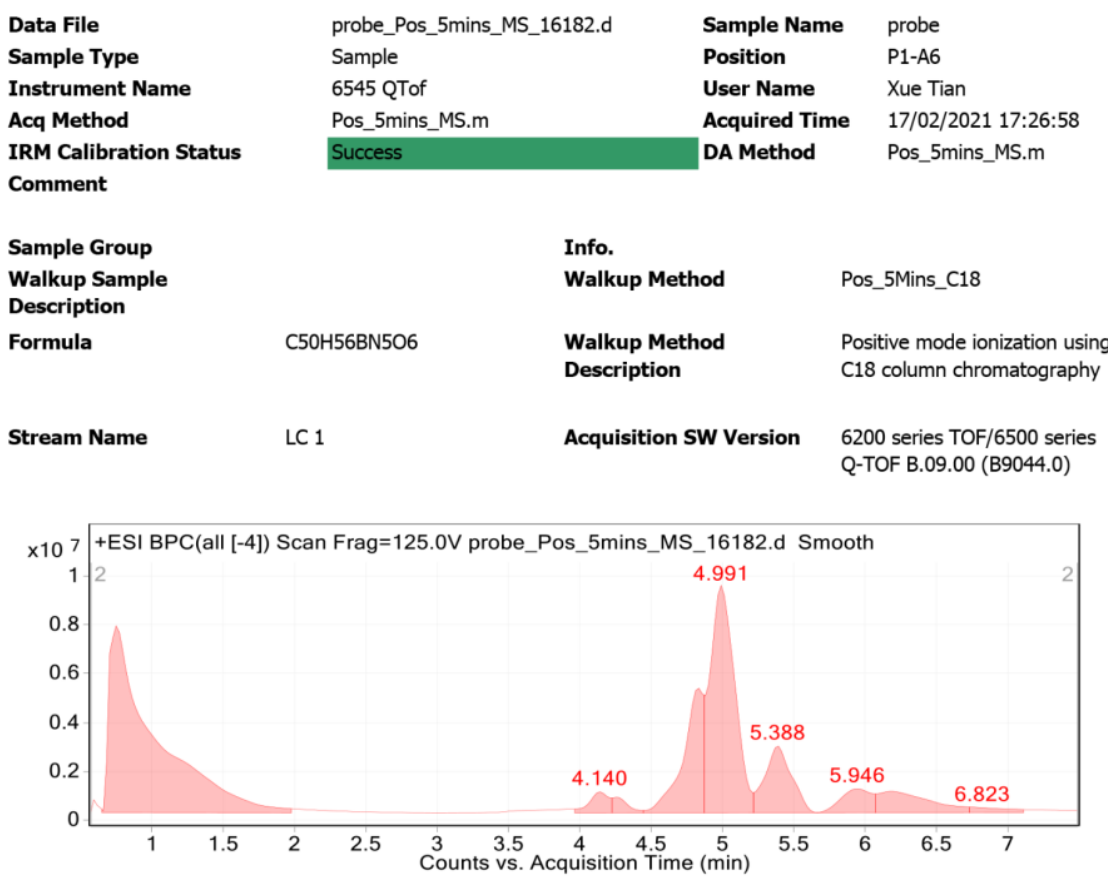

Figure 1: Base peak chromatogram

User Chromatogram Peak List

\begin{tabular}{|r|r|r|r|r|r|}
\hline $\begin{array}{l}\text { RT } \\
(\mathbf{m i n})\end{array}$ & \multicolumn{1}{|l|}{ Area } & \multicolumn{1}{l|}{ Area \% } & Area Sum (\%) & Base Peak (m/z) & \multicolumn{1}{l|}{ Width (min) } \\
\hline 0.75 & 172405396 & 100.00 & 40.54 & 102.1310 & 0.296 \\
\hline 4.14 & 8164761 & 4.74 & 1.92 & 185.1194 & 0.136 \\
\hline 4.26 & 4836815 & 2.81 & 1.14 & 185.1193 & 0.126 \\
\hline 4.83 & 49970070 & 28.98 & 11.75 & 752.3743 & 0.134 \\
\hline 4.99 & 112419298 & 65.21 & 26.43 & 834.4552 & 0.194 \\
\hline 5.39 & 35990489 & 20.88 & 8.46 & 443.3425 & 0.180 \\
\hline 5.95 & 14730643 & 8.54 & 3.46 & 125.9897 & 0.228 \\
\hline 6.19 & 22688600 & 13.16 & 5.33 & 141.9625 & 0.353 \\
\hline 6.82 & 4112857 & 2.39 & 0.97 & 922.0228 & 0.254 \\
\hline
\end{tabular}

Compound Table
\begin{tabular}{|c|c|c|c|c|c|c|}
\hline & $\begin{array}{c}\text { RT } \\
\text { Compound Label }\end{array}$ & $\begin{array}{c}\text { Observed mass } \\
(\mathbf{m} / \mathbf{z})\end{array}$ & $\begin{array}{c}\text { Neutral observed } \\
\text { mass (Da) }\end{array}$ & $\begin{array}{c}\text { Theoretical mass } \\
(\text { Da) }\end{array}$ & $\begin{array}{c}\text { Mass error } \\
(\mathbf{p p m})\end{array}$ & $\begin{array}{c}\text { Isotope match } \\
\text { score (\%) }\end{array}$ \\
\hline Cpd 1: C50 H56 B N5 06 & 4.98 & 834.4407 & 832.4358 & 832.4360 & -0.21 & 99.34 \\
\hline
\end{tabular}

Mass errors of between -5.00 and $5.00 \mathrm{ppm}$ with isotope match scores above $60 \%$ are considered confirmation of molecular formulae 


\section{Walkup MS Report}

\section{Compound specific information}

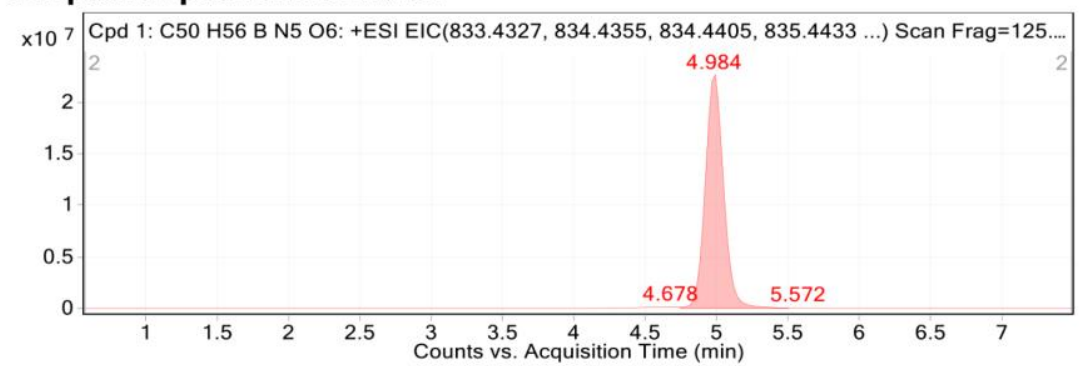

Figure: Extracted ion chromatogram (EIC) of compound.

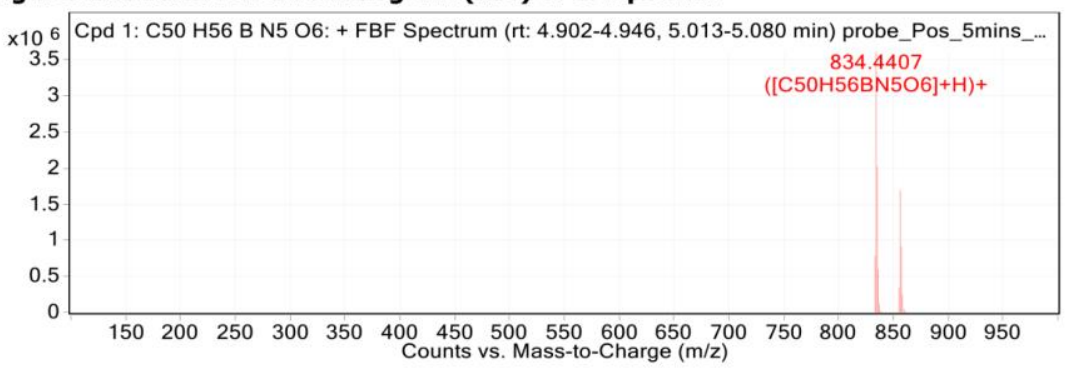

Figure: Full range view of Compound spectra and potential adducts.

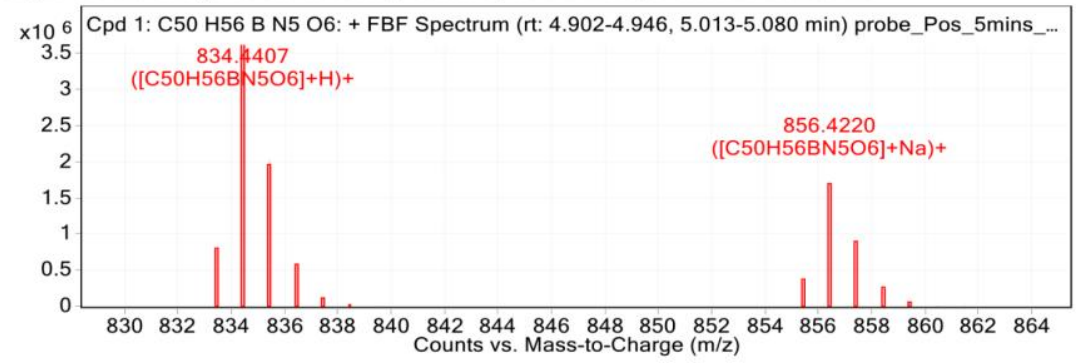

Fiqure: Zoomed Compound spectra view

(red boxes indicating expected theoretical isotope spacing and abundance)

Compound isotope peak List

\begin{tabular}{|r|r|r|l|l|}
\hline $\boldsymbol{m} / \boldsymbol{z}$ & $\boldsymbol{z}$ & \multicolumn{1}{|l}{ Abund } & Formula & Ion \\
\hline 833.4427 & 1 & 781395.0 & C50H56BN5O6 & $(\mathrm{M}+\mathrm{H})+$ \\
\hline 834.4407 & 1 & 3620850.0 & C50H56BN5O6 & $(\mathrm{M}+\mathrm{H})+$ \\
\hline 835.4430 & 1 & 2019427.8 & C50H56BN5O6 & $(\mathrm{M}+\mathrm{H})+$ \\
\hline 836.4457 & 1 & 597028.3 & C50H56BN5O6 & $(\mathrm{M}+\mathrm{H})+$ \\
\hline 837.4485 & 1 & 113882.2 & C50H56BN5O6 & $(\mathrm{M}+\mathrm{H})+$ \\
\hline 855.4240 & 1 & 344530.7 & C50H56BN5O6 & $(\mathrm{M}+\mathrm{Na})+$ \\
\hline 856.4220 & 1 & 1689579.3 & C50H56BN5O6 & $(\mathrm{M}+\mathrm{Na})+$ \\
\hline 857.4248 & 1 & 915320.8 & C50H56BN5O6 & $(\mathrm{M}+\mathrm{Na})+$ \\
\hline 858.4279 & 1 & 248062.0 & C50H56BN5O6 & $(\mathrm{M}+\mathrm{Na})+$ \\
\hline 859.4297 & 1 & 52547.4 & C50H56BN506 & $(\mathrm{M}+\mathrm{Na})+$ \\
\hline
\end{tabular}

--- End Of Report --.

Figure S24. LC-MS of ATP-LW. 


\section{Walkup MS Report}

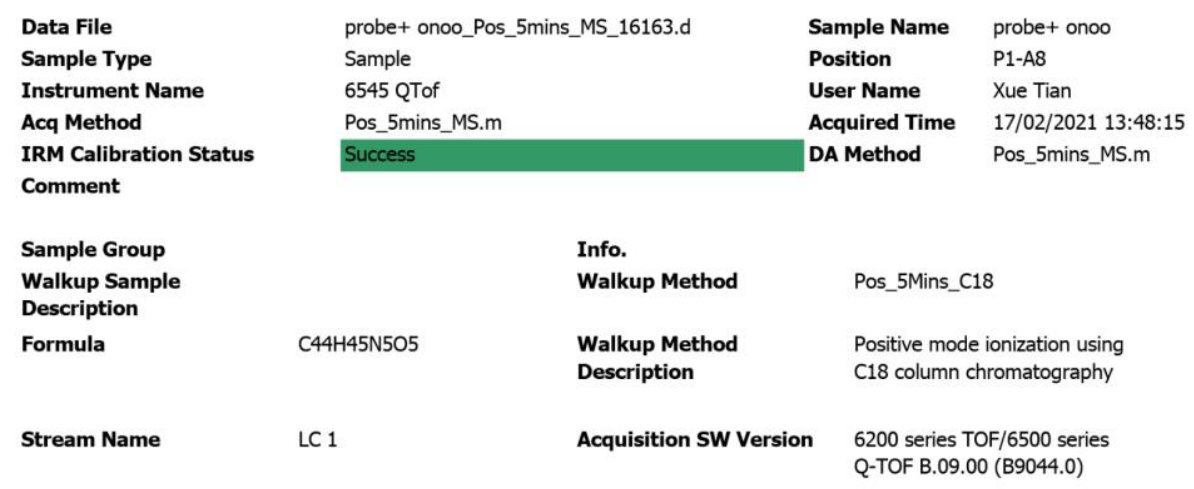

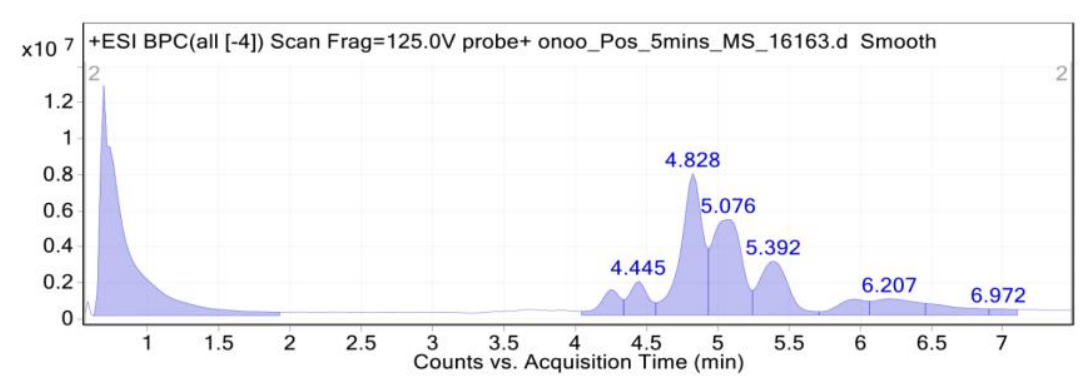

Figure 1: Base peak chromatogram

User Chromatogram Peak List

User Chromatogram Peak List
\begin{tabular}{|r|r|r|r|r|r|}
\hline $\begin{array}{l}\text { RT } \\
(\mathbf{m i n})\end{array}$ & \multicolumn{1}{l|}{ Area } & \multicolumn{1}{c|}{ Area \% } & Area Sum (\%) & Base Peak (m/z) & \multicolumn{1}{l|}{ Width (min) } \\
\hline 0.70 & 150450217 & 100.00 & 34.79 & 101.0065 & 0.150 \\
\hline 4.26 & 13784563 & 9.16 & 3.19 & 185.1189 & 0.145 \\
\hline 4.45 & 17231152 & 11.45 & 3.98 & 442.2563 & 0.140 \\
\hline 4.83 & 83984528 & 55.82 & 19.42 & 724.3612 & 0.158 \\
\hline 5.08 & 75543142 & 50.21 & 17.47 & 952.5616 & 0.226 \\
\hline 5.39 & 42642889 & 28.34 & 9.86 & 443.3420 & 0.219 \\
\hline 5.96 & 13102935 & 8.71 & 3.03 & 125.9896 & 0.225 \\
\hline 6.21 & 19124430 & 12.71 & 4.42 & 141.9624 & 0.312 \\
\hline 6.57 & 12575443 & 8.36 & 2.91 & 922.0219 & 0.300 \\
\hline 6.97 & 4062947 & 2.70 & 0.94 & 922.0218 & 0.165 \\
\hline
\end{tabular}

Compound Table

\begin{tabular}{|c|c|c|c|c|c|c|}
\hline & $\begin{array}{c}\text { RT } \\
\text { Compound Label }\end{array}$ & $\begin{array}{c}\text { Observed mass } \\
(\mathbf{m} / \mathbf{z})\end{array}$ & $\begin{array}{c}\text { Neutral observed } \\
\text { mass } \mathbf{( D a )}\end{array}$ & $\begin{array}{c}\text { Theoretical mass } \\
(\mathbf{D a})\end{array}$ & $\begin{array}{c}\text { Mass error } \\
(\mathbf{p p m})\end{array}$ & $\begin{array}{c}\text { Isotope match } \\
\text { score (\%) }\end{array}$ \\
\hline Cpd 1: C44 H45 N5 05 & 4.83 & 724.3490 & 723.3419 & 723.3421 & -0.22 & 99.42 \\
\hline
\end{tabular}




\section{Walkup MS Report}

\section{Compound specific information}

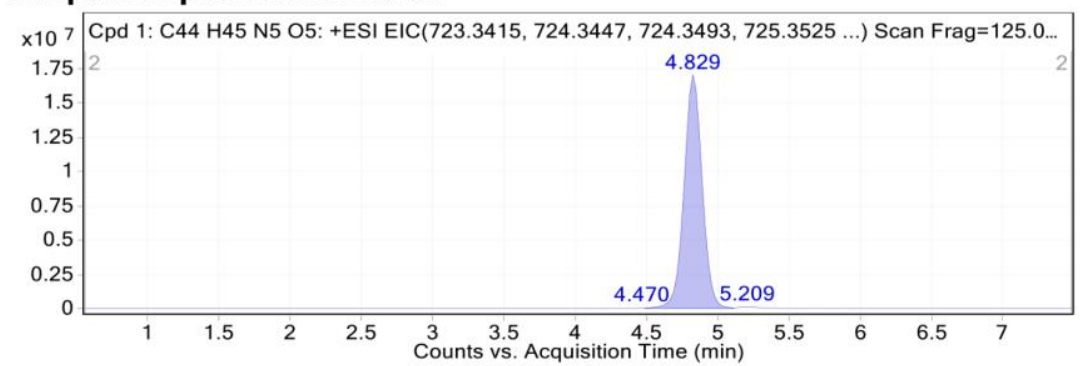

Figure: Extracted ion chromatogram (EIC) of compound.

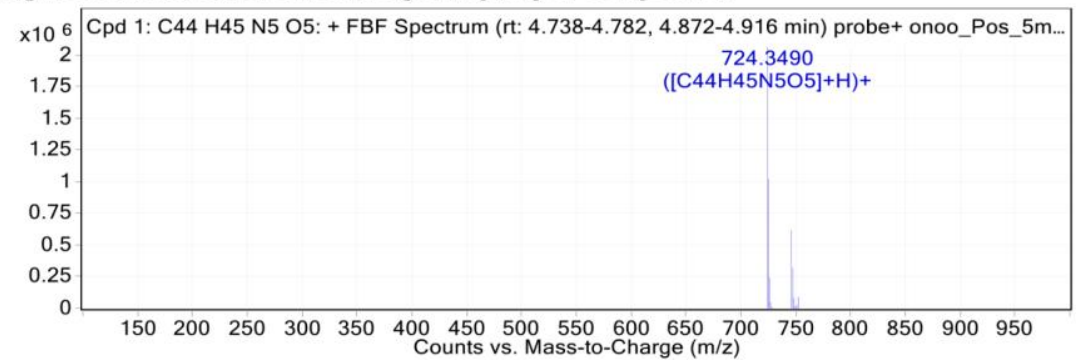

Figure: Full range view of Compound spectra and potential adducts.

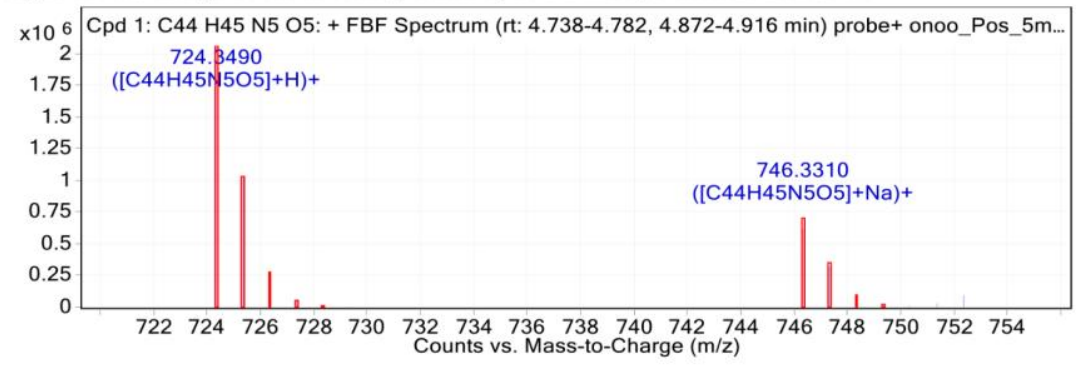

Figure: Zoomed Compound spectra view

(red boxes indicating expected theoretical isotope spacing and abundance)

Compound isotope peak List

\begin{tabular}{|l|l|l|l|l|l|}
\hline $\boldsymbol{m} / \boldsymbol{z}$ & $\mathbf{z}$ & \multicolumn{1}{l}{ Abund } & Formula & Ion \\
\hline 724.3490 & 1 & 2061421.5 & C44H45N5O5 & $(\mathrm{M}+\mathrm{H})+$ \\
\hline 725.3522 & 1 & 1020952.1 & C44H45N5O5 & $(\mathrm{M}+\mathrm{H})+$ \\
\hline 726.3553 & 1 & 242437.1 & C44H45N5O5 & $(\mathrm{M}+\mathrm{H})+$ \\
\hline 727.3575 & 1 & 47171.6 & $\mathrm{C} 44 \mathrm{H} 45 \mathrm{~N} 505$ & $(\mathrm{M}+\mathrm{H})+$ \\
\hline 746.3310 & 1 & 617253.4 & $\mathrm{C} 44 \mathrm{H} 45 \mathrm{~N} 505$ & $(\mathrm{M}+\mathrm{Na})+$ \\
\hline 747.3337 & 1 & 320428.3 & C44H45N5O5 & $(\mathrm{M}+\mathrm{Na})+$ \\
\hline 748.3364 & 1 & 83406.3 & $\mathrm{C} 44 \mathrm{H} 45 \mathrm{~N} 505$ & $(\mathrm{M}+\mathrm{Na})+$ \\
\hline 749.3389 & 1 & 17693.1 & $\mathrm{C} 44 \mathrm{H} 45 \mathrm{~N} 505$ & $(\mathrm{M}+\mathrm{Na})+$ \\
\hline 751.3600 & 1 & 28271.3 & $\mathrm{C} 44 \mathrm{H} 45 \mathrm{~N} 505$ & $(\mathrm{M}+\mathrm{Na})+$ \\
\hline 752.3592 & 1 & 90236.4 & C44H45N5O5 & $(\mathrm{M}+\mathrm{Na})+$ \\
\hline
\end{tabular}

--- End Of Report -..

Figure S25. LC-MS of reaction solution of ATP-LW $(1 \mu \mathrm{M})$ with ONOO $^{-}(2 \mu \mathrm{M})$. The peak at $\mathrm{m} / \mathrm{z}=724.3490$ indicates the conversion from boronic pinacol ester to naphthol. 

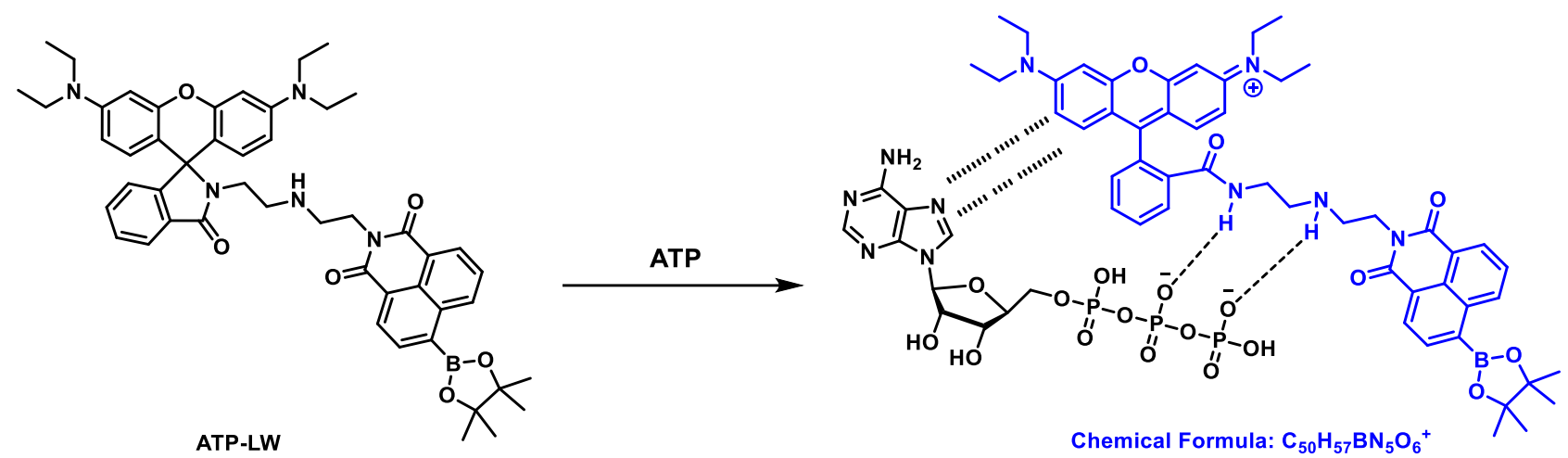

Scheme S4. Reaction mechanism between probe ATP-LW and ATP.

Probe ATP-LW (5 mM, in DMSO) was diluted to $10 \mu \mathrm{M}$ in water, then ATP (4 mM) was added. The formation of the product highlighted in blue was determined based on Figure S26. 


\section{Walkup MS Report}

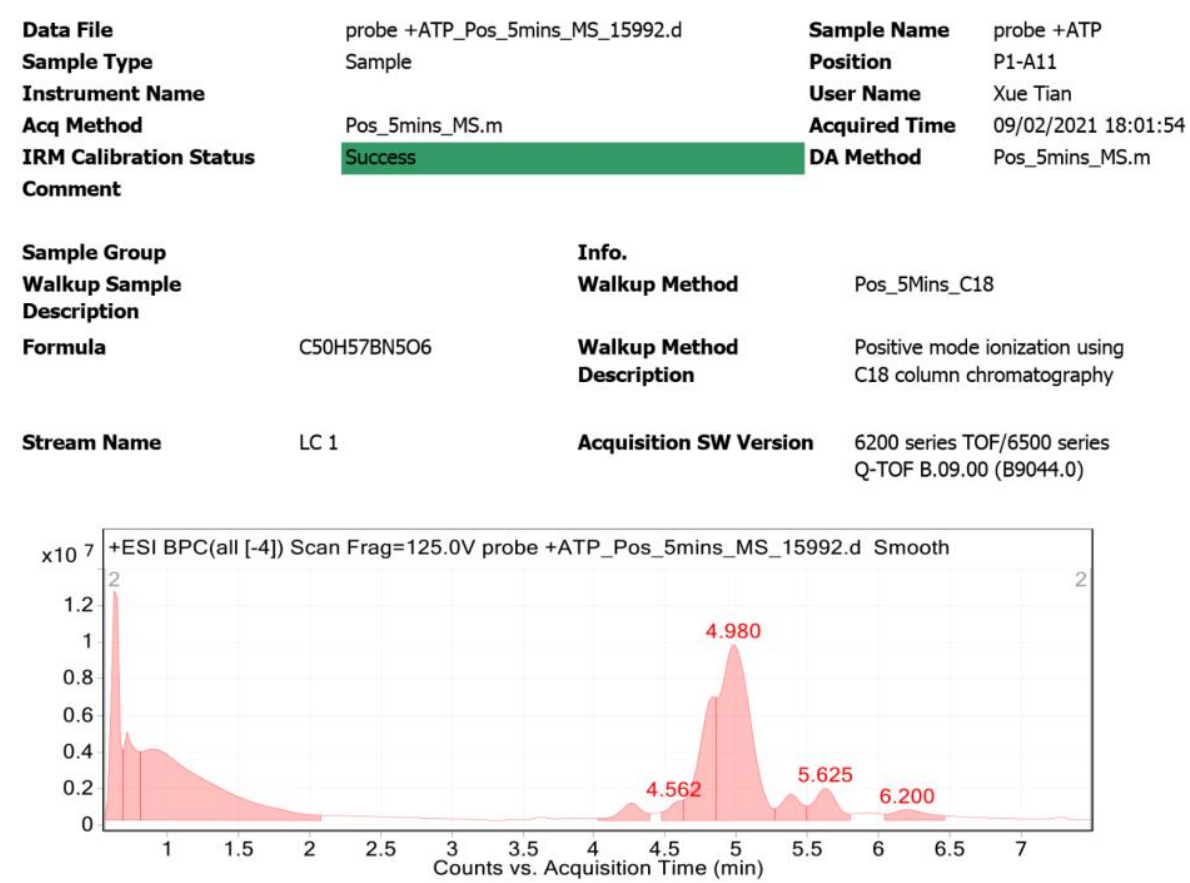

Figure 1: Base peak chromatogram

User Chromatogram Peak List

User Chromatogram Peak List
\begin{tabular}{|r|r|r|r|r|r|}
\hline $\begin{array}{l}\text { RT } \\
(\mathbf{m i n})\end{array}$ & \multicolumn{1}{l|}{ Area } & \multicolumn{1}{l|}{ Area \% } & Area Sum (\%) & Base Peak (m/z) & \multicolumn{1}{l|}{ Width (min) } \\
\hline 0.64 & 50192390 & 36.12 & 10.68 & 508.0155 & 0.063 \\
\hline 0.72 & 30390507 & 21.87 & 6.46 & 101.0066 & 0.104 \\
\hline 0.91 & 133932251 & 96.37 & 28.49 & 508.0141 & 0.461 \\
\hline 4.26 & 10136397 & 7.29 & 2.16 & 185.1201 & 0.159 \\
\hline 4.56 & 7589038 & 5.46 & 1.61 & 696.3138 & 0.121 \\
\hline 4.84 & 55158993 & 39.69 & 11.73 & 752.3784 & 0.123 \\
\hline 4.98 & 138970659 & 100.00 & 29.56 & 834.4581 & 0.215 \\
\hline 5.38 & 14060146 & 10.12 & 2.99 & 443.3447 & 0.142 \\
\hline 5.63 & 19373665 & 13.94 & 4.12 & 666.4784 & 0.163 \\
\hline 6.20 & 10278688 & 7.40 & 2.19 & 141.9629 & 0.266 \\
\hline
\end{tabular}

Compound Table
\begin{tabular}{|c|c|c|c|c|c|c|}
\hline Compound Label & $\begin{array}{c}\text { RT } \\
(\mathbf{m i n})\end{array}$ & $\begin{array}{c}\text { Observed mass } \\
(\mathbf{m} / \mathbf{z})\end{array}$ & $\begin{array}{c}\text { Neutral observed } \\
\text { mass } \mathbf{( D a )}\end{array}$ & $\begin{array}{c}\text { Theoretical mass } \\
(\mathbf{D a})\end{array}$ & $\begin{array}{c}\text { Mass error } \\
(\mathbf{p p m})\end{array}$ & $\begin{array}{c}\text { Isotope match } \\
\text { score }(\%)\end{array}$ \\
\hline Cpd 1: C50 H57 B N5 06 & 4.96 & 834.4406 & 833.4420 & 833.4438 & -2.24 & 99.46 \\
\hline
\end{tabular}

Mass errors of between -5.00 and $5.00 \mathrm{ppm}$ with isotope match scores above $60 \%$ are considered confirmation of molecular formulae 


\section{Walkup MS Report}

\section{Compound specific information}

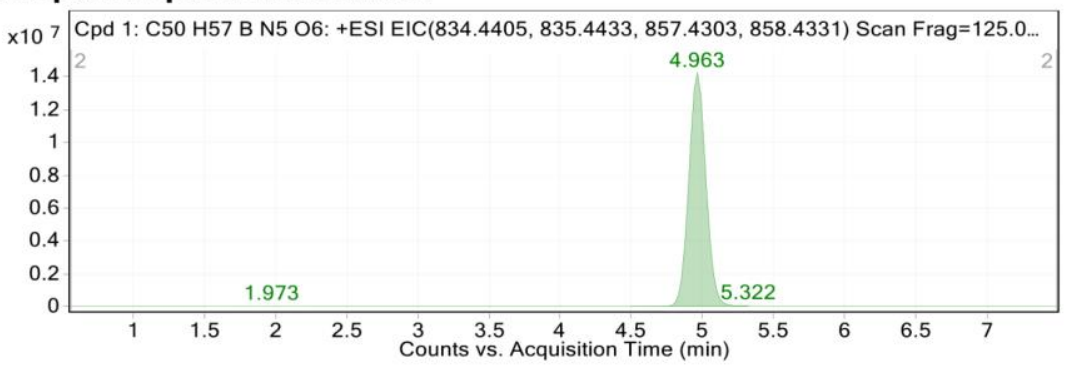

Figure: Extracted ion chromatogram (EIC) of compound.

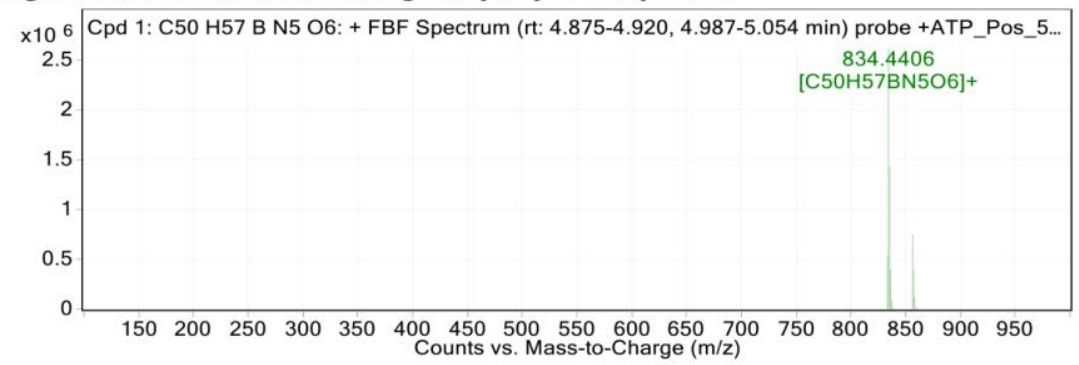

Figure: Full range view of Compound spectra and potential adducts.

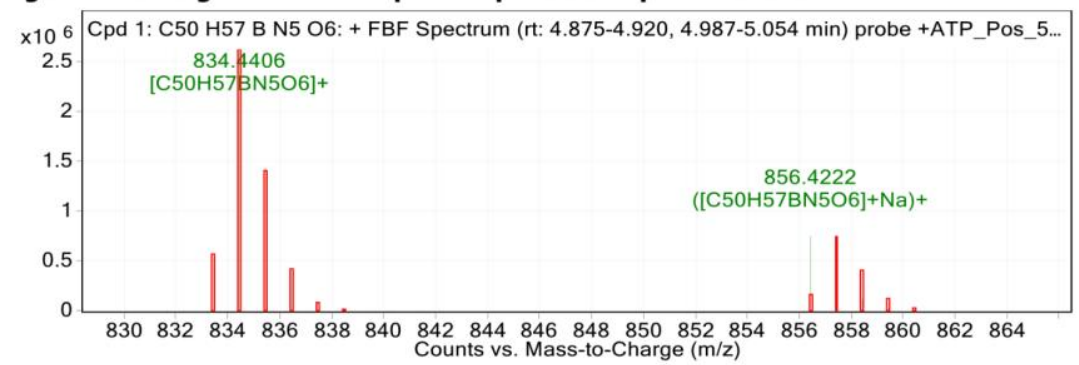

Figure: Zoomed Compound spectra view

(red boxes indicating expected theoretical isotope spacing and abundance)

Compound isotope peak List
\begin{tabular}{|r|r|r|l|l|}
\hline $\boldsymbol{m} / \boldsymbol{z}$ & $\boldsymbol{z}$ & \multicolumn{1}{|l|}{ Abund } & Formula & Ion \\
\hline 833.4430 & 1 & 540591.1 & C50H57BN506 & $\mathrm{M}+$ \\
\hline 834.4406 & 1 & 2617015.5 & C50H57BN506 & $\mathrm{M}+$ \\
\hline 835.4431 & 1 & 1435080.1 & C50H578N506 & $\mathrm{M}+$ \\
\hline 836.4458 & 1 & 399682.7 & C50H57BN506 & $\mathrm{M}+$ \\
\hline 837.4476 & 1 & 85636.1 & C50H57BN506 & $\mathrm{M}+$ \\
\hline 838.4457 & 1 & 16059.3 & C50H57BN506 & $\mathrm{M}+$ \\
\hline 856.4222 & 1 & 747684.4 & C50H57BN506 & $(\mathrm{M}+\mathrm{Na})+$ \\
\hline 857.4250 & 1 & 400063.3 & C50H57BN506 & $(\mathrm{M}+\mathrm{Na})+$ \\
\hline 858.4273 & 1 & 116222.5 & C50H57BN506 & $(\mathrm{M}+\mathrm{Na})+$ \\
\hline 859.4286 & 1 & 26244.7 & C50H57BN506 & $(\mathrm{M}+\mathrm{Na})+$ \\
\hline
\end{tabular}

--- End Of Report ---

Figure S26. LC-MS of reaction solution of ATP-LW $(10 \mu \mathrm{M})$ with ATP $(4 \mathrm{mM})$. 


\section{Protocols for cell culture}

Human hepatocytes (HL-7702) were purchased from the Cell Bank of the Chinese Academy of Sciences (Shanghai, China). Cells were cultured in high-glucose DMEM supplemented with $10 \%$ fetal bovine serum, $1 \%$ penicillin and $1 \%$ streptomycin $\left(\mathrm{w} \mathrm{v}^{-1}\right)$ at $37{ }^{\circ} \mathrm{C}$ in a $5 \% \mathrm{CO}_{2} / 95 \%$ air MCO-15AC incubator (SANYO, Tokyo, Japan).

\section{MTT assay and fluorescence imaging in live cells}

\subsection{MTT assay}

Standard 3-(4,5-dimethylthiazol-2-yl)-2,5-diphenyltetrazolium bromide (MTT) assays were carried out to evaluate the toxicity of probe ATP-LW. Hepatocytes $\left(10^{6}\right.$ cells $\left.\mathrm{mL}^{-1}\right)$ were seeded into 96 -well microtiter plates with total volumes of $200 \mu \mathrm{L}$ well ${ }^{-1}$. After $12 \mathrm{~h}$ of incubation, various concentrations of ATP-LW $(0 \mathrm{M}$, $1 \times 10^{-3} \mathrm{M}, 1 \times 10^{-4} \mathrm{M}, 1 \times 10^{-5} \mathrm{M}, 1 \times 10^{-6} \mathrm{M}, 1 \times 10^{-7} \mathrm{M}, 1 \times 10^{-8} \mathrm{M}$ and $1 \times 10^{-9} \mathrm{M}$ ) were added, and the cells were cultured for another $24 \mathrm{~h}$. Subsequently, an MTT solution $\left(20 \mu \mathrm{L}, 5 \mathrm{mg} \mathrm{mL}^{-1}\right.$, in DMEM) was added to each well. After $4 \mathrm{~h}$, the MTT solution was removed, and DMSO $(150 \mu \mathrm{L})$ was added to each well. Finally, the absorbance at $490 \mathrm{~nm}$ was measured using a Triturus microplate reader.

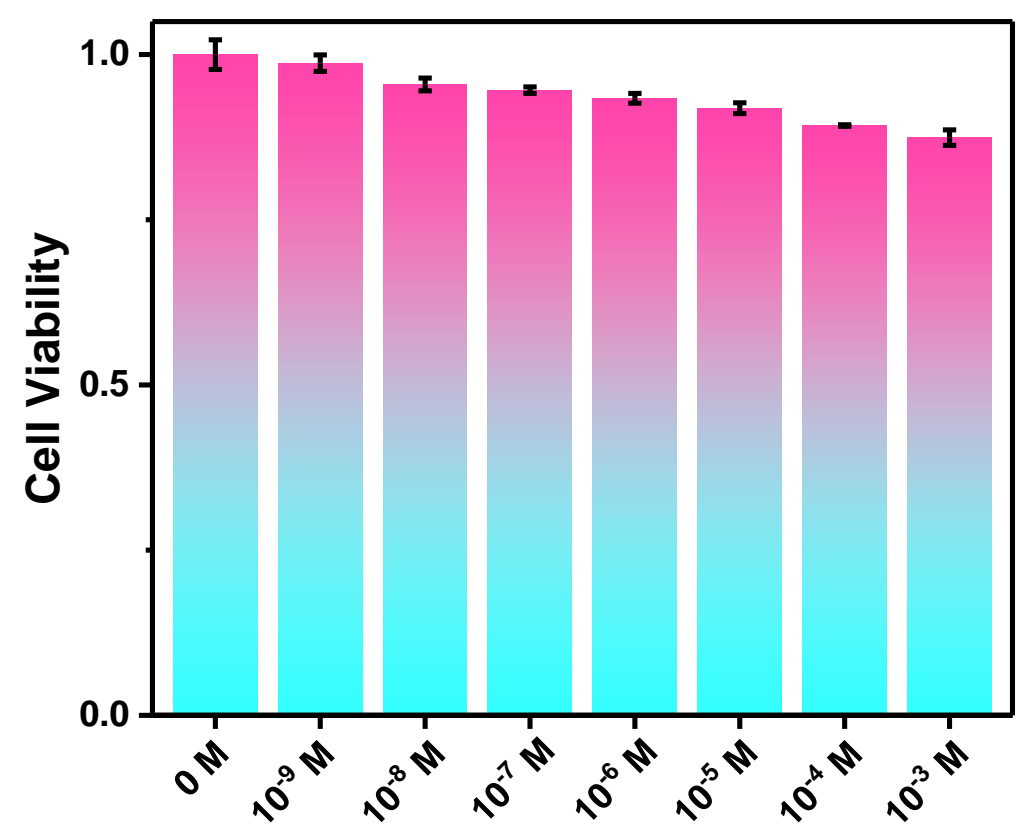

Figure S27. Cell toxicity of ATP-LW towards HL-7702 cells with an incubation time of $24 \mathrm{~h}$. Error bar represents s.d.

10.2 One-photon fluorescence imaging of HL-7702 cells under treatment with SIN-1 or uric acid/SIN-1

Experimental procedure for Figure 4

The control group cells were stained with probe ATP-LW $(20 \mu \mathrm{M})$ for $20 \mathrm{~min}$. The SIN-1 stimulated group cells were incubated with SIN-1 $(1 \mathrm{mM})$ for $1 \mathrm{~h}$, then stained with probe ATP-LW $(20 \mu \mathrm{M})$ for $20 \mathrm{~min}$. The uric acid/SIN-1 stimulated group cells were incubated with uric acid $(500 \mu \mathrm{M})$ for 1 
$\mathrm{h}$, followed by adding SIN-1 $(1 \mathrm{mM})$ for $1 \mathrm{~h}$ and then stained with probe ATP-LW $(20 \mu \mathrm{M})$ for $20 \mathrm{~min}$. The cell culture medium of each group was removed, and all cells were washed with $1.0 \mathrm{~mL}$ of PBS three times before fluorescence imaging. One-photon confocal photographs were taken using a Leica SP8 high-resolution fluorescence microscope equipped with the Leica Application Suite X software package.

10.3 One-photon fluorescence imaging of HL-7702 cells under treatment with oligomycin A or oligomycin A/ATP

\section{Experimental procedure for Figure 5}

HL-7702 cells were divided into three groups. The control group cells were stained with probe ATP-LW $(20 \mu \mathrm{M})$ for $20 \mathrm{~min}$. The oligomycin A group cells were incubated with oligomycin A $(25 \mu \mathrm{M})$ for $1 \mathrm{~h}$, then stained with probe ATP-LW $(20 \mu \mathrm{M})$ for $20 \mathrm{~min}$. The oligomycin A/ATP stimulated group cells were incubated with oligomycin A $(25 \mu \mathrm{M})$ for $1 \mathrm{~h}$ prior to treating with ATP $(10 \mathrm{mM})$ for $1 \mathrm{~h}$. They were then stained with probe ATP-LW $(20 \mu \mathrm{M})$ for $20 \mathrm{~min}$. The cell culture medium of each group was removed, and all cells were washed with $1.0 \mathrm{~mL}$ of PBS three times before fluorescence imaging. One-photon confocal photographs were taken imaged by Leica SP8 high-resolution fluorescence microscope and Leica Application Suite X software.

10.4 One-photon fluorescence imaging of HL-7702 cells under treatment with SIN-1/ATP which validates no interference for both green channel excited by $514 \mathrm{~nm}$ and red channel under excitation at $488 \mathrm{~nm}$

\section{Experimental procedure for Figure S28}

Control group cells were stained with probe ATP-LW $(20 \mu \mathrm{M})$ for $20 \mathrm{~min}$. The SIN-1 + ATP group cells were incubated with SIN-1 $(1 \mathrm{mM})$ for $1 \mathrm{~h}$, followed by adding ATP $(10 \mathrm{mM})$ for $1 \mathrm{~h}$ and then stained with probe ATP-LW $(20 \mu \mathrm{M})$ for $20 \mathrm{~min}$. The cell culture medium of each group was removed, and all cells were washed with $1.0 \mathrm{~mL}$ of PBS three times before fluorescence imaging. One-photon confocal photographs were taken imaged by Leica SP8 high-resolution fluorescence microscope equipped with the Leica Application Suite X software. 

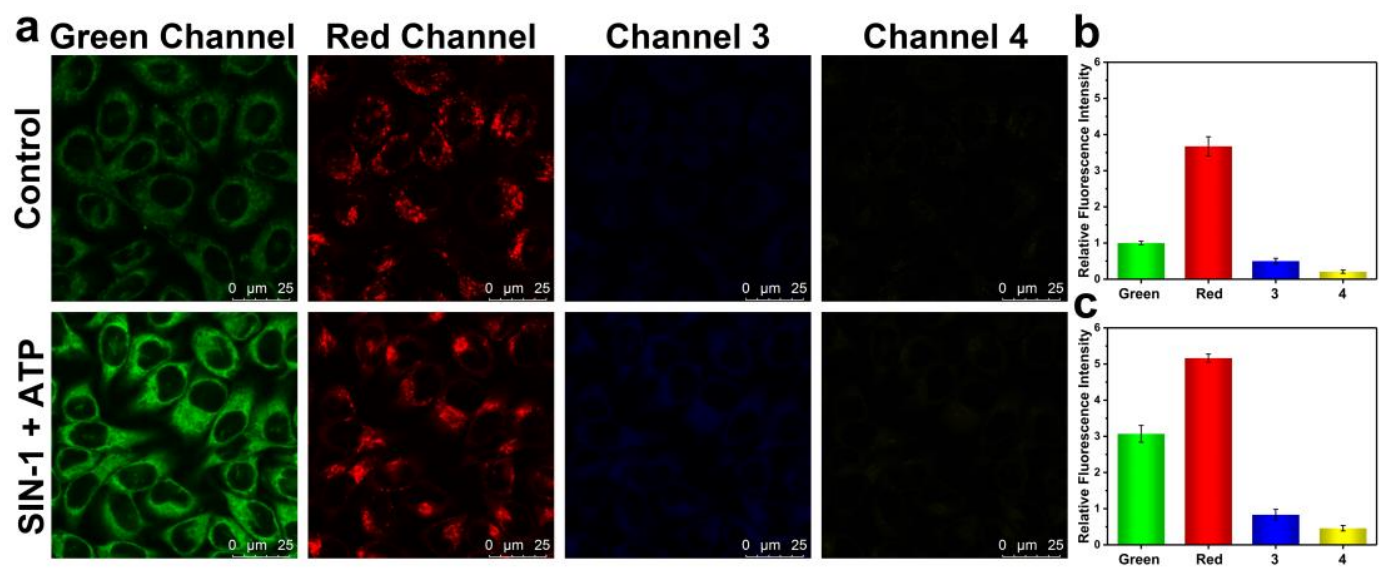

Figure S28. One-photon confocal imaging of $\mathrm{ONOO}^{-}$and ATP levels in hepatocytes. (a) One-photon fluorescence images of HL-7702 cells with the addition of SIN-1 (1 mM, $1 \mathrm{~h})$ followed by addition of ATP (10 $\mathrm{mM}, 1 \mathrm{~h}$ ) in the channels of $\mathrm{ONOO}^{-}$, ATP, channel 3 and 4. Control group: Cells were stained with probe ATP$\mathbf{L W}(20 \mu \mathrm{M})$ for $20 \mathrm{~min}$. SIN-1 + ATP group: Cells were pretreated with SIN-1 (1 mM) for $1 \mathrm{~h}$ and followed by adding ATP $(10 \mathrm{mM})$ for $1 \mathrm{~h}$ and then stained with probe ATP-LW $(20 \mu \mathrm{M})$ for $20 \mathrm{~min}$. Green fluorescence channel for $\mathrm{ONOO}^{-}: \lambda_{\mathrm{ex}}=488 \mathrm{~nm}, \lambda_{\mathrm{em}}=500-575 \mathrm{~nm}$. Red fluorescence channel for ATP: $\lambda_{\mathrm{ex}}=514 \mathrm{~nm}, \lambda_{\mathrm{em}}=$ $575-650 \mathrm{~nm}$. Channel 3: $\lambda_{\mathrm{ex}}=488 \mathrm{~nm}, \lambda_{\mathrm{em}}=575-650 \mathrm{~nm}$. Channel 4: $\lambda_{\mathrm{ex}}=514 \mathrm{~nm}, \lambda_{\mathrm{em}}=520-575 \mathrm{~nm}$. (b) Relative fluorescence intensity output of control group. (c) Relative fluorescence intensity output of SIN-1 + ATP group. Note: The green fluorescence intensity of control group is defined as 1.0. The data are expressed as the mean $\pm \mathrm{SD}$. Similar results were obtained in five independent experiments.

\subsection{One-photon fluorescence imaging of APAP-induced injury in HL-7702 cells}

\section{Experimental procedure for Figure 6}

HL-7702 cells were divided into three groups. The control group cells were stained with probe ATP-LW $(20 \mu \mathrm{M})$ for $20 \mathrm{~min}$. The model group cells were incubated with APAP $(15 \mathrm{mM})$ for $2 \mathrm{~h}$, then stained with probe ATP-LW $(20 \mu \mathrm{M})$ for $20 \mathrm{~min}$. To investigate injury remediation, HL-7702 cells were pretreated with NAC ( $2 \mathrm{mM})$ for $2 \mathrm{~h}$ and then incubated with APAP $(15 \mathrm{mM})$ for $2 \mathrm{~h}$, followed by staining with probe ATP$\mathbf{L W}(20 \mu \mathrm{M})$ for $20 \mathrm{~min}$. The cell culture medium of each group was removed, and all cells were washed with $1.0 \mathrm{~mL}$ of PBS three times before fluorescence imaging. One-photon confocal photographs were taken imaged by Leica SP8 high-resolution fluorescence microscope equipped with the Leica Application Suite X software.

\subsection{One-photon fluorescence imaging of various doses of APAP-induced injury in HL-7702 cells.}

\section{Experimental procedure for Figure S29}

Control group cells were stained with probe ATP-LW $(20 \mu \mathrm{M})$ for $20 \mathrm{~min}$. The model group cells were incubated with APAP $(10,20 \mathrm{mM})$ for $2 \mathrm{~h}$, then stained with probe ATP-LW $(20 \mu \mathrm{M})$ for $20 \mathrm{~min}$. The cell culture medium of each group was removed, and all cells were washed with $1.0 \mathrm{~mL}$ of PBS three times before fluorescence imaging. One-photon confocal photographs were taken imaged by Leica SP8 high-resolution fluorescence microscope equipped with the Leica Application Suite X software. 


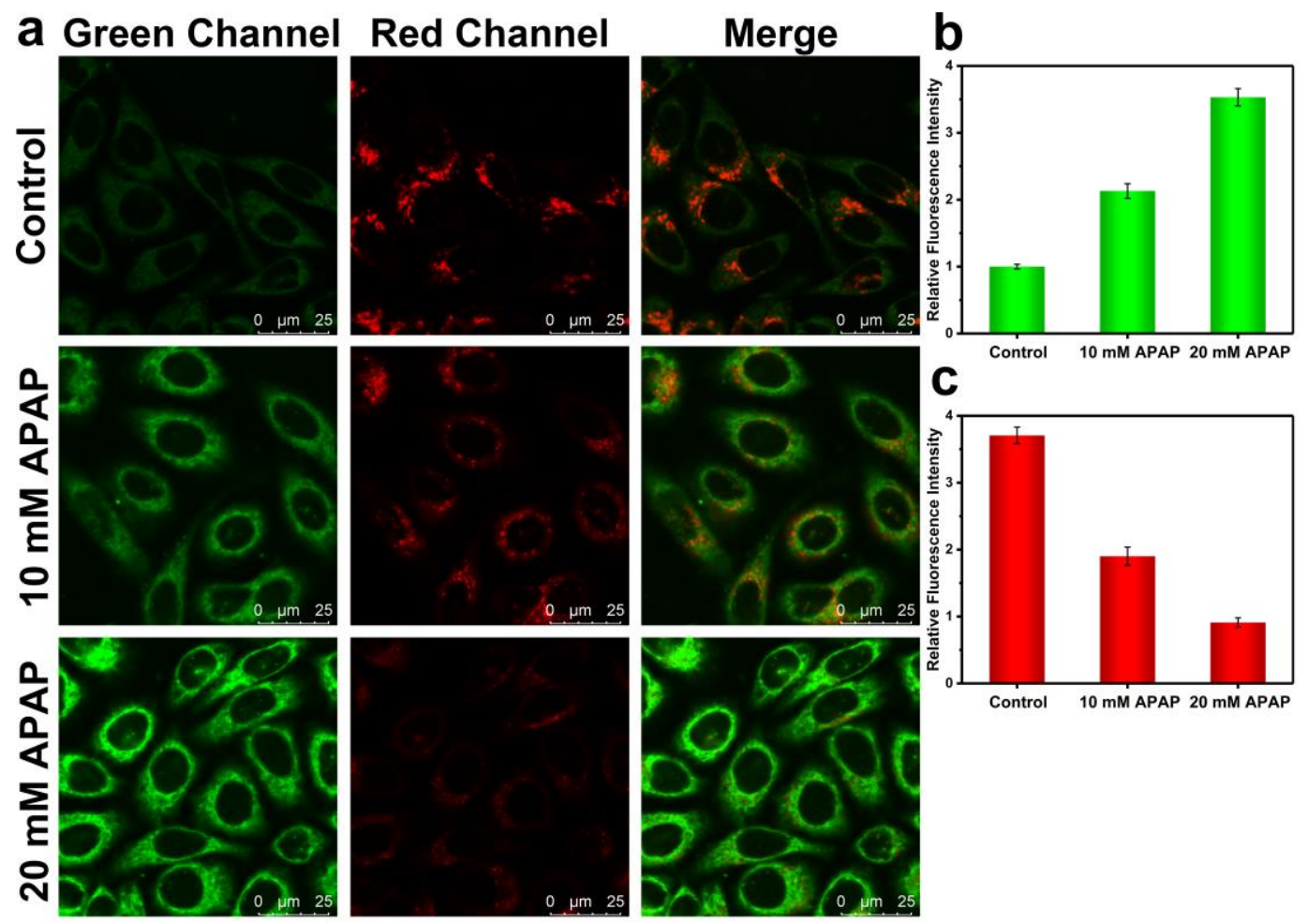

Figure S29. One-photon confocal images of various doses of APAP-induced injury with HL-7702 cells. (a) One-photon fluorescence images of HL-7702 cells with the addition of APAP (10, $20 \mathrm{mM}, 2 \mathrm{~h}$ ) in the channels of $\mathrm{ONOO}^{-}$and ATP. Control group: Cells were stained with probe ATP-LW $(20 \mu \mathrm{M})$ for $20 \mathrm{~min}$. $10 \mathrm{mM}$ APAP group: Cells were incubated with APAP $(10 \mathrm{mM})$ for $2 \mathrm{~h}$, and then stained with probe ATP-LW $(20 \mu \mathrm{M})$ for $20 \mathrm{~min} .20 \mathrm{mM}$ APAP group: Cells were pretreated with APAP $(20 \mathrm{mM})$ for $2 \mathrm{~h}$ and then incubated with probe ATP-LW $(20 \mu \mathrm{M})$ for another $20 \mathrm{~min}$. Green fluorescence channel for $\mathrm{ONOO}^{-}: \lambda_{\mathrm{ex}}=488 \mathrm{~nm}, \lambda_{\mathrm{em}}=500-$ $575 \mathrm{~nm}$. Red fluorescence channel for ATP: $\lambda_{\mathrm{ex}}=514 \mathrm{~nm}, \lambda_{\mathrm{em}}=575-650 \mathrm{~nm}$. (b) Green relative fluorescence intensity output of three groups. (c) Red relative fluorescence intensity output of three groups. Note: The green fluorescence intensity of control group is defined as 1.0. The data are expressed as the mean \pm SD. Similar results were obtained in five independent experiments. 
10.7 Two-photon fluorescence imaging of APAP-induced injury in HL-7702 cells.

\section{Experimental procedure for Figure 7}

HL-7702 cells were divided into three groups. The control group cells were stained with probe ATP-LW $(20 \mu \mathrm{M})$ for $20 \mathrm{~min}$. The model group cells were incubated with APAP $(20 \mathrm{mM})$ for $2 \mathrm{~h}$, then stained with probe ATP-LW $(20 \mu \mathrm{M})$ for $20 \mathrm{~min}$. To investigate injury remediation, HL-7702 cells were pretreated with NAC $(2 \mathrm{mM})$ for $2 \mathrm{~h}$ and then incubated with APAP $(20 \mathrm{mM})$ for $2 \mathrm{~h}$, followed by staining with probe ATP$\mathbf{L W}(20 \mu \mathrm{M})$ for $20 \mathrm{~min}$. The cell culture medium of each group was removed, and all cells were washed with $1.0 \mathrm{~mL}$ of PBS three times before fluorescence imaging. Two-photon photographs were taken using a Zeiss LSM 880 NLO microscope equipped with the ZEN 2 lite software.

\subsection{Co-localization assay of ATP-LW.}

Experimental procedure for Figure S30. HL-7702 cells were incubated with probe ATP-LW $(20 \mu \mathrm{M})$ for $20 \mathrm{~min}$ and then incubated with the indicated commercial organelle-specific dye for $15 \mathrm{~min}$.

Experimental procedure for Figure S31. HL-7702 cells were incubated with APAP (15 mM) for $2 \mathrm{~h}$, and then stained with probe ATP-LW $(20 \mu \mathrm{M})$ for $20 \mathrm{~min}$, followed by staining with each corresponding commercial organelle-specific dye for another $15 \mathrm{~min}$. 

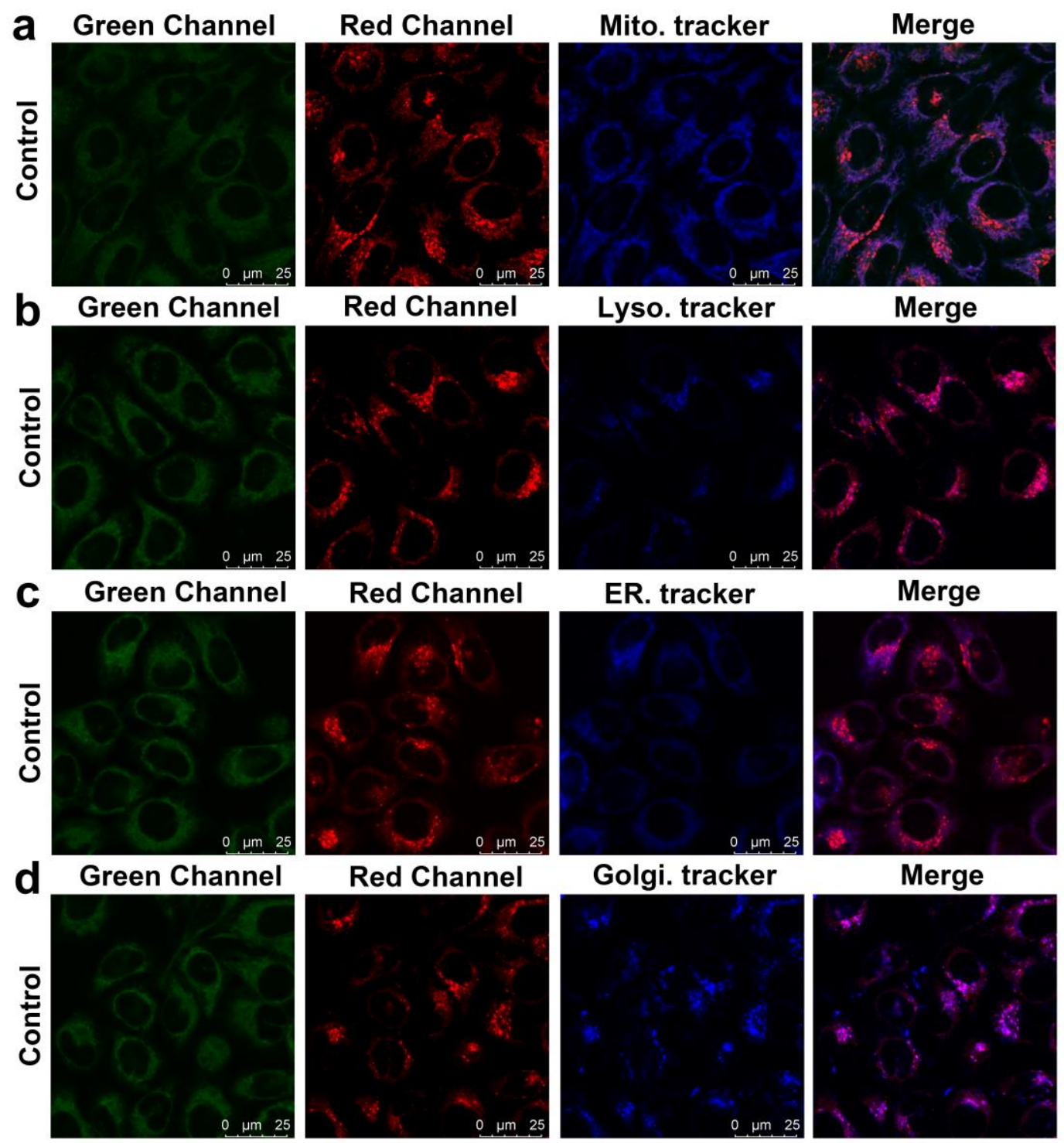

Figure S30. Confocal images of HL-7702 cells stained with probe ATP-LW and the indicated commercial organelle-specific dyes. (a) Fluorescence images of probe ATP-LW $\left(20 \mu \mathrm{M}\right.$, green channel, $\lambda_{\mathrm{ex}}=488 \mathrm{~nm}$, collected $500-575 \mathrm{~nm}$; red channel, $\lambda_{\mathrm{ex}}=514 \mathrm{~nm}$, collected 575-650 nm) and Mito-Tracker ${ }^{\circledR}$ Deep Red $(1 \mu \mathrm{M}$, blue channel, $\lambda_{\mathrm{ex}}=633 \mathrm{~nm}$, collected $\left.645-763 \mathrm{~nm}\right)$ in control group cells. (b) Fluorescence images of probe ATP-LW $(20 \mu \mathrm{M}$, green channel, $\lambda_{\mathrm{ex}}=488 \mathrm{~nm}$, collected $500-575 \mathrm{~nm}$; red channel, $\lambda_{\mathrm{ex}}=514 \mathrm{~nm}$, collected 575-650 nm) and LysoTracker ${ }^{\circledR}$ Deep Red $\left(1 \mu \mathrm{M}\right.$, blue channel, $\lambda_{\mathrm{ex}}=633 \mathrm{~nm}$, collected $\left.645-763 \mathrm{~nm}\right)$ in control group cells. (c) Fluorescence images of probe ATP-LW $\left(20 \mu \mathrm{M}\right.$, green channel, $\lambda_{\mathrm{ex}}=488 \mathrm{~nm}$, collected 500-575 nm; red channel, $\lambda_{\mathrm{ex}}=514 \mathrm{~nm}$, collected $\left.575-650 \mathrm{~nm}\right)$ and ER-Tracker ${ }^{\circledR}$ Red $\left(1 \mu \mathrm{M}\right.$, blue channel, $\lambda_{\mathrm{ex}}=633 \mathrm{~nm}$, collected 636$800 \mathrm{~nm})$ in control group cells. (d) Fluorescence images of probe ATP-LW $\left(20 \mu \mathrm{M}\right.$, green channel, $\lambda_{\mathrm{ex}}=488 \mathrm{~nm}$, collected 500-575 nm; red channel, $\lambda_{\mathrm{ex}}=514 \mathrm{~nm}$, collected 575-650 nm) and Golgi-Tracker ${ }^{\circledR}$ Red (40 $\mu \mathrm{M}$, blue channel, $\lambda_{\mathrm{ex}}=561 \mathrm{~nm}$, collected 650-700 nm) in control group cells. Merged images (a), (b), (c), (d) are overlays of the red channel of probe ATP-LW and the blue channel of each commercial organelle-specific dye. The Pearson's correlation for mitochondria, lysosomes, endoplasmic reticulum and Golgi apparatus corresponding to these studies are $0.6932,0.7686,0.5728$ and 0.6446 , respectively. 

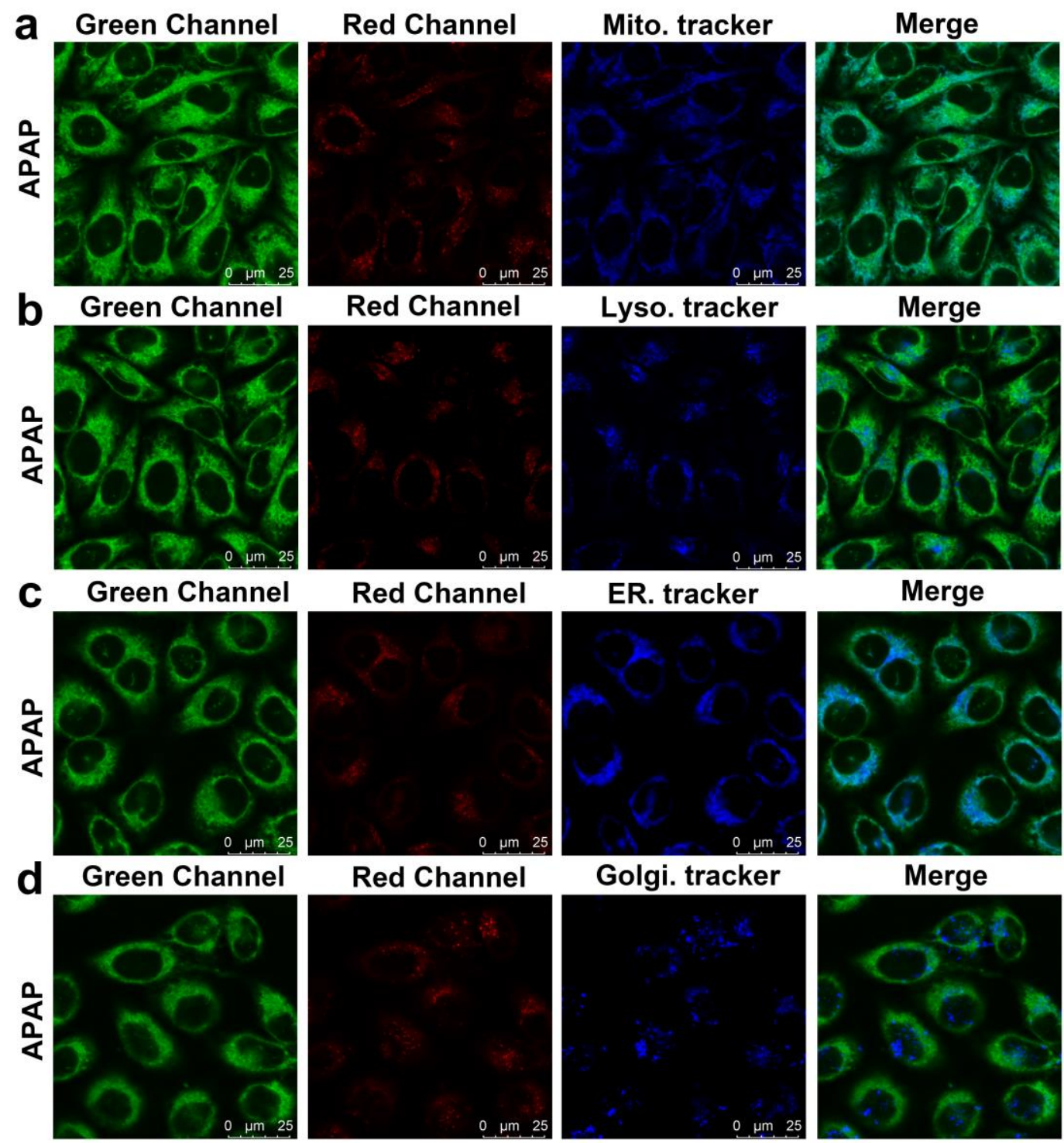

Figure S31. Confocal images of APAP HL-7702 cells stained with probe ATP-LW and the indicated commercial organelle-specific dyes. (a) Fluorescence images of probe ATP-LW $\left(20 \mu \mathrm{M}\right.$, green channel, $\lambda_{\mathrm{ex}}=488 \mathrm{~nm}$, collected $500-575 \mathrm{~nm}$; red channel, $\lambda_{\mathrm{ex}}=514 \mathrm{~nm}$, collected 575-650 nm) and Mito-Tracker ${ }^{\circledR}$ Deep Red (1 $\mu \mathrm{M}$, blue channel, $\lambda_{\mathrm{ex}}=633 \mathrm{~nm}$, collected $\left.645-763 \mathrm{~nm}\right)$ in APAP $(15 \mathrm{mM}, 2 \mathrm{~h})$ pretreated cells. (b) Fluorescence images of probe ATP$\mathbf{L W}\left(20 \mu \mathrm{M}\right.$, green channel, $\lambda_{\mathrm{ex}}=488 \mathrm{~nm}$, collected $500-575 \mathrm{~nm}$; red channel, $\lambda_{\mathrm{ex}}=514 \mathrm{~nm}$, collected $\left.575-650 \mathrm{~nm}\right)$ and Lyso-Tracker ${ }^{\circledR}$ Deep Red $\left(1 \mu \mathrm{M}\right.$, blue channel, $\lambda_{\mathrm{ex}}=633 \mathrm{~nm}$, collected 645-763 nm) in APAP $(15 \mathrm{mM}, 2 \mathrm{~h})$ pretreated cells. (c) Fluorescence images of probe ATP-LW $\left(20 \mu \mathrm{M}\right.$, green channel, $\lambda_{\mathrm{ex}}=488 \mathrm{~nm}$, collected 500$575 \mathrm{~nm}$; red channel, $\lambda_{\mathrm{ex}}=514 \mathrm{~nm}$, collected $\left.575-650 \mathrm{~nm}\right)$ and ER-Tracker ${ }^{\circledR} \operatorname{Red}\left(1 \mu \mathrm{M}\right.$, blue channel, $\lambda_{\mathrm{ex}}=633 \mathrm{~nm}$, collected 636-800 nm) in APAP (15 mM, 2 h) pretreated cells. (d) Fluorescence images of probe ATP-LW (20 $\mu$ M, green channel, $\lambda_{\mathrm{ex}}=488 \mathrm{~nm}$, collected $500-575 \mathrm{~nm}$; red channel, $\lambda_{\mathrm{ex}}=514 \mathrm{~nm}$, collected 575-650 nm) and GolgiTracker ${ }^{\circledR}$ Red $\left(40 \mu \mathrm{M}\right.$, blue channel, $\lambda_{\mathrm{ex}}=561 \mathrm{~nm}$, collected $\left.650-700 \mathrm{~nm}\right)$ in APAP $(15 \mathrm{mM}, 2 \mathrm{~h})$ pretreated cells. Merge images of (a), (b), (c), (d) are overlay of green channel of probe ATP-LW and blue channel of commercial organelle-specific dyes, respectively. The Pearson's correlation for the mitochondria, lysosomes, endoplasmic reticulum and Golgi apparatus corresponding to these studies are $0.8727,0.5054,0.7087$ and 0.2858 , respectively. 


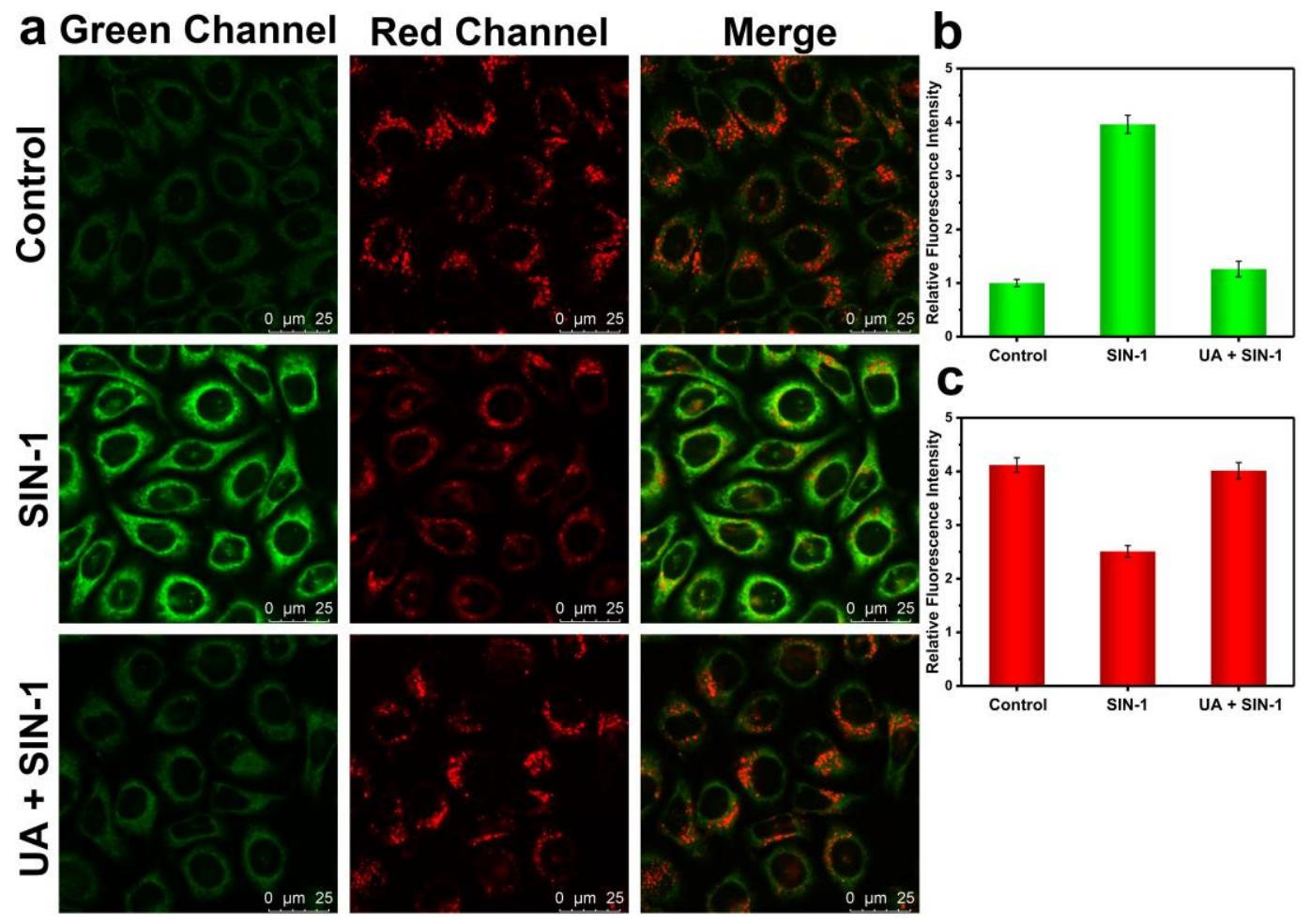

Figure S32. Original image for Figure 4: One-photon confocal imaging of $\mathrm{ONOO}^{-}$and ATP levels in hepatocytes treated with SIN-1 or SIN-1/uric acid. (a) One-photon fluorescence images of HL-7702 cells recorded after the addition of SIN-1 $(1 \mathrm{mM}, 1 \mathrm{~h})$ and uric acid $(500 \mu \mathrm{M}, 1 \mathrm{~h})$ with monitoring over the green $\left(\mathrm{ONOO}^{-}\right)$and red (ATP) channels. Control group: Cells were stained with probe ATP-LW $(20 \mu \mathrm{M})$ for $20 \mathrm{~min}$. SIN-1 group: cells were incubated with SIN-1 $(1 \mathrm{mM})$ for $1 \mathrm{~h}$, then stained with probe ATP-LW $(20 \mu \mathrm{M})$ for $20 \mathrm{~min}$. UA + SIN-1 group: Cells were pretreated with uric acid $(500 \mu \mathrm{M})$ for $1 \mathrm{~h}$ and followed by adding SIN-1 $(1 \mathrm{mM})$ for $1 \mathrm{~h}$ and then stained with probe ATP-LW $(20 \mu \mathrm{M})$ for $20 \mathrm{~min}$. Green fluorescence channel for $\mathrm{ONOO}^{-}: \lambda_{\mathrm{ex}}=488 \mathrm{~nm}, \lambda_{\mathrm{em}}=500-575 \mathrm{~nm}$. Red fluorescence channel for ATP: $\lambda_{\mathrm{ex}}=514 \mathrm{~nm}, \lambda_{\mathrm{em}}=575-650 \mathrm{~nm}$. (b) Green relative fluorescence intensity output of three groups. (c) Red relative fluorescence intensity output of three groups. Note: The green fluorescence intensity of the control group is defined as 1.0. The data are expressed as the mean $\pm \mathrm{SD}$. Concordant results were obtained from five independent experiments. 


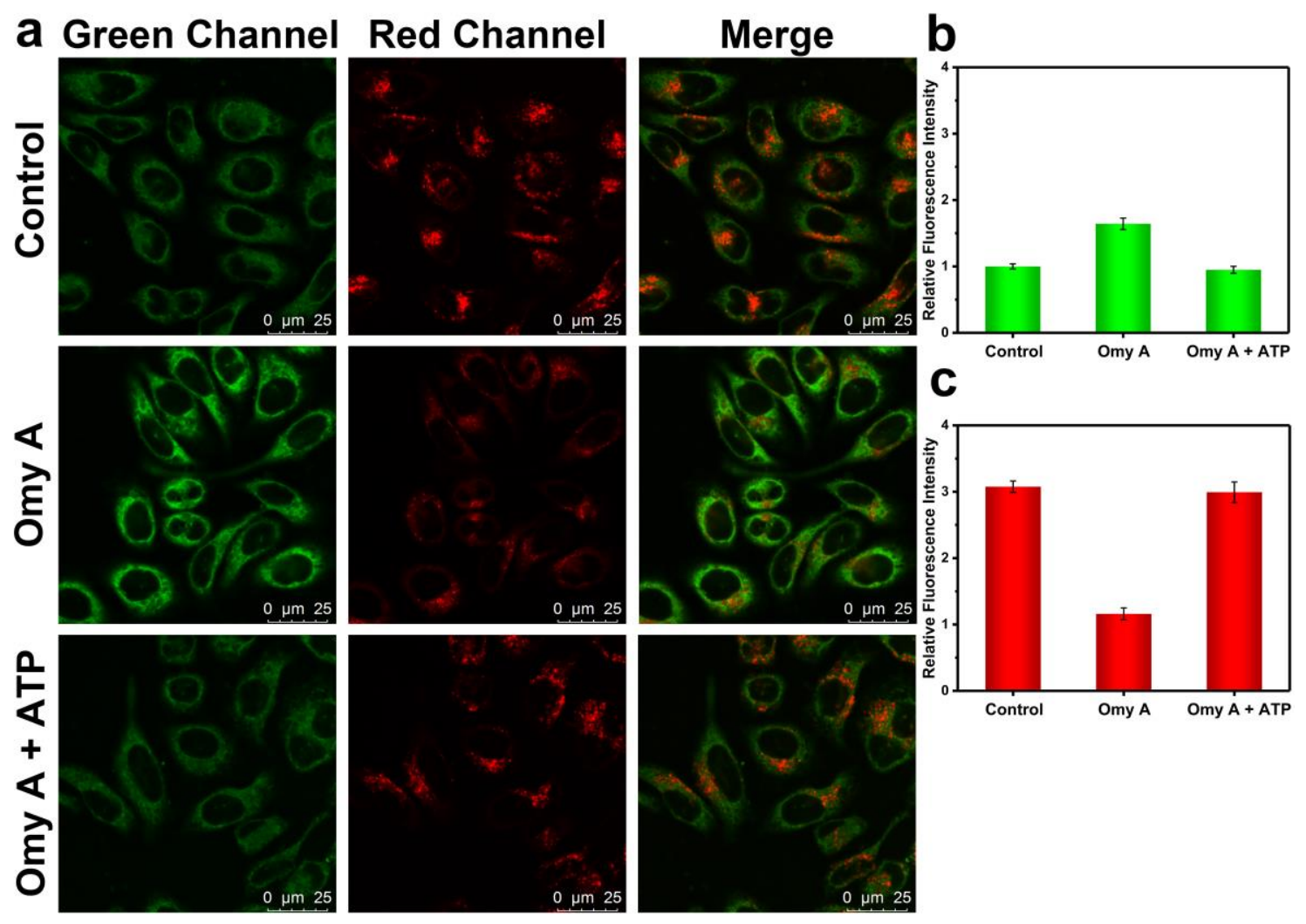

Figure S33. Original image for Figure 5: One-photon confocal imaging of $\mathrm{ONOO}^{-}$and ATP levels in hepatocytes treated with omy A or omy A/ATP. (a) One-photon fluorescence images of HL-7702 cells with the addition of omy A $(25 \mu \mathrm{M}, 1 \mathrm{~h})$ and ATP $(10 \mathrm{mM}, 1 \mathrm{~h})$ for green $\left(\mathrm{ONOO}^{-}\right)$and red (ATP) channels. Control group: Cells were stained with probe ATP-LW $(20 \mu \mathrm{M})$ for 20 min. Omy A group: Cells were incubated with omy A $(25 \mu \mathrm{M})$ for $1 \mathrm{~h}$, then stained with probe ATP-LW $(20 \mu \mathrm{M})$ for $20 \mathrm{~min}$. Omy A + ATP group: Cells were pretreated with omy A $(25 \mu \mathrm{M})$ for $1 \mathrm{~h}$ and followed by adding ATP $(10 \mathrm{mM})$ for $1 \mathrm{~h}$ and then stained with probe ATP-LW $(20 \mu \mathrm{M})$ for $20 \mathrm{~min}$. Green fluorescence channel for $\mathrm{ONOO}^{-}: \lambda_{\mathrm{ex}}=488 \mathrm{~nm}, \lambda_{\mathrm{em}}=500-575 \mathrm{~nm}$. Red fluorescence channel for ATP: $\lambda_{\mathrm{ex}}=$ $514 \mathrm{~nm}, \lambda_{\mathrm{em}}=575-650 \mathrm{~nm}$. (b) Green relative fluorescence intensity output of three groups. (c) Red relative fluorescence intensity output of three groups. Note: The green fluorescence intensity of the control group is defined as 1.0. The data are expressed as the mean $\pm \mathrm{SD}$. Concordant results were obtained from five independent experiments. 


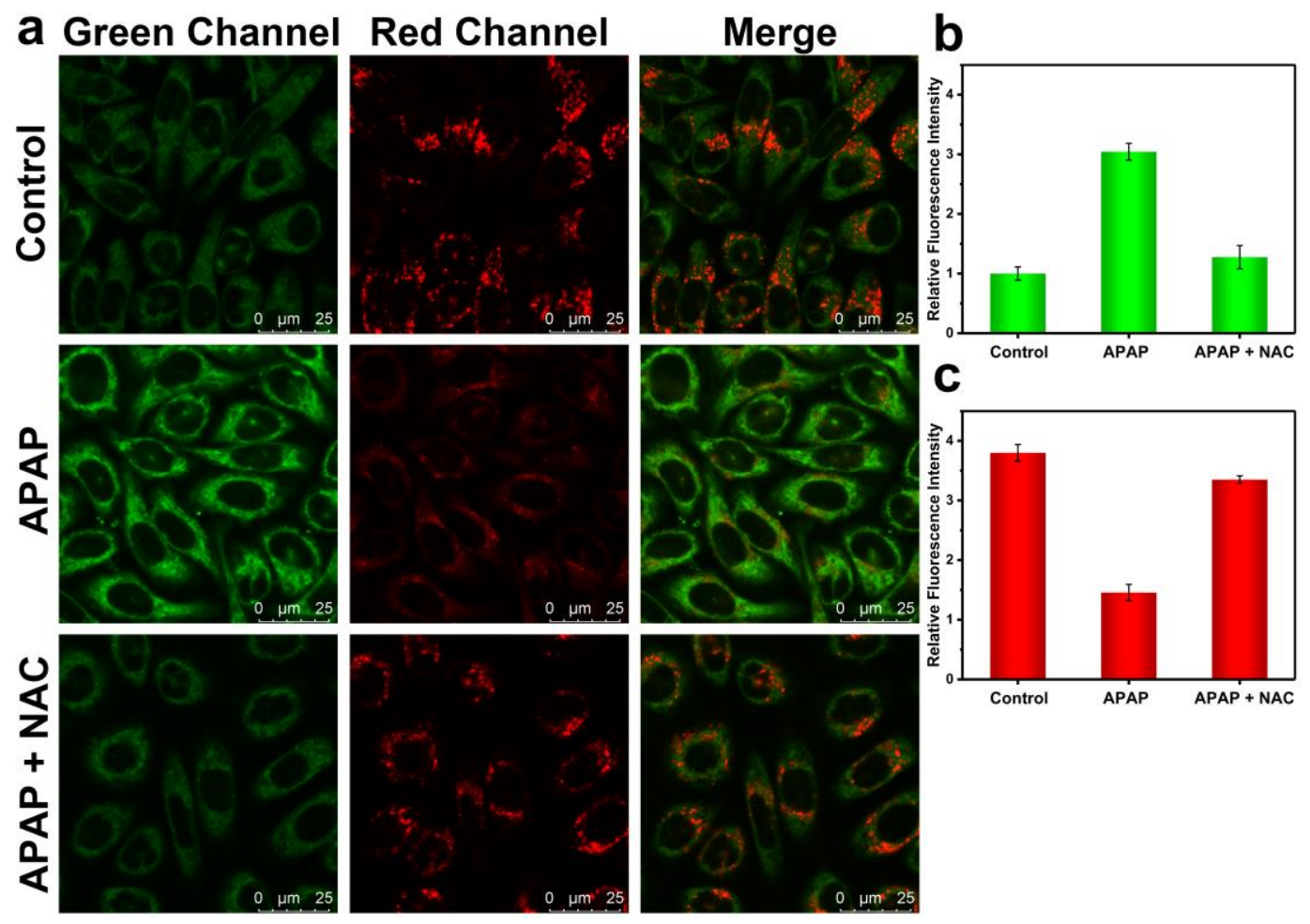

Figure S34. Original image for Figure 6: One-photon confocal images of APAP-induced injury and its remediation by NAC in HL-7702 cells. (a) One-photon fluorescence images of HL-7702 cells with the addition of APAP (15 mM, $2 \mathrm{~h})$ and NAC $(2 \mathrm{mM}, 2 \mathrm{~h})$ for green $\left(\mathrm{ONOO}^{-}\right)$and red (ATP) channels. Control group: Cells were stained with probe ATP-LW $(20 \mu \mathrm{M})$ for $20 \mathrm{~min}$. APAP group: Cells were incubated with APAP $(15 \mathrm{mM})$ for $2 \mathrm{~h}$, and then stained with probe ATP-LW $(20 \mu \mathrm{M})$ for $20 \mathrm{~min}$. APAP + NAC group: Cells were pretreated with NAC ( $2 \mathrm{mM})$ for $2 \mathrm{~h}$ and then incubated with APAP $(15 \mathrm{mM})$ for $2 \mathrm{~h}$, followed by staining with probe ATP-LW $(20 \mu \mathrm{M})$ for another $20 \mathrm{~min}$. Green fluorescence channel for $\mathrm{ONOO}^{-}: \lambda_{\mathrm{ex}}=488 \mathrm{~nm}, \lambda_{\mathrm{em}}=500-575 \mathrm{~nm}$. Red fluorescence channel for ATP: $\lambda_{\mathrm{ex}}=514 \mathrm{~nm}, \lambda_{\mathrm{em}}=575-650 \mathrm{~nm}$. (b) Green relative fluorescence intensity output of three groups. (c) Red relative fluorescence intensity output of three groups. Note: The green fluorescence intensity of the control group is defined as 1.0. The data are expressed as the mean $\pm \mathrm{SD}$. Concordant results were obtained from five independent experiments. 


\section{NMR spectra}

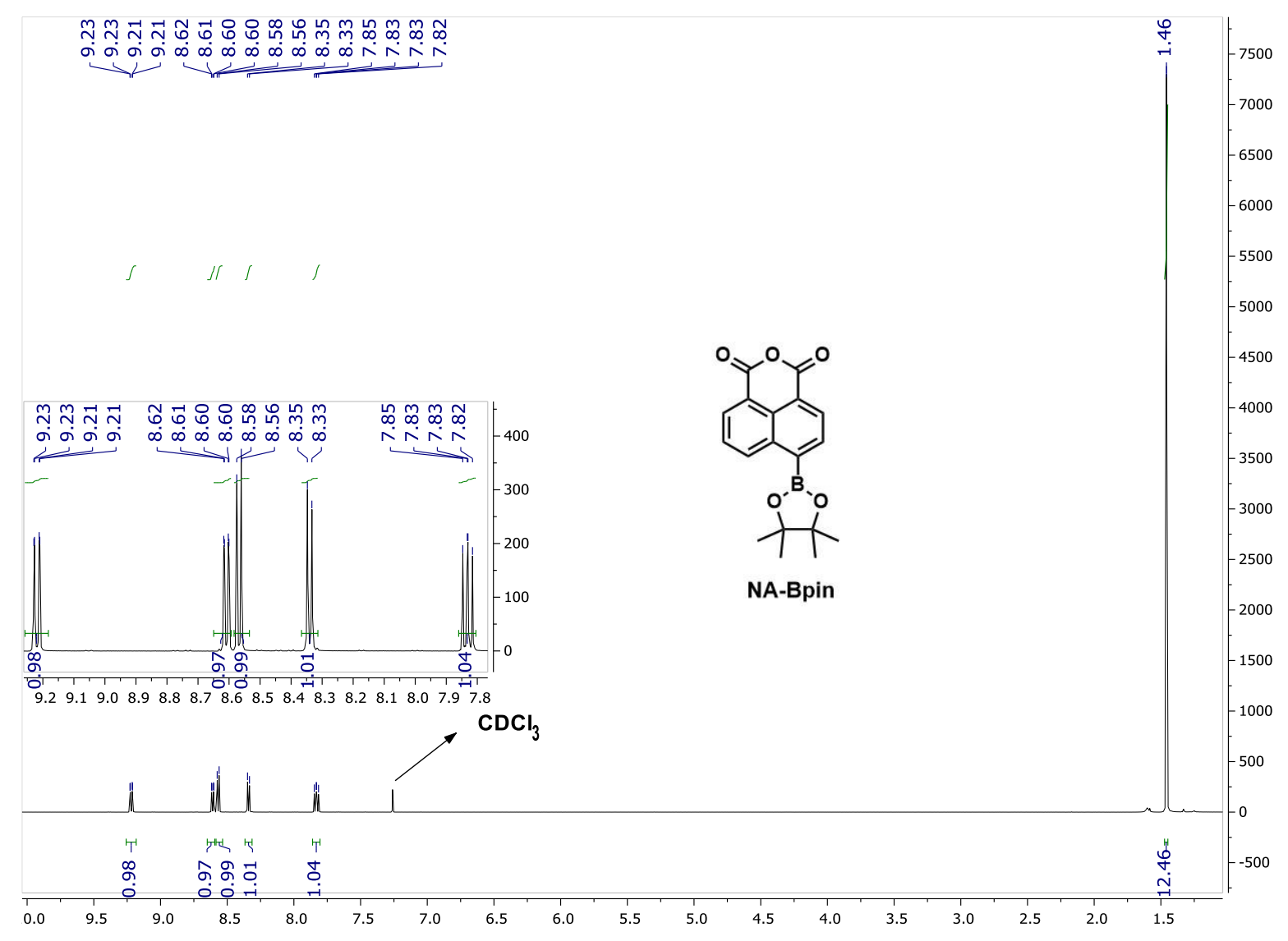

Figure S35. ${ }^{1} \mathrm{H} \mathrm{NMR}\left(500 \mathrm{MHz}, \mathrm{CDCl}_{3}\right)$ of NA-Bpin. 


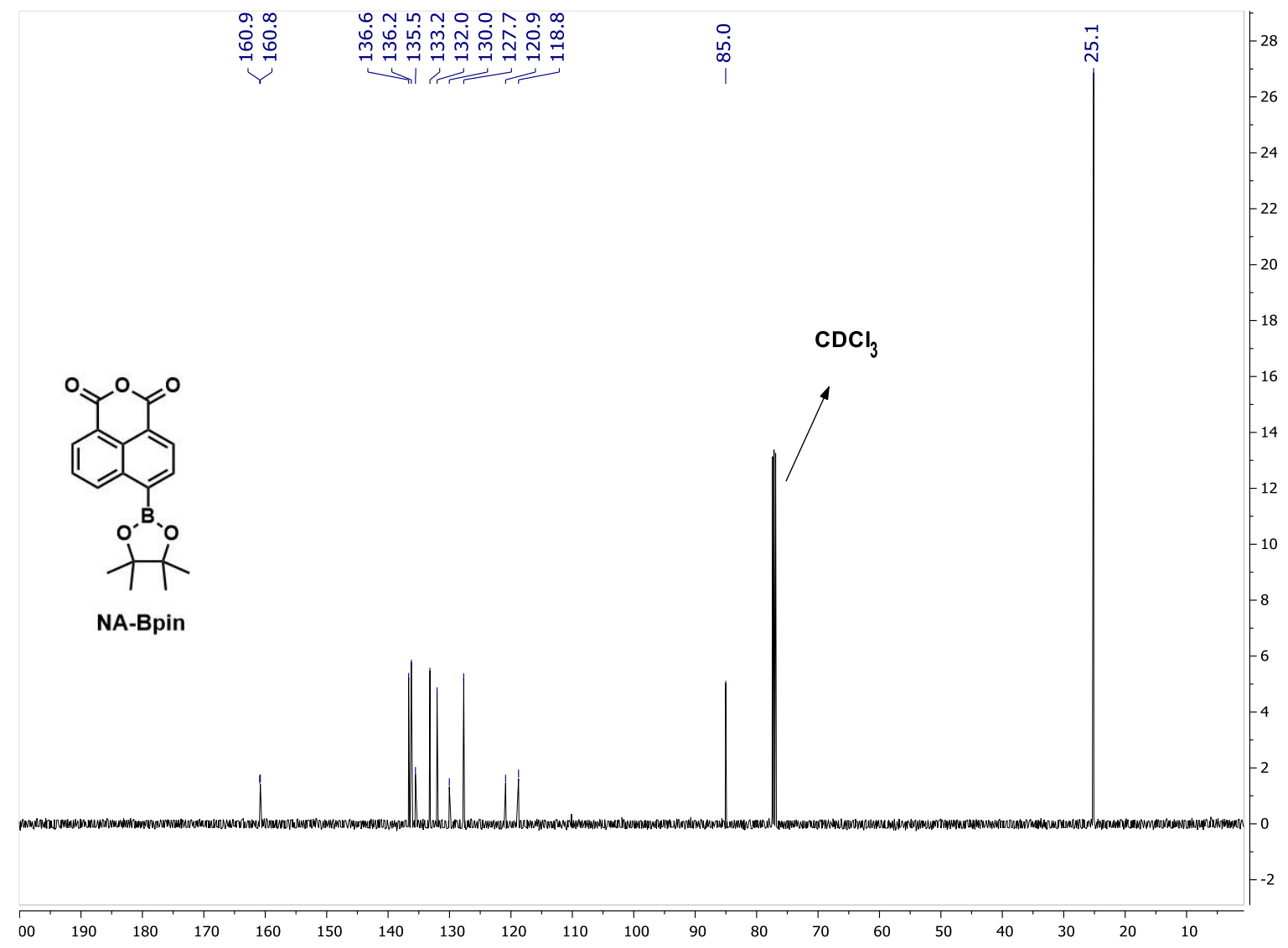

Figure S36. ${ }^{13} \mathrm{C}$ NMR $\left(126 \mathrm{MHz}, \mathrm{CDCl}_{3}\right)$ of NA-Bpin.

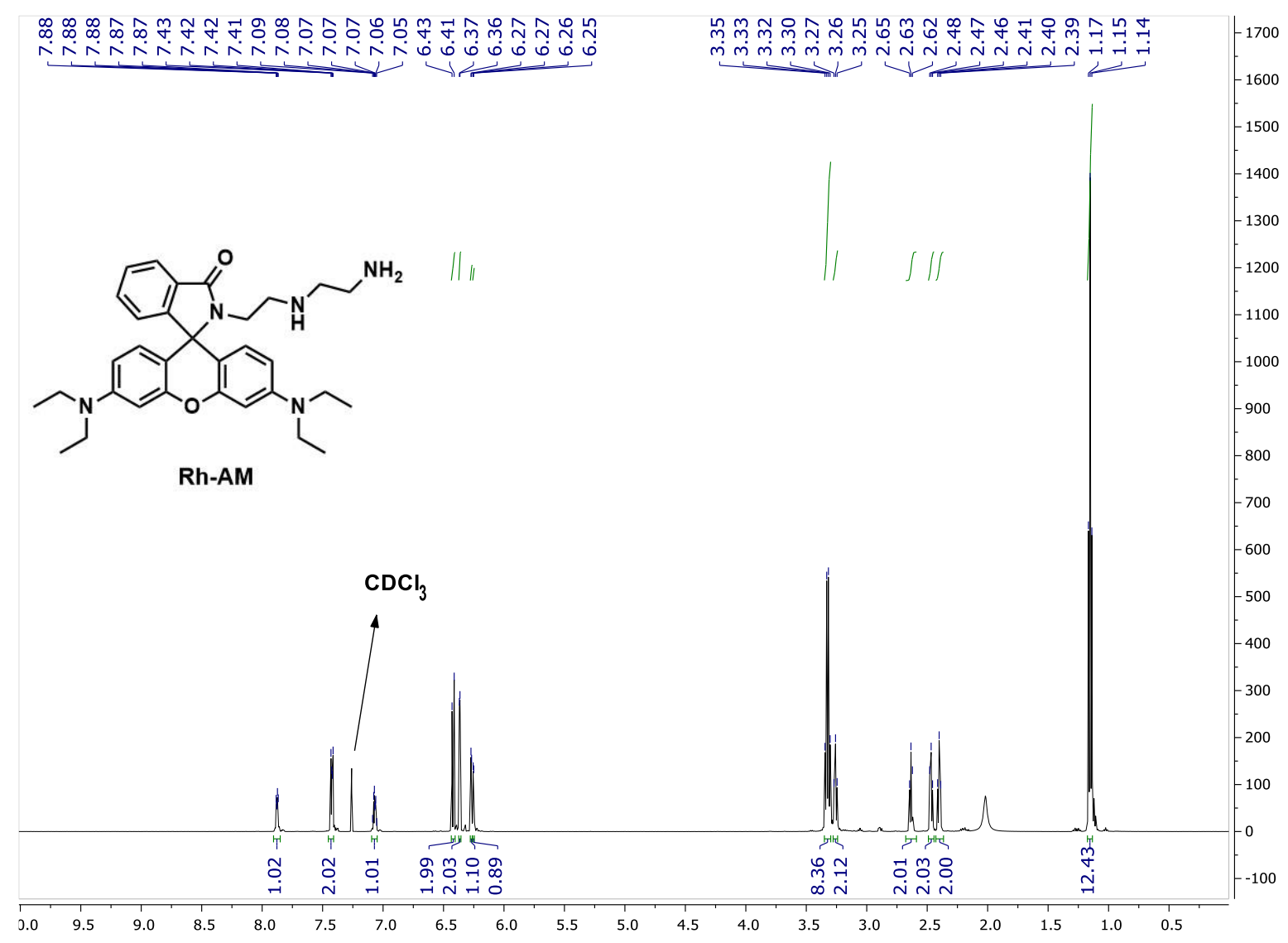

Figure S37. ${ }^{1} \mathrm{H}$ NMR $\left(500 \mathrm{MHz}, \mathrm{CDCl}_{3}\right)$ of $\mathbf{R h}-\mathbf{A M}$. 


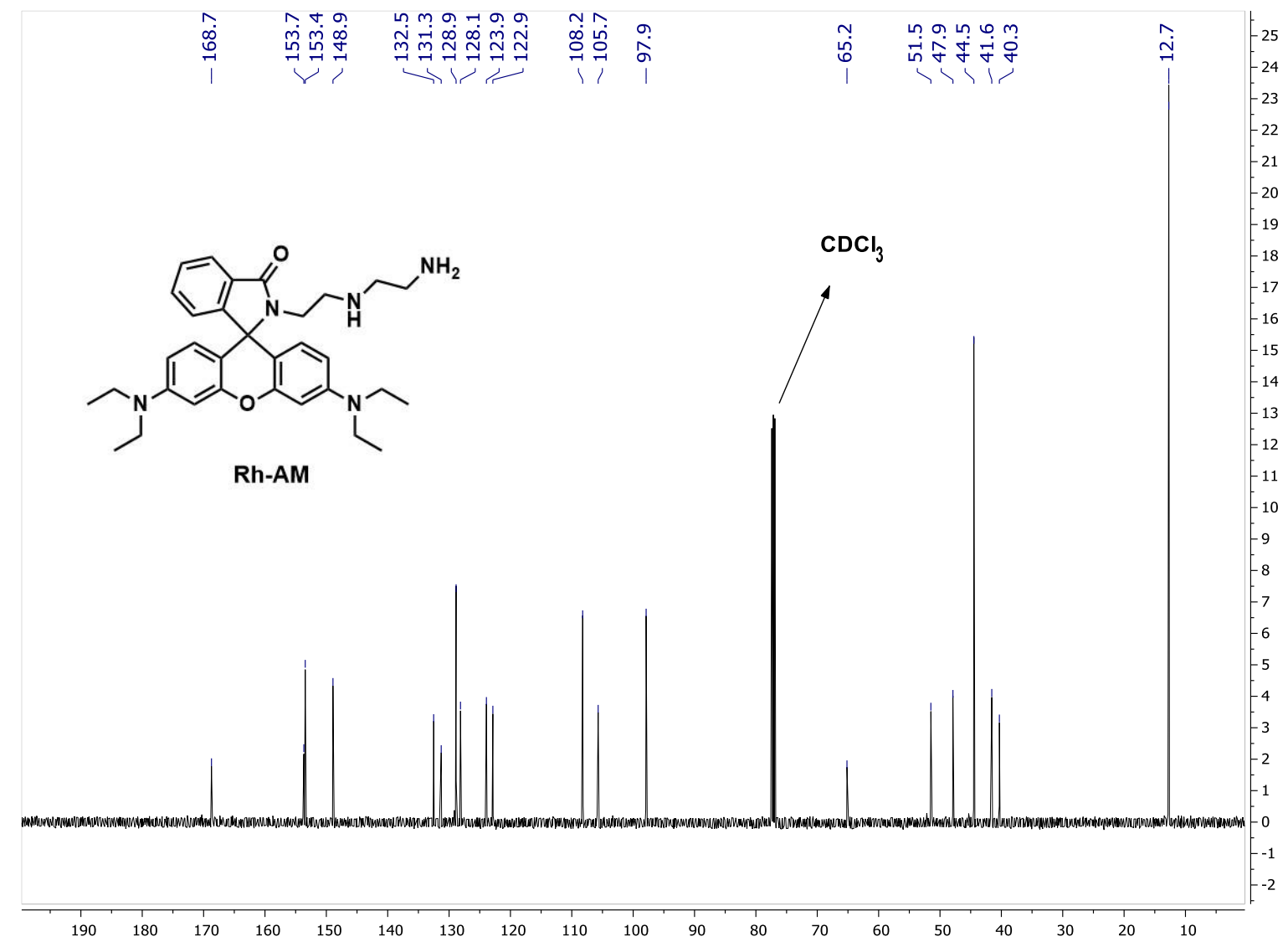

Figure S38. ${ }^{13} \mathrm{C}$ NMR $\left(126 \mathrm{MHz}, \mathrm{CDCl}_{3}\right)$ of $\mathbf{R h}-\mathbf{A M}$.

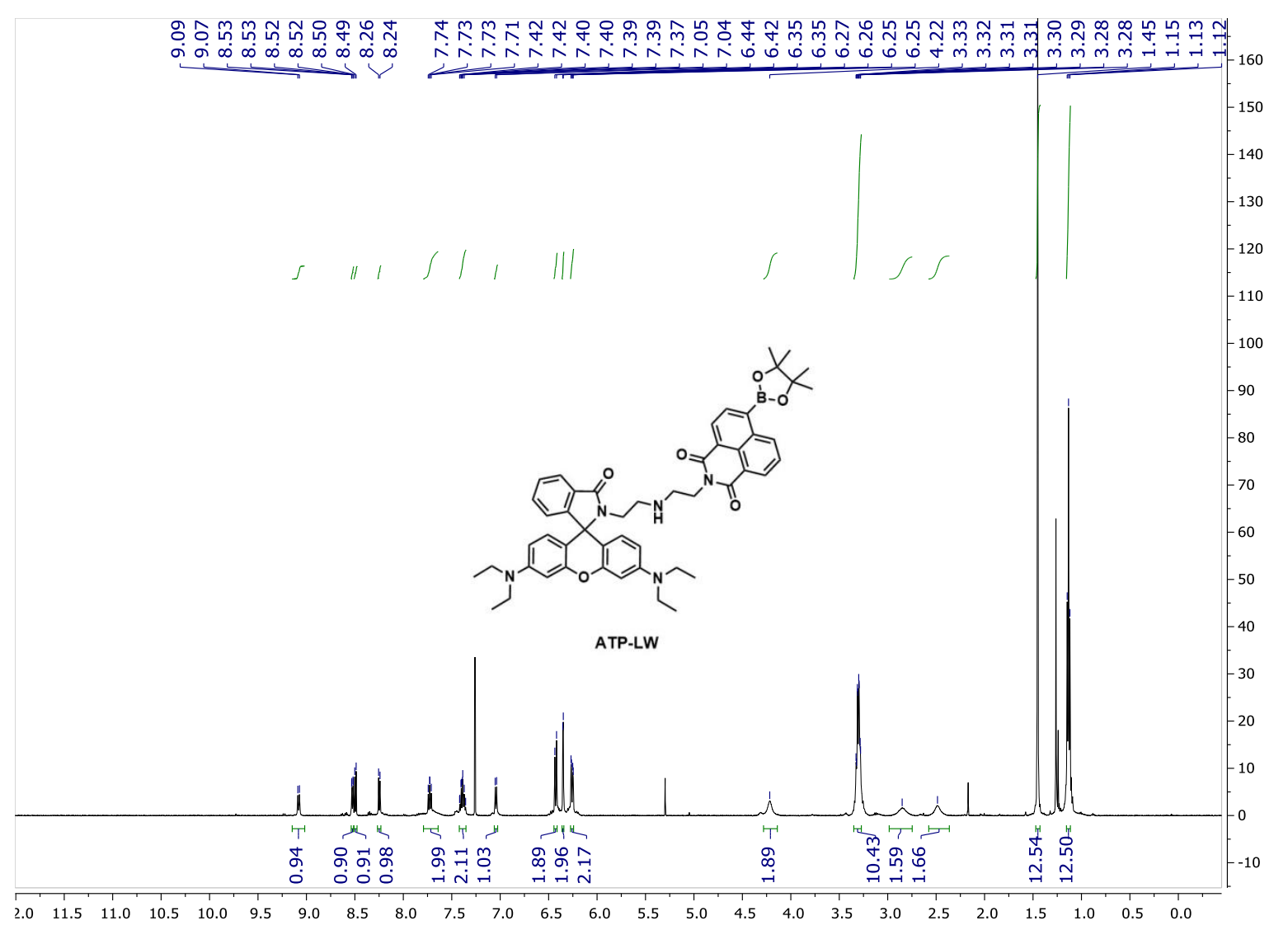

Figure S39. ${ }^{1} \mathrm{H}$ NMR $\left(500 \mathrm{MHz}, \mathrm{CDCl}_{3}\right)$ of ATP-LW. 


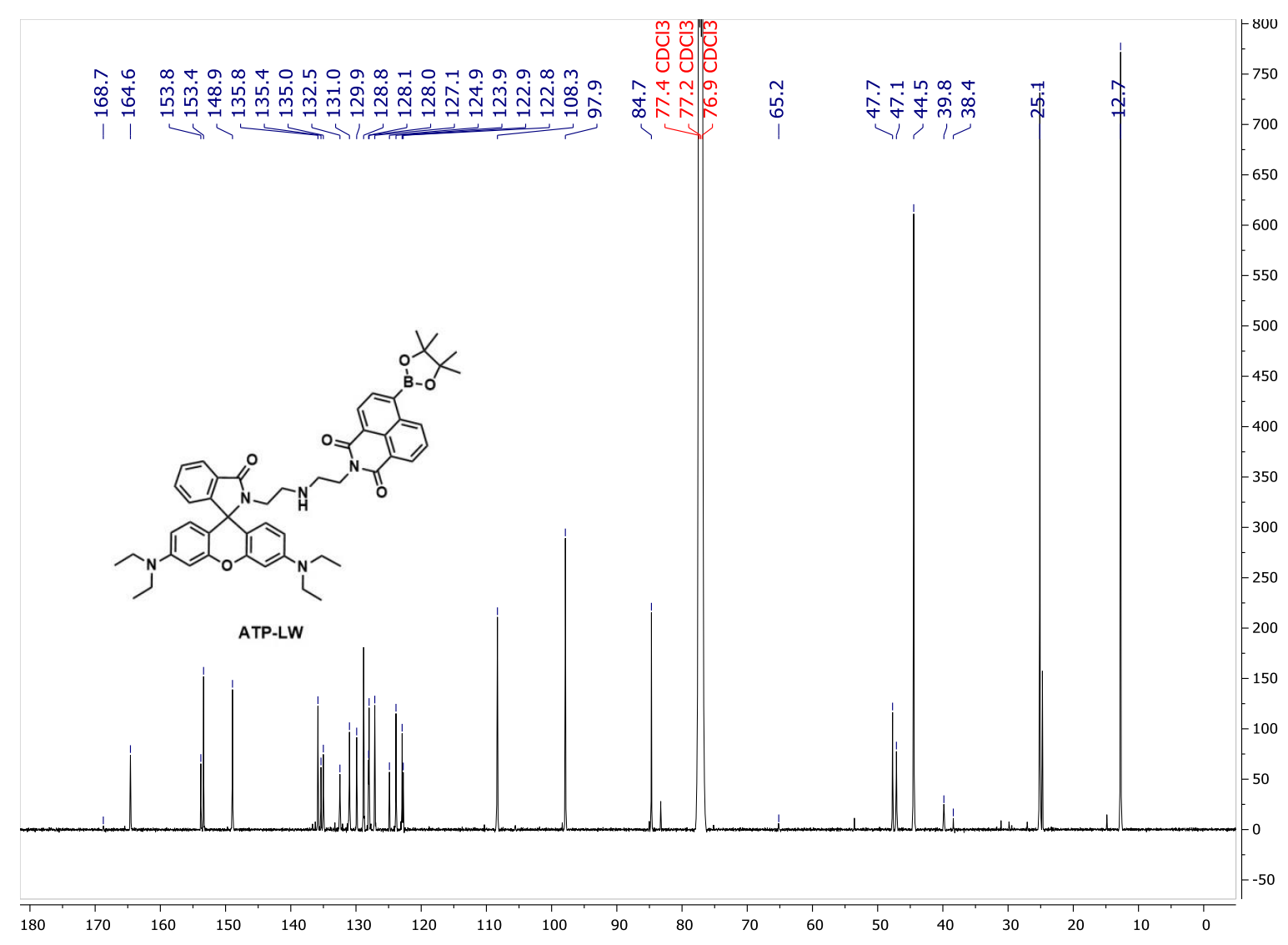

Figure S40. ${ }^{13} \mathrm{C}$ NMR $\left(126 \mathrm{MHz}, \mathrm{CDCl}_{3}\right)$ of ATP-LW.

\section{Author contributions}

Luling $\mathrm{Wu}$ - Designed the probe with Chusen Huang, synthesized the probe, designed the solution and cell experiments, drafted the manuscript/ESI and helped respond to the referees' comments.

Jihong Liu - Carried out all the biological work under supervision of Ping Li and Bo Tang.

Xue Tian - Carried out all the solution work.

Robin R. Groleau - Carried out and advised on NMR characterization and reviewed the manuscript.

Beidong Feng - Performed the transient absorption spectral experiments under the supervision of Hua Zhang Yonggang Yang, Hua Zhang - Carried out the theoretical calculations

Hai-Hao Han, Han-Min Wang, Yi Zang, Jia Li, and Xiao-Peng He - Carried out cellular experiments; however, these data are not added in the manuscript/ESI since it was found that only exogenous stimuli were effective in imaging fluctuations in $\mathrm{ATP} / \mathrm{ONOO}^{-}$concentrations.

Yang Wang - Synthesized a related probe that was ultimately not included in the manuscript/ESI.

Chusen Huang - Supervisor of Yang Wang who designed the probe in conjunction with Luling Wu

Fang Huang - Carried out preliminary theoretical calculations prior to this task being taken over by the group of Hua Zhang.

Steven D. Bull - Supervisor of Robin R. Groleau, Luling Wu and Xue Tian

Tony D. James - Lead supervisor, reviewed and edited the manuscript/ESI

Jonathan L. Sessler - Supervisor of Adam C. Sedgwick and reviewed the manuscript/ESI with Adam C. Sedgwick; helped finalize both documents. 


\section{References}

1. Manyike, P. T.; Kharasch, E. D.; Kalhorn, T. F.; Slattery, J. T., Contribution of CYP2E1 and CYP3A to acetaminophen reactive metabolite formation. Clin. Pharmacol. Ther. 2000, 67, 275-282.

2. Chen, W.; Koenigs, L. L.; Thompson, S. J.; Peter, R. M.; Rettie, A. E.; Trager, W. F.; Nelson, S. D., Oxidation of acetaminophen to its toxic quinone imine and nontoxic catechol metabolites by baculovirus-expressed and purified human cytochromes P450 2E1 and 2A6. Chem. Res. Toxicol. 1998, 11, 295-301.

3. Hinson, J. A.; Roberts, D. W.; James, L. P., Mechanisms of acetaminophen-induced liver necrosis. In Adverse Drug Reactions, Uetrecht, J., Ed. Springer Berlin Heidelberg: Berlin, Heidelberg, 2010; pp 369-405.

4. Chen, J.; Huang, D.; She, M.; Wang, Z.; Chen, X.; Liu, P.; Zhang, S.; Li, J., Recent progress in fluorescent sensors for drug-induced liver injury assessment. ACS Sens. 2021, 6, 628-640.

5. Lee, K. K.; Imaizumi, N.; Chamberland, S. R.; Alder, N. N.; Boelsterli, U. A., Targeting mitochondria with methylene blue protects mice against acetaminophen-induced liver injury. Hepatology 2015, 61, 326-336.

6. Du, K.; Ramachandran, A.; Weemhoff, J. L.; Chavan, H.; Xie, Y.; Krishnamurthy, P.; Jaeschke, H., Editor's highlight: metformin protects against acetaminophen hepatotoxicity by attenuation of mitochondrial oxidant stress and dysfunction. Toxicol. Sci. 2016, 154, 214-226.

7. Jaeschke, H.; McGill, M. R.; Ramachandran, A., Oxidant stress, mitochondria, and cell death mechanisms in druginduced liver injury: Lessons learned from acetaminophen hepatotoxicity. Drug Metab. Rev. 2012, 44, 88-106.

8. Wu, L.; Han, H.-H.; Liu, L.; Gardiner, J. E.; Sedgwick, A. C.; Huang, C.; Bull, S. D.; He, X.-P.; James, T. D., ESIPTbased fluorescence probe for the rapid detection of peroxynitrite 'AND' biological thiols. Chem. Comm. 2018, 54, 1133611339.

9. Rushworth, G. F.; Megson, I. L., Existing and potential therapeutic uses for N-acetylcysteine: The need for conversion to intracellular glutathione for antioxidant benefits. Pharmacol. Ther. 2014, 141, 150-159.

10. Armstrong, J. S.; Whiteman, M.; Rose, P.; Jones, D. P., The coenzyme $\mathrm{Q}_{10}$ analog decylubiquinone inhibits the redox-activated mitochondrial permeability transition: role of mitcohondrial respiratory complex III. J. Biol. Chem. 2003, 278, 49079-49084.

11. Briston, T.; Roberts, M.; Lewis, S.; Powney, B.; M. Staddon, J.; Szabadkai, G.; Duchen, M. R., Mitochondrial permeability transition pore: sensitivity to opening and mechanistic dependence on substrate availability. Sci. Rep. 2017, 7,10492 .

12. Lee, S. J.; Jin, Y.; Yoon, H. Y.; Choi, B.-O.; Kim, H. C.; Oh, Y.-K.; Kim, H.-S.; Kim, W.-K., Ciclopirox protects mitochondria from hydrogen peroxide toxicity. Br. J. Pharmacol. 2005, 145, 469-476.

13. Radi, R.; Cassina, A.; Hodara, R.; Quijano, C.; Castro, L., Peroxynitrite reactions and formation in mitochondria. Free Radical Biol. Med. 2002, 33, 1451-1464.

14. Hunter, D. R.; Haworth, R. A., The $\mathrm{Ca}^{2+}$-induced membrane transition in mitochondria: I. The protective mechanisms. Arch. Biochem. Biophys. 1979, 195, 453-459.

15. Bonora, M.; Pinton, P., The mitochondrial permeability transition pore and cancer: molecular mechanisms involved in cell death. Front. Oncol. 2014, 4, 302.

16. White, R. J.; Reynolds, I. J., Mitochondrial depolarization in glutamate-stimulated neurons: an early signal specific to excitotoxin exposure. J. Neurosci. 1996, 16, 5688-5697.

17. Okuno, D.; Iino, R.; Noji, H., Rotation and structure of $\mathrm{F}_{0} \mathrm{~F}_{1}$-ATP synthase. J. Biochem. 2011, 149, 655-664.

18. Diez, M.; Zimmermann, B.; Börsch, M.; König, M.; Schweinberger, E.; Steigmiller, S.; Reuter, R.; Felekyan, S.; Kudryavtsev, V.; Seidel, C. A. M.; Gräber, P., Proton-powered subunit rotation in single membrane-bound $F_{0} F_{1}-A T P$ synthase. Nat. Struct. Mol. Biol. 2004, 11, 135-141.

19. Moles, A.; Torres, S.; Baulies, A.; Garcia-Ruiz, C.; Fernandez-Checa, J. C., Mitochondrial-lysosomal axis in 
acetaminophen hepatotoxicity. Front. Pharmacol. 2018, 9, 453.

20. Liang, X.; Xu, X.; Qiao, D.; Yin, Z.; Shang, L., Dual mechanism of an intramolecular charge transfer (ICT)-FRETbased fluorescent probe for the selective detection of hydrogen peroxide. Chem. Asian J. 2017, 12, 3187-3194.

21. Bag, B.; Biswal, B., Alteration of selectivity in rhodamine based probes for Fe(iii) and $\mathrm{Hg}$ (ii) ion induced dual mode signalling responses. Org. Biomol. Chem. 2012, 10, 2733-2738.

22. Fang, Y.; Shi, W.; Hu, Y.; Li, X.; Ma, H., A dual-function fluorescent probe for monitoring the degrees of hypoxia in living cells via the imaging of nitroreductase and adenosine triphosphate. Chem. Comm. 2018, 54, 5454-5457.

23. Frisch, M. J.; Trucks, G. W.; Schlegel, H. B.; Scuseria, G. E.; Robb, M. A.; Cheeseman, J. R.; Scalmani, G.; Barone, V.; Petersson, G. A.; Nakatsuji, H.; Li, X.; Caricato, M.; Marenich, A. V.; Bloino, J.; Janesko, B. G.; Gomperts, R.; Mennucci, B.; Hratchian, H. P.; Ortiz, J. V.; Izmaylov, A. F.; Sonnenberg, J. L.; Williams-Young, D.; Ding, F.; Lipparini, F.; Egidi, F.; Goings, J.; Peng, B.; Petrone, A.; Henderson, T.; Ranasinghe, D.; Zakrzewski, V. G.; Gao, J.; Rega, N.; Zheng, G.; Liang, W.; Hada, M.; Ehara, M.; Toyota, K.; Fukuda, R.; Hasegawa, J.; Ishida, M.; Nakajima, T.; Honda, Y.; Kitao, O.; Nakai, H.; Vreven, T.; Throssell, K.; Montgomery, J. A., Jr.; Peralta, J. E.; Ogliaro, F.; Bearpark, M. J.; Heyd, J. J.; Brothers, E. N.; Kudin, K. N.; Staroverov, V. N.; Keith, T. A.; Kobayashi, R.; Normand, J.; Raghavachari, K.; Rendell, A. P.; Burant, J. C.; Iyengar, S. S.; Tomasi, J.; Cossi, M.; Millam, J. M.; Klene, M.; Adamo, C.; Cammi, R.; Ochterski, J. W.; Martin, R. L.; Morokuma, K.; Farkas, O.; Foresman, J. B.; Fox, D. J., Gaussian 16, Revision B.01, Gaussian, Inc., Wallingford CT. 2016.

24. Zhao, Y.; Truhlar, D. G., The M06 suite of density functionals for main group thermochemistry, thermochemical kinetics, noncovalent interactions, excited states, and transition elements: two new functionals and systematic testing of four M06-class functionals and 12 other functionals. Theor. Chem. Acc. 2008, 120, 215-241.

25. Schäfer, A.; Huber, C.; Ahlrichs, R., Fully optimized contracted Gaussian basis sets of triple zeta valence quality for atoms Li to Kr. J. Chem. Phys. 1994, 100, 5829-5835.

26. Weigend, F.; Ahlrichs, R., Balanced basis sets of split valence, triple zeta valence and quadruple zeta valence quality for H to Rn: Design and assessment of accuracy. Phys. Chem. Chem. Phys. 2005, 7, 3297-3305.

27. Chai, J.-D.; Head-Gordon, M., Long-range corrected hybrid density functionals with damped atom-atom dispersion corrections. Phys. Chem. Chem. Phys. 2008, 10, 6615-6620.

28. Takano, Y.; Houk, K. N., Benchmarking the conductor-like polarizable continuum model (CPCM) for aqueous solvation free energies of neutral and ionic organic molecules. J. Chem. Theory Comput. 2005, 1, 70-77. 